University of San Diego

Digital USD

1986-08-01

\title{
Influences Affecting Career/Life Planning Aspirations as Perceived by Intellectually-Gifted, Ethnically-Diverse Adolescent Girls: A Case Study
}

Marian H. Warren EdD

University of San Diego

Follow this and additional works at: https://digital.sandiego.edu/dissertations

Part of the Leadership Studies Commons

\section{Digital USD Citation}

Warren, Marian H. EdD, "Influences Affecting Career/Life Planning Aspirations as Perceived by Intellectually-Gifted, Ethnically-Diverse Adolescent Girls: A Case Study" (1986). Dissertations. 509. https://digital.sandiego.edu/dissertations/509 


\author{
INFLUBNCES AFFECTING CAREER/LIFE PLANNING \\ ASPIRATIONS AS PERCEIVED BY INTELLECTUALLY-GIFTED, \\ ETHNICALLY-DIVERSE ADOLESCENT GIRLS: \\ A CASE STUDY \\ by \\ Marian H. Warren
}

A dissertation submitted in partial fulfillment

of the requirements for the degree of

Doctor of Education

University of San Diego

August, 1986

Dissertation Comittee

Susan M. Zgliczynski, Ph.D.

Robert I. Infantino, Ed.D.

Robert E. Nelson, Ed.D. 
INFLUENCES AFFECTING CAREER/LIFE PLANNING ASPIRATIONS

AS PERCEIVED BY INTELLECTUALLY-GIFTED, ETHNICALLY-DIVERSE, ADOLESCENT

GIRLS: A CASE STUDY

\author{
MARIAN H. WARREN \\ University of San Diego \\ 1986 \\ Director: Susan M. Zgliczynski, Ph.D.
}

With the exception of a few Asian-American women, there continues to be fewer women from ethnically-diverse cultures in high status careers. Yet little is known about the specific variables which affect the life planning and future aspirations of young, gifted black, Hispanic and Pan/Asian women.

Studies conducted and reported have focused primarily on white, middle-class adolescents or college students. The importance of this study is the addition to the sparse amount of existing literature related to the influences affecting the future life planning of the intellectuallygifted, ethnically-diverse, adolescent female.

The purpose of this case study was to examine and assess cultural influences as transmitted by the parents and community and as perceived by the intellectually-gifted black, Pan/Asian and Hispanic-American adolescent female. The seven questions designed to guide this research included 
an exploration of the girls' perceptions of the parentdaughter relationship, the extent of the parent-daughter interaction relative to career choice, whether career goals were clearly defined, the girl's perception of herself and her ability to pursue a career commensurate with her ability, and other influences perceived by the girl as affecting career choice/future life planning.

The sample consisted of fourteen black, twenty Hispanic, and seventeen Pan/Asian-American girls attending seventh or eighth grade in San Diego County.

Quantitative data were obtained through a fifty-one item questionnaire designed by the researcher. Qualitative data were obtained through group interviews with 20 percent of the sample population. Statistical treatment of the data were completed through chi-square analysis of selected questionnaire items. Interview responses were discussed qualitatively and a composite of the black, Hispanic and Pan/Asian-American sample subjects was drawn.

Findings of the study included: 1) the girls had high occupational aspirations but career goals were not clearly defined; 2) the majority of the girls did not know the requirements needed to reach their particular goals; 3 ) the girls perceived their parents as being generally supportive of what they wanted to do, although the Pan/Asian parents strongly indicated their desire for the daughters to select medically-related careers, while the black parents stressed the importance of having at least a college degree; 
Hispanic parents were more affiliative than directive; 5) double messages from parents about the importance of a career but the importance of remaining at home if the girls married; 6) double messages from the community about the equality of men and women in relation to career choice but the girls perceived that, in all reality, men had more options; 7) the Pan/Asian and Hispanic girls cited money and marriage as barriers to career attainment; and 8) peers were perceived as having little effect on career choice.

It is hoped that the results of this study will assist parents, teachers and counselors who provide career guidance become more aware of the attitudes, values and perceptions affecting the career choices of gifted Hispanic, Pan/Asian, and black adolescent girls. Limitations and suggestions for career guidance were discussed. 
DEDICATION

THIS DISSERTATION IS DEDICATED TO

MY CHILDREN

NATALIE AND TIM

AND TO MY PARENTS

FOR SPIRITUAL SUPPORT

ii 


\section{ACKNOWLEDGEMENTS}

Appreciation and thanks to Dr. Susan M. Zgliczynski, my committee director, for her encouragement, support and ideas for this study.

Dr. Robert I. Infantino's encouragement and many contributions -- particularly in editing and critiquing the writing.

Dr. Robert Nelson for his participation as a committee member and his commitment to gifted education.

Dr. Edward F. DeRoche, Dean of the School of Education, for being a good friend, listener and for having a sense of humor .

Dr. Joseph C. Rost for his support, his belief in me and his determination in pushing me to succeed.

Special thanks to my dear friend, Diane, for her long hours of work word processing. This research was deciphered with accuracy and extreme patience. Most of all, I thank her for her friendship and caring. I am deeply indebted to her.

Thanks to my good friends, Dr. Emerald Randolph, Jeanne Stegeman and Harlan Vancleave for planting the idea for research. To Terry and Naomi Tanaka for use of their word processor, encouragement and help. The Rev. James $W$. Watkins for editing the rough draft and his invaluable 
contribution as mentor and friend. Dr. Pat Anderson, Academic Computing Center at the University of San Diego, for her hours of help processing data. The Rev. Margaret Stone for believing in me.

The University of San Diego Copley Library Staff -particularly Devin Milner for assistance and cooperation in collection of literature for this research.

To all my relatives and good friends who have, from time to time, expressed interest, encouragement and spiritual sustenance.

Finally, to the individual school district personnel and the girls who participated in the study, I thank you. I enjoyed being with you. 
LIST OF TABLES

LIST OF APPENDICES

\section{CHAPTER}

I. INTRODUCTION 1

$\begin{array}{ll}\text { Statement of the Problem } & 10\end{array}$

Statement of the Research Questions 11

Definition of Terms 13

$\begin{array}{ll}\text { Significance of the study } & 14\end{array}$

$\begin{array}{ll}\text { Assumptions of the study } & 16\end{array}$

$\begin{array}{ll}\text { Limitations of the study } & 17\end{array}$

II. REVIEW OF THE LITERATURE 18

History of Identification of the
Culturally-Diverse Gifted student

Current Identification Practices of
Culturally-Diverse Gifted Students

Identification Procedures in California 37

Gifted Identification Procedures in
San Diego County

Culture and Sex-Role Ideology . 41

The Family as Perpetrators of
Attitudes and Values

$\checkmark$ 
Socioeconomic status $\quad 65$

Parental Occupation 91

Single Parent Homes 96

$\begin{array}{ll}\text { Peer Influence } & 99\end{array}$

$\begin{array}{ll}\text { Summary } & 114\end{array}$

III. RESEARCH DESIGN AND METHODOLOGY 118

Selection of Subject Sample 121

Development of Instrument 124

The Pilot Program 127

Interview Schedule $\quad 130$

$\begin{array}{ll}\text { Procedure } & 131\end{array}$

Research Questions $\quad 135$

Data Analysis $\quad 137$

IV. ANALYSIS OF DATA 138

Research Question $1 \quad 139$

Research Question $2 \quad 149$

$\begin{array}{ll}\text { Research Question } 3 & 160\end{array}$

Research Question $4 \quad 172$

$\begin{array}{ll}\text { Research Question } 5 & 180\end{array}$

Research Question $6 \quad 188$

Research Question $7 \quad 191$

Gifted Program Participation 201

Research Question $8 \quad 205$

$v i$ 
Page

Composites

206

The Black Adolescent Girl 206

The Hispanic Adolescent Girl 208

The Pan/Asian Adolescent Girl 210

V. SUMMARY AND RECOMMENDATIONS 213

Study Objectives $\quad 214$

Research Design and Instrumentation 215

$\begin{array}{ll}\text { Findings and Implications } & 217\end{array}$

Recommendations for Further Study 224

$\begin{array}{lr}\text { BIBLIOGRAPHY } & 226\end{array}$

$\begin{array}{ll}\text { APPENDICES } & 263\end{array}$

vii 


\section{LIST OF TABLES}

Table

Page

1 Questionnaire Item 2: Which of your parents do you feel you are most like?

2 Questionnaire Item 3: How well do you feel your natural mother understands you and what you want out of life?

3 Questionnaire Item 4: How well do you feel your natural father understands you and what you want out of life?

4 Questionnaire Item 5: How close do you feel to your mother and father?

5 Questionnaire Item 8: As you were growing up, how much did your parents encourage you to do things for yourself?

6 Questionnaire Item 9: As you were growing up, how much freedom did your parents give you in making your own decisions?

7 Report of intellectually-gifted, ethnicallydiverse, adolescent girls' discussions with parents.

8 Questionnaire Item 6: How much do you and your parents agree about your plans for the future?

9 Questionnaire Item 10: How much have your parents encouraged you to do well in school? 158

10 Questionnaire Item 28: Report of intellectually-gifted, ethnically-diverse, adolescent girls' discussions with parents and educational plans.

11 Questionnaire Item 1: Are your natural parents living together, divorced or separated, one or both parents deceased?

12 Questionnaire Item 11: How far did your parents go in school? 


\section{LIST OF TABLES (Cont'd)}

Table

Page

13 Questionnaire Item 14: What is your natural father's occupation?

Questionnaire item 15: What is your natural mother's occupation?

14 Mother's and father's general occupational areas.

15 Questionnaire Item 16: How many children are in your family and what are their ages?

16 Questionnaire Item 17: About what total income do your parents earn every year?

17 Questionnaire Item 19: Were you born in the United States? If not, where were your born and at what age did you come to the United States?

18 Questionnaire Item 46: What career/ occupation would you like to pursue?

19 Questionnaire Item 47: What career/ occupation will be probably pursue?

20 Desired Career by Occupational Category

21 Questionnaire Item 49: What do you think will be most important to you as an adult?

22 Questionnaire Item 35: What are your favorite subjects in school?

23 Questionnaire Item 39: Are you doing as well in school academically as you want to? If not, why not?

24 Questionnaire Item 50: As you were growing up, how much did your parents encourage you to do things for yourself?

25 Questionnaire Item 7: Are there other adults with whom you discuss your future plans? 
Table

Page

26 Have you talked to a school counselor or teacher about career plans?

27 Report of intellectually-gifted, ethnically-diverse, adolescent girls' discussions with peers.

28 Questionnaire Item 48: Are there reasons you may not be able to pursue the career/occupation you have chosen? 


\section{LIST OF APPENDICES}

Appendix Page

A Parent Letter of Informed Consent 264

B Survey Instrument $\quad 267$

C Interview Schedule $\quad 282$

$x i$ 
CHAPTER I

INTRODUCTION

The American public schools are, in the opinion of the people of the United states, basic and necessary parts of our democracy. We are convinced that they must, and we hope that they do, provide equal opportunity for every child.

(Warner, et. al., 1944 in Sherer, 1967)

Although written more than four decades ago, this belief in education is an expression of the democratic dream. How does the intellectually-gifted girl fit into this dream, especially if that girl is from an ethnicallydiverse culture?

There is no question that, historically, educational opportunities for women have been limited. "While many early educators simply ignored the education of females, some were explicit in designing education to maintain subservience to men." (Davis and Rimm, 1985; p. 307).

Current statistics show that even today the concept of equal opportunity for many women does not exist. The San Diego Union (1985) reported that the U. S. Census Bureau (1985) statistics showed that the entry of women into the job market accounted for two-thirds of the increase in 
employment between 1972 and 1983. While the percentage of women in managerial and professional jobs rose from 33 percent to 41 percent between 1971 and 1983 , about 22 percent of all working women were in managerial or professional careers in 1983, as compared to 17 percent in 1972. Also, women remain concentrated in "female intensive" occupations -- jobs that have 60 percent or more women. Primarily, these "female intensive" occupations included secretarial jobs, elementary school teaching, bookkeeping, cashier and office clerk --most of which, according to the report, are low-paying jobs.

Additionally, the San Diego Union report shows a continued gap in income between men and women holding the same jobs. In 1983, men in professional specialty jobs had median earnings of $\$ 29,550$, compared with women who earned $\$ 19,200$ in the same position. The report also indicated that 15 percent of the income gap can be explained by the fact that women are far more likely to interrupt their employment for family, thus limiting chances for promotion and higher pay.

Vetter (1986) reported that women's salaries reflect their lesser opportunities for advancement, "They earn less than men in every field of science, in every employment sector, at every degree level, and at every level of experience" (p. 62). However, beginning salaries of men and women with bachelor's degrees more nearly approximate each other than at any other career stage. 
Yet, women who are members of minority populations appear to fare no better..."the employment situations of minority women are affected by racism and sexism," according to AAUW (Sept. 1984, p. 6). Between 1967 and 1980, the population of black women employed as professionals increased by 45 percent. However, these women are concentrated in a few low-paying jobs, with clerical work accounting for almost one-third. In 1982, the percentage of black women employed as managers and administrators was less than one-fourth that of white men. The average wage gap with white men was $54 \%$ per hour for black women and $49 \%$ per hour for Hispanic women.

The Phi Delta Kappan (February, 1986) reported that Hispanics earn the lowest wages of any major population group in the United states because they are the least educated. Obtaining their report from the National Council of La Raza and the Full Employment Action Council, Phi Delta Kappa noted that "the low level of education attained by most Hispanics is 'inextricably bound' to how much they earn in the labor market" (p. 474).

"Higher education not only raises wage rates, it lowers the probability and duration of unemployment spells, which ultimately translate to lower earnings" (p. 474). Citing the Current Population Survey of the U. S. Census Bureau, La Raza reported that Hispanics completed less schooling and learned less than blacks or whites. Additional statistics show that Hispanics will account for at least eight percent of the labor force by 1995 but they 
will be less educated and unable to fill the jobs available. An earlier report by La Raza showed that at least 35 percent of the Hispanic 19-21 year olds had dropped out of high school as compared to 25 percent of the blacks and 15 percent of the whites. In 1983, only 50.3 percent of Hispanic 18-19 year olds had graduated from high school as compared to 75.6 percent of the whites and 59.1 percent of the blacks. Yet, Hispanic females, it was noted, are more likely to drop out of school than are Hispanic males. One reason suggested is that it is quite socially acceptable for women to drop out of school to marry and to have children. They may be following the expectations of their culture which may not see the value or necessity of having a high school diploma.

In a report on black, urban youth, Gibbs (1984) indicated that while other demographic groups in our society have made "significant social progress" during the last 20 years, black youth (particularly ages 15-24) have not. When compared to other socioeconomic groups, blacks show higher unemployment rates, more babies born out-ofwedlock and more extensive substance abuse.

In 1985, average salary offers to women graduates were 98 percent of offers to men in mathematics and 89 percent in the biological sciences. Only in computer sciences, environmental sciences and biological sciences has the ratio improved. The salary gap that exists at the beginning of a doctoral career in science widens with age. "In 1984, female medical researchers with five or less 
years' post-doctoral experience made 94 percent of their male counterparts' salary. That salary gap stretches to 73 percent at 21-25 years' experience" (p. 63).

In higher education, women comprised 51 percent of the students enrolled in four year colleges and universities and 55 percent of the students enrolled in two year colleges, yet they continue to account for a small proportion of enrollments in high income-yielding advanced programs -- 8 percent of the doctorates in computer science in 1981-82; 5 percent in engineering; 25 percent in medicine and 33 percent in law. The number of women faculty in higher education institutions remains less than the increase in the number of female students. In May of 1984, women comprised 26 percent of higher education faculty members; 10 percent of full professors; 20 percent of associate professors, 35 percent of assistant professors; and 52 percent of the instructors. Approximately half of women faculty are tenured compared to 70 percent of the male professors who are tenured. The average woman's salary at every professional level is 85 percent that of her male counterpart. Ninety percent of men with experience are full professors while only half of the women with the same level of experience have attained that level (AAUW, 1984).

Vetter (1986) in Science 186 noted that in 1984 approximately equal numbers of men and women receiving PhD.s had university fellowships, yet women in science were less likely to have had research assistantships in which 
they were paid to do research. In 1985, women constituted only 17 percent of PhD.s employed in science; 35 percent of women with science PhD.s were involuntarily unemployed.

Rubin (1986) reported that Princeton University did not accept women in graduate physics until 1971, in graduate astronomy until 1975 and in graduate math programs until 1976.

Many researchers believe that high level intellectual ability can be found in every ethnic and racial group, as Terman reported in his classic Genetic Studies of Genius in 1947 and as Mcclelland (1965) wrote nearly twenty years 1ater:

As students from impoverished backgrounds and from racial and ethnic minorities have achieved when provided with appropriate educational opportunities, they have demonstrated that the right kinds of education can indeed transform potential into actual talented performance.

$$
\text { (In Sato, 1974, p. 572) }
$$

Safter and Bruch (1981) developed a Differentiated Guidance Model (DGG) to clarify the process for determining individual guidance plans for particular gifted students. It is the belief of the authors that the gifted differ from each other in more ways than they resemble each other. Chosen from the literature, the variables -- the type of giftedness, socioeconomic status value orientation of the family and the grade or developmental level of the child -- 
"appear to be crucial for determination of guidance and counseling procedures for the gifted child" (p. 167). Among the "differentiated needs" of the gifted are those of the gifted female:

Gifted Female

1. Experience conflict between sex-role stereotype and expectancies and career, including nontraditional career choice.

2. Demonstrate uncertainty concerning the balance of family and career.

3. Frequently lack non-sexist dissemination of information for academic preparation and career exploration beginning in elementary school.

(p. 169)

\section{Culturally-Diverse Gifted Female}

1. Have the outer pressures of the dominant culture and the inner pressures of the often nonsupportive minority culture.

2. Experience alienation from peers, family and subculture as a result of upward mobility, or intense pressure to succeed as a means of upward mobility.

3. Find teachers focus traditionally on deficits while strengths are overlooked.

$$
\text { (p. 170) }
$$

Writing about the career development of minority women is difficult for a number of reasons. One reason was noted 
by Payton (1985) who wrote "...for both what we are and the image we project may be as much the consequence of how we have been portrayed as they are a consequence of genetics, gender, and/or socialization" (p. 75).

In fact, Cross (1983) suggested that the needs of the girl who comes from a culturally diverse environment may be even greater than the needs of the girl from the Anglo culture. The gifted girl from the dominant or Anglo culture may face problems associated with vocational choices, pressures from parents, and being developmentally ahead of her peers. She may also be concerned about whether she will relinquish social acceptability and of being perceived as unfeminine by being academically successful. The ethnically-diverse girl may, in addition, encounter discrepancies between the expectations of her culture as well as those of the dominant society. The Mexican, black and Asian girl may be listening to and intuiting some very real cultural expectations and values transmitted through her parents, peers and her community. These beliefs and attitudes may provide her with a dilemma between what she may have the capability and interest in doing with her life and what she perceives others expect her to do.

The gifted girl's motivation and desire to know, understand and develop mastery then can be instilled or blunted by family, peers, teachers and the community. Talented youngsters outside the cultural or ethnic mainstream may experience special obstacles in their development because of lack of understanding, support and/or stimulation (Perino and Male, 1981). 
If the ethnically-diverse girl is perceived as disadvantaged or intellectually inferior, she, in turn, is likely to have no motivation to excel in school nor to pursue a professional career.

Chusmir (1983) cited Fox and Renas (1977) who explained that career choices start with a mix of four variables which form an individual's career aspirations: (a) environmental stimuli, such as advertising and books; (b) education; (c) reference groups, including counselors; and (d) personal characteristics (p. 43). These factors help to create a person's self-perception. This, in turn, influences career aspirations (Chusmir, 1983).

The choice of a career is a personal one which may be based on a realistic look at and assessment of an individual's interests and abilities. On the other hand, the decision of a future occupation/career may be the result of drifting in the direction of least resistance. What about the community and her friends? Does she perceive their cultural values as being influential in her life planning decisions?

"The problems and, therefore, the solutions lie partly within the family and its representation of the subculture, partly with the dominant society and expressed through the people of the mainstream culture and partly with the school as translator of the dominant society's values and attitudes."

(Clark, 1979, pp. 305-306) 
Altman and Grossman (1977) indicated that these values and attitudes relate to the actual choice of career that young people make.

Little is known about the specific variables which direct the life planning of the gifted female from a nonAnglo culture. Most studies related to career choice and occupational aspirations have limited utility because minority women have been excluded from the sample (McNair \& Brown, 1983). The current study differs then in that it focuses only on females who are members of a minority population -- black, Pan/Asian and Hispanic.

\section{Statement of the Problem}

It is the belief of this researcher that an awareness and increased understanding of the cultural attitides and beliefs which the ethnically-diverse girl perceives as influencing her life planning can assist parents, teachers, counselors and all who work with these gifted girls as each girl plans for her future.

The primary focus of this paper was to examine and assess cultural influences as transmitted by the parents and perceived by the ethnically-diverse, intellectually-gifted adolescent girl as affecting her future life planning.

The secondary purpose was to examine and assess influences the adolescent, intellectually-gifted, ethnically-diverse girl perceives as being transmitted by 
the community which impact her future plans. These findings are to provide parents, teachers, career counselors and gifted coordinators with an increased understanding of the perceptions the ethnically-diverse gifted girl perceives as affecting her future plans.

In order to accomplish these purposes, this case study examined the perceptions of three groups of girls: a group of 14 intellectually-gifted black girls, a group of 20 intellectually-gifted Mexican-American girls and a group of 17 intellectually-gifted Asian girls. The research questions selected to guide this study were as follows:

1. What is the extent of the ethnically-diverse, intellectually-gifted adolescent girl's relationship with her parents?

2. What is the extent of the ethnically-diverse, intellectually-gifted adolescent girl's interaction with each parent relative to career choice/future life planning?

3. What influences, as related to the family's sociological environment affect the career choice/future life planning of the ethnicallydiverse, intellectually-gifted adolescent girl?

4. Are occupational choice/life planning goals clearly defined by the ethnically-diverse, intellectually-gifted adolescent girl? 
5. What is the ethnically-diverse, intellectuallygifted adolescent girl's perception of herself and her ability to pursue a career commensurate with her ability?

6. Who else does the girl perceive as influencing her future life plans?

7. Does the ethnically-diverse, intellectuallygifted adolescent girl perceive that the lifestyle plans of her peers influence her own life planning?

8. To what extent do the perceptions regarding cultural/parental influences vary for the intellectually-gifted adolescent girls between the three ethnic groups? 


\section{Definition of Terms}

Gifted - As defined in California (California state Department of Education publication, 1979), mentally gifted minors are those youngsters in the upper two percent of general mental ability. The gifted students' talent may lie in one or several academic fields, but this talent may also be a unique ability with respect to a certain aptitude or in connection with one cognitive, perceptual or affective area (Clark, 1980).

Ethnically Diverse - For the purpose of this study, ethnically diverse will be members of the Mexican American, black or Pan/Asian cultures.

Traditional Role - Wife and mother.

Traditional Career - For the purpose of this study, traditional career will refer to those careers women have traditionally chosen. These might include nursing, teaching, secretarial work, bank teller. These careers may or may not require a college degree. The Department of Labor identifies traditional careers as those in which the representation of women is over 62 percent. 
Non-Traditional Career - For the purpose of this study, non-traditional careers will indicate those not usually chosen by women. These require a college degree and, in some cases, graduate study. Such careers include those of architect, physician, engineer, attorney, and research scientist. Non-traditional careers for women are those in which the representation of women is under 30 percent.

\section{Significance of the study}

Among global trends related to career guidance, the most apparent movement has been toward increased women's literacy and education (Sundal-Hansen, 1985). While major trends include continuing education for women in the United States, Labor Department statistics (1980-1981) suggest that many women are still underrepresented and underpaid in many professions.

Changing roles of women provide one of the dominant trends across cultures today. According to Sundal-Hansen (1985), one of the most dramatic changes in women's roles is seen in the increased participation within the work force.

However, as indicated in the introduction, the distribution of women is concentrated in a few generally traditional occupations. In noting the dearth of women in high-status, non-traditional careers, Miller (1981) states that intellectually gifted females are among the most subordinated and underachieving groups on this planet. 
One of the most evident and dramatic changes in the cultural fabric in recent decades is the change in attitudes about women's roles. There has been a large-scale influx of women in the labor force and a shift in their aspirations toward higher status jobs and away from clerical and service occupations (p. 410). Yet, occupations are still frequently segregated by sex and women as a group and ethnicallydiverse women, in particular, are still paid less than men (Young, 1983).

Women need to be provided with an "expanded concept of career" which includes choices that may be inclusive of career and family. This means helping women understand how the various parts of their lives fit together and to be able to gain a sense of self-direction by shaping the parts in ways meaningful and satisfying to them (Sundal-Hansen, 1985).

The gifted girl from a black, Mexican-American or Asian background can be a leader in education, science, human relations, business or any field she chooses. Being aware of her talents and intellect and not being abie to use them denies her fulfillment and deprives society of a valuable resource. If educators believe in providing equal opportunity for all children, it is imperative that they also assist the ethnically-diverse, gifted girl in selecting a life goal commensurate with her abilities.

Yet, as indicated in the review, very little is known about the cultural attitudes, beliefs and values which 
influence the life planning of the black, Mexican-American or Asian girl who is intellectually gifted. The importance of this study is the addition to the sparse amount of literature about the gifted girl from a minority background. It is the belief of the researcher that an awareness and increased understanding of the cultural attitudes and beliefs the ethnically-diverse girl perceives as influencing her life planning is important. Knowledge of variables affecting her future can assist teachers, parents, counselors and others who work with the gifted black, Mexican-American and/or Asian girl to provide information about career options to monitor and to assist the girl in planning a future commensurate with her ability.

\section{Assumptions of the study}

1. It is assumed that the participants will respond to the questionnaire in a manner which will allow them to express their perceptions honestly and thoughtfully.

2. It is assumed that in responding to the interview, participants will not be fearful or hesitant in revealing their true feelings.

3. It is assumed that during the interview the researcher will respond to and record answers from the subjects in an unbiased manner. 


\section{Limitations of the study}

This case study was designed to look at cultural influences, as transmitted by parents and peers and perceived by ethnically-diverse gifted girls. One limitation is that the participants in the study may not have been selected for inclusion in a gifted program by means of an intelligence test score, but instead meet the criteria as determined by the specific school districts in which the study will be conducted. The study was limited to self-report of perceptions. The answers given to the questions on the Family Background Questionnaire (demographic items) was limited to the individual student's knowledge of and/or access to information requested in the instrument. Due to the sensitivity of the questions, some school districts would not allow the researcher access to ethnically-diverse, intellectually-gifted girls. An additional limitation was that the researcher selected the sample from a district which would allow the study to be conducted. 
CHAPTER II

REVIEW OF THE LITERATURE

This chapter has as its focus a review of literature relative to the research topic, Influences Affecting Occupational Aspirations of Ethnically-Diverse, Intellectually-Gifted Adolescent Girls. The literature includes a description of practices in the identification of ethnically-diverse gifted students; the identification process in California; the influence of culture and sex role ideology on aspirations of females; the influence of family on the development of values and attitudes of the female; the effect of parent occupation and socioeconomic status on career choice of the adolescent; and peer influence on adolescent achievement and aspiration.

It became apparent in early as well as later stages of this review that studies pertaining to intellectuallygifted, ethnically-diverse adolescent women were limited. A comprehensive search encompassed many sources. Strategies included use of ERIC Clearinghouse on Gifted and Handicapped, and the Lockheed DIALOG System on Psychological Abstracts and the Lockheed DIALOG on Sociological Abstracts. Descriptors used were human females and gifted, occupational choice, junior high school students, middle school students, 
perception, Mexican-Americans, black, Asians, parent-child relations, sex-role attitudes and ethnic values.

Professional journals, abstracts, periodicals, books, microfilms and dissertations were researched in library collections at the University of San Diego, San Diego State University, the University of California at San Diego and the University of California at Los Angeles.. -

Much of the research related to career choice/life planning has been conducted with gifted Anglo youngsters. These include studies by Jepsen (1981) and Fox (1982). Jepsen, for example, found that longitudinal career patterns for Anglo gifted revealed the importance of self-directed decisions and family background on adult careers. Fox conducted an investigation of social processes and sex differences that might hinder or enhance the development of interest, self-confidence and competence in the study of mathematics among seventh grade girls (Fox, 1982).

Results of Fox's study indicated no significant difference among five groups of boys and girls regarding socioeconomic and family constellation variables, but highly motivated girls who had accelerated their study of mathematics had lower levels of self-confidence than highly motivated boys. Mothers of boys noticed the son's ability at an earlier age than mothers of girls, and most parents felt daughter's scores might not be as important because daughter's careers would need to be interrupted for child raising. Although all the girls were extremely talented in 
mathematics, they had not been viewed as unusually gifted by teachers.

It should be noted that when a study provides an appropriate and applicable insight into cultural influences related to career choice of the intellectually-gifted that study will be included.

History of Identification of the Culturally-Diverse Gifted Student

"Schools in the United States are generally oriented toward the education of the average student. It is the repository of the middle-class culture and value system, which operates as major educational influences, that shape the lives of students" (Khatena, 1982, p. 236). The potential of many gifted learners has been overlooked in schools, particularly the student from a minority culture (Sato, 1974; Bernal, 1976; Wells, 1985). Jackson (1950) listed six problems of the gifted black student -- problems which might also be applied to certain populations of gifted young people from Mexican and Asian cultures. These students were:

1. Less likely than their white counterparts to be identified as superior.

2. Less likely to be in a school which gives special attention to their needs.

3. Less likely to have adequate educational and vocational guidance. 
4. Less likely to have an intellectually stimulating environment and, consequently, less likely to achieve the upper limit of their potential.

5. More likely to be of low socioeconomic status and, therefore, less likely to persist and achieve at high levels in school.

6. More likely to become preoccupied with racial matters to the detriment of achievement in other areas (Colangelo and Zaffran, p. 312).

Adolescents from minority cultures have some particular needs and problems. Some adults pay less attention to gifted minority students than white students so they are more likely to be overlooked for placement in advanced classes. Some adults perceive bright minority youngsters as "difficult" because the adults resent their questions or their assertiveness. In addition, the most intelligent students are more apt to be aware of prejudice and be preoccupied with racial or ethnic matters (Nielsen, 1982).

Yet, while giftedness is not the product of "white, middle-class America, generations of educational programs serving the gifted have been composed almost exclusively of such individuals" (Alexander and Muia, 1982, p. 45). Reasons given for this exclusivity include: (1) the fact that the discovery of giftedness is hindered by traditional definitions of giftedness which favors the traits found in white, middle-class students; (2) standardized tests used to 
assess giftedness tend to be culturally biased and, thus, overlook the culturally different individual's potential; and (3) the culturally different (child) must often function in an atmosphere that treats him or her as disadvantaged or inferior.

\section{Current Identification Practices of Culturally-Diverse} Gifted Students

Testing has been part of the educational process for many years and was primarily used to evaluate learning and occasionally for IQ information for placement of a child (Yarborough and Johnson, 1983). The history of identification of intellectually-gifted youngsters has been closely tied to standardized tests of $I Q$ and achievement (Colangelo, 1985; Tuttle and Becker, 1985). Zettel (1979) notes that the most common standard of measuring intelligence is the attainment of at least two standard deviations above the norm on an achievement test or a score of $130+$ on an intelligence measure.

However, the use of standardized tests which are not normed for ethnic populations has been cited as one of the reasons for the small number of identified gifted students among certain ethnic populations. "In fact, they may reflect racial and/or socioeconomic bias and reinforce existing inequalities in the selection of these children..." (McKenzie, 1986, p. 93). 
"Research neither supports nor refutes the many methods recommended for identifying gifted youngsters"...and the lack of substantial research has prompted various sources of criticism toward present identification and/or selection methods (Alvino, McDonnel and Richert, 1981, p. 124).

High and Udall (1983) reported finding a school district which had a minority population of 43 percent, but only 11 percent had been identified and admitted to the gifted program -- apparently the result of using inappropriate identification measures.

As early as 1959, Pegnato and Birch asserted that standardized intelligence tests are culturally biased because they assume a common cultural background in terms of associations, experiences and verbal facility with the English language as spoken by the majority of students in the United States.

Baer, cited by Adkins and Sherwood (1984), criticized the use of standardized tests as being highly unreliable and that culturally-diverse children could be excluded on the "basis of test scores and other forms of institutional discrimination that camouflage their giftedness (p. 337).

Reynolds (in Maestas, 1985) summarized the concern of the researchers when he cited potential bias as "inappropriate test content, inappropriate standardization samples, examiner and language bias, inequitable social consequences, measurement of different constructs and differential predictive ability". 
Using a frame of reference that is considered middleclass in terms of test items and norm groups, results show that the average performance of culturally-diverse children tend to be one standard deviation below the mean on aptitude and achievement tests (Passow, 1973).

In 1981, 1,000 members of the gifted community in the nation were surveyed for their perceptions and judgments of the most frequently and effectively used test instruments and techniques in identifying gifted and talented persons (Alvino, McDonnel and Richert, 1981). The data were analyzed for existent and recurring patterns and trends in relation to the federally-defined categories of gifted identification (general intellectual ability, special academic aptitude, creativity or productive thinking, ability in visual or performing arts and leadership ability). Also included were items about certain federallydesignated subpopulations (disadvantaged, ethnic minority, limited English speaking, rural and exceptionally gifted).

The trends which emerged from the comparative analysis of the data indicate some disturbing and inappropriate recurrent practices in the identification of gifted individuals, according to the researchers. From a psychometric view, many tests/instruments are being used for purposes and populations completely antithetical to those for which they were intended or designed. For example, some practitioners use $I Q$ and achievement tests to identify nonintellectual, nonacademic talents such as creativity, talent 
in the arts and leadership ability. In general, "results showed that most identification of gifted students continues to be of general intellectual ability through use of intelligence (IQ) tests, and secondly, rampant use of informal and subjective measures is taking place" (Alvino, McDonnel and Richert, 1981, p. 130).

Results prompted the researchers to conclude that in many respects the decade since the appearance of the Marland Report (1972), the first national study on the state of the art of gifted education, has not seen significant progress in correcting problems of identification as cited in the report.

In 1983, Yarborough and Johnson surveyed 87 gifted/talented programs for identification practices. Practices revealed on the 1981 survey apparently were no different in 1983. Yarborough and Johnson indicated that dependence on measures of cognitive ability was the prevailing basis for selection in a gifted and/or talented program. Achievement tests were used in 93 percent or 38 of the 41 responding who described their district as gifted/talented. Sixty percent or 52 of the 87 who responded used individual intelligence tests, and 51 percent or 44 used group tests to identify students for placement in gifted programs. IQ tests were most used in programs for the academically gifted. Seventy-three percent or 64 programs used individual tests and 61 percent or 53 used group tests. IQ tests were also used in 60 programs to 
identify children who would take part in personal development classes. The authors of the study report that this finding was in direct contradiction to "popular rhetoric" which insists that behavioral data replace the role of hard-line cognitive test scores. Yet, Yarborough and Johnson wrote that "disappointingly, some newer types of tests...tests of creativity...culture-free tests, or even specific attitude tests were rarely used. A mere 17 percent or 31 programs used culture-free tests (p. 137). Grades were used more often in identification processes than any type of interview.

Alexander and Muia (1982) indicated that the effects of native language or dialect on test performance has not been studied sufficiently. Tuttle and Becker (1983) and Masten (1985) suggested that the cultural bias of traditional tests lies partly in the fact that most tests rely on the printed word and the English language. Standardized tests assume a common cultural background in terms of associations, experiences and verbal facility with the English language, as spoken by the majority of Anglo students in the United states. The assumptions of these tests is that students will have knowledge of the information being asked (Pegnato and Birch, 1959; Tannenbaum, 1983).

There is reason to believe that culturally different societies reinforce different intellectual abilities selectively (Bernal and Reyna, 1974). For example, the typical culturally different student may have a divergent 
profile of abilities, thereby raising the risks of having the best minds from these groups go undetected, according to Bernal.

In 1974, Bernal and Reyna surveyed 300 Mexican-American adults to identify their definitions of giftedness. These definitions were then "distilled" into behavior-rating and adjectival scales for parent evaluators to use in the identification of their children. Results showed that Mexican-American parents believed the requirements for giftedness were verve, style, intelligence, free use of imagination, being more aware and associating with adults. For the children studied, the researchers found that significant representations existed for gifted and nongifted and that adjectival as well as behavioral ratings distinguished the Mexican-American groups.

Clark (1980) indicated that the incidence of giftedness differs from one cultural group to another. Differences result from differing values, attitudes and opportunities as well as cooperation, production of certain kinds of talent, and spiritual leadership. "What is valued by the culture is produced by the culture" (p. 338).

Sullivan (1973) suggested the development of a social and humanistic psychology emphasizing the importance of how the individual interacts with his/her environment. If the particular strengths of minority children were defined, educators could utilize this social and humanistic psychology in the assessment of these strengths. 
Jensen (1973) cited by Nielsen (1982) as one of the most famous defenders of intelligence test claimed that 80 percent of the test score is due to inherited abilities that experience cannot alter. Basing his conclusions on intelligence test scores from World War II servicemen and subsequent research in which scores of black Americans were lower than other minority groups, he contended that tests are not culturally biased because blacks and Caucasians usually miss the same difficult questions.

Davis (1978) reported that the gifted black child performs better than white peers in the last three categories of the federal definition (leadership ability, visual and performing arts and psychomotor ability). However, since these three categories have received less attention, test procedures are less well developed and large numbers of black children are probably left unidentified. "There is a great deal of giftedness among the culturally different and the waste or underuse of these resources is tragic" (Masten, 1985, p. 83).

During the last ten years, there has been a "flurry of bias and validity investigations" with - respect to the identification of Mexican-American students (Valencia and Rankin, 1985). Evidence indicates a strong link between performance on an intelligence test and language fluency. In fact, one of the strongest predictors of intellectual ability is child and parental language (Valencia, Henderson and Rankin, 1981; Valencia, 1983; Valencia and Rankin, 
1985). Yet, psychometric studies conducted with MexicanAmerican subjects have assumed those children to be dominant and fluent in English (Valencia and Rankin, 1985).

Valencia and Rankin (1982) sampled 304 Mexican-American children attending preschools in California to examine possible MSCA (McCarthy Scales of Children's Abilities) content test bias. The dominant language of 142 children was English and that of 162 Spanish. Results showed that in 12 of the 21 MSCA comparisons, there was a significant difference in favor of English-speaking children.

Attempts have been made to rectify the limitations of standardized tests or to find satisfactory methods of identifying intellectually-gifted children from ethnicallydiverse cultures through the use of "culture-free" or "culture-fair" tests. In 1975, Samuda focused attention on expansion and elaboration of psychometric devices rather than on their discontinuance when measuring the abilities of minorities. However, these "culture-fair" or "culture-free" tests "have proved disappointing and have fallen short of their goals; for minority students have been shown to perform....at least as badly as on conventional intelligence measurements" (Coleman, 1960, p. 94).

One cannot tell whether these accusations are valid today; however, attempts to correct some of these alleged deficiencies have included such steps as the translation and norming of the Weschsler (WISC-R) in Mexico as part of the System of Multicultural Assessment (SOMPA). In addition, the 
Spanish-speaking version of the WISC-R is avilable for Spanish-speaking children in the United States (Valencia and Rankin, 1985). The Abbreviated Binet for the Disadvantaged (ABDA; Bruch, 1971) was developed from the stanford-Binet, which was administered to and biased in favor of black populations. The Black Intelligence Test of Cultural Homogeneity (BITCH; Williams, 1972) condemns intelligence testing as "scientific racism" that underwrites racial discrimination. Other opponents, according to Nielsen (1982) cited poor education, nutritional deficits, weak test-taking skills, inadequate parenting and culturally biased questions as reasons for low test scores by minority groups.

For certain other cultures, particularly Native American and Asian, Alexander and Muia (1982) indicated the availability of culturally sensitive or culturally appropriate instruments is even more limited. The structure of Intellect-Learning Abilities Test (SOI-LA) developed by Meeker and Meeker (1976) has been used in the assessment of potentially gifted Navajos. The de-emphasizing of verbal abililties and the emphasis on figural abilities is applicable with other tests as well.

While IQ tests may be fair to people from a variety of cultural backgrounds, Kirschenbaum (1983) believed there is a direct relationship between socioeconomic status and test performance. Citing a study by Freeman (1979) regarding the relationship between socioeconomic status, IQ and giftedness, it was found that $I Q$ is progressively 
contaminated by home environment in the superior IQ range. In addition, gifted youngsters from low socioeconomic homes are less likely to obtain high scores on IQ tests.

In addition, Torrance (in Tannenbaum, 1982) believed traditional tests are biased when administered to culturally diverse youngsters because such tests place emphasis on rapid response, verbal comprehension and answers that are correct because they are expected to be learned in the middle class home of the child who belongs to the dominant culture. Torrance has developed the Torrance Test of Creative Thinking Abilities. He believes this instrument produces a truer picture of giftedness because of the fact that the items explore more than just cognitive ability. Other tests used to measure giftedness, which Khatena (1982) mentioned, are the sOI (structure of Intellect - Meeker, 1975), Learning Abilities Test and the Black Intelligence Test of Cultural Homo-geneity, which consists of 100 multiple choice questions to be answered as Black people would answer them.

Chambers, Barron and Sprecher (1980) conducted a study constructed with items based on traits of adult gifted persons, to compare the child's traits with those of his peers. The results showed:

1. That it is possible to identify MexicanAmerican children with potential for future high-level, intellectual/creative contributions in a simplistic effective manner. 
2. The abilities and traits necessary for future high level intellectual/creative behavior appear to be similar for both culturally different and culturally similar children. It was noted, however, that lack of adequate verbal skills in culturally different children prevented measurement of some traits.

Using results of the study, it was hypothesized that five percent of the Mexican-American children within a school who show the greatest potential for future contributions of a high intellectual creative nature could be admitted to programs in which they had been left out because of the high cut-off score of widely used, verbally based IQ tests.

However, attempts to devise solutions should be treated with caution because of two additional considerations, according to Baca (1970):

The reader should be careful not to generalize from one diverse population to another. It is even difficult, if not impossible, to generalize within a single minority group because of the regional, cultural, linguistic and other types of differences that prevail (p. 583).

One of the few studies reported about the identification of culturally-diverse students was that of 
Asian children from a low socioeconomic background (or considered culturally disadvantaged). Chen and Goon (1976) chose schools in Manhattan's Lower East Side. Contrary to current criticism at the time about test bias with ethnically-diverse children, these researchers found no evidence of bias in identification. Within the seven public schools, enrollments of Asians ranged from 11.12 percent to 99.04 percent of the entire school population. Of the sixth grade students recommended for gifted programs, 38.9 to 100.0 percent of the children tested qualified as intellectually gifted.

A significant finding was the greater the number of Asians in the population, the greater the number of Asian students identified as gifted. Thus, the proportion of Asian students among the total number of gifted students in the population was greater. This fact, although reported ten years ago, corresponds to the statistics in the introduction which stated that Asian women were overrepresented in the number receiving college degrees as compared to their number in the population.

While the subject sample of Chen and Goon's research possessed several barriers leading toward success, i.e. nonEnglish speaking, backgrounds, no active parental influence upon school performance, presence of a non-Asian teacher, low socioeconomic status -- the incidence of giftedness was high. The researchers hypothesized that (1) it may be that teachers and students in the study may have exhibited a 
greater number of culturally unbiased behaviors, and (2) perhaps culture and social class are not major deterrents in the education of ethnically-diverse children.

One of the more controversial yet most frequently used sources in the identification process is teacher recommendation. Many researchers belive this to be one of the least reliable sources of information as compared to standardized IQ tests, achievement test scores, parent nomination or peer nomination (Martinson, 1974; Stanley, 1978; Fox, 1981). Alvino and Wieler (1979) indicated that if teacher recommendation became the principal source of identification, 50 percent of the gifted would go unidentified.

Judy (1984) cited a 1957 thesis by Burkhardt which addressed one of the reasons regarding the disadvantage of teacher identification:

Teachers often confuse achievement with
intelligence. They are inclined to favor the
friendly, mild-mannered, well-behaved and
hard-working child and to slight the
restless, over-inquisitive and non-conforming
child in judging intelligence and that they
often fail to consider age-in-grade
differences as well.

(p. 16)

While high ability may be found in every ethnic and racial group (Martinson, 1972; Terman and Oden, 1947), there 
are demonstrable differences in the percentages of children from various racial groups who fall into the category of gifted (Barbe, 1965). These differences show superiority in northern European ethnic groups as opposed to southern European ethnic groups and racial minorities (Kirk and Gallagher, 1983).

Kirk and Gallagher stated that social scientists believe certain cultural advantages accrue to the "favored groups, advantages that allow the gifted to maximize their cognitive development" (p. 78). This concept is given further support by the high proportion of gifted children from Jewish and Oriental families. Both of these cultures, according to the authors, encourage the pursuit of intellectual activities. Thus, consideration needs to be given to the different values of particular cultures when making judgments about whether certain young people fit into a gifted description.

Still, every social structure and every period of history responds differently to human potential, and individuals earn renown because their 'chemistry' fits the current need, time and milieu. The 'milieu' reflects tradition and what society is experiencing at a given moment (Tannenbaum, 1983).

Powell (1983) quoted Tulkin (1972) who concisely described the difficulties the minority group member may face:

A majority culture...promote a narrow 
definition of success in order to insure that the power of the society remains in the hands of a relatively select group within the society. Thus, maintaining that any deviation represents cultural deprivation, the white middle class is guarding its position as the source of culture and power in this nation. Cultural deprivation then is not just a psychological or educational issue; it is also very much a political issue.

(p. 109)

Harty, Adkins and Sherwood (1984) conducted an extensive study of giftedness identification measures in which the dependent variable was thirteen identification measures and the independent variable three groups of second and third grade students. Measures of scholastic aptitude, giftedness potential assessment (learning and creativity), student peer identification and locus of control were found to be sensitive discriminators of giftedness. Giftedness potential assessment (creativity and learning), basic skills math and locus of control were found to discriminate least among economically disadvantaged and/or minority students. Teacher judgment, student self and parent perception were considered insensitive discriminators of giftedness and somewhat biased toward disadvantaged and/or children from 
ethnic minorities. Scholastic aptitude was a sensitive discriminator of giftedness across the three treatment groups and was, thus, considered one of the better discriminators of giftedness.

Gallagher (1985) defended the criticism of teacher identification by writing: "When teachers rate students on scales of Rating the Behavior Characteristics of Superior students,...one may find higher ratings for Anglo than Hispanic or Black students. This has been sometimes interpreted as representing $a$ form of teacher bias or discrimination. However, the teachers (may be) faithfully reproducing what they observe and what they observe is the result of differential stimulation and encouragement for school learning. At school age such differential encouragement can result in clearly different behavior in the classroom" (p. 433).

Payton (1985) wrote: "Until there is truly a culturefree test for assessing either intelligence or academic achievement, the Scholastic Aptitude Test (SAT) and the American College Test (ACT) will continue to underestimate the abilities of most minorities" (p. 86).

\section{Identification Procedures in California}

A gifted and talented pupil is defined as a "pupil enrolled in a public elementary or secondary school of this state who is identified as possessing demonstrated or 
potential abilities that give evidence of high performance capability in one or more of the following categories which are used to define such capability: intellectual creative, specific academic, or leadership ability; high achievement; performing and visual arts talent...." (California Education Code, Sections 52201 and 52202).

Each school district has the responsibility for the development of a method of identification which results in a summary of evidence supporting the extraordinary ability(ies)/talent( $s$ ) of a pupil. The methods set forth in the California Adminstrative Code, Title 5, Section 3820 include: (a) standards which insure the identification of pupils who possess a capacity for excellence far beyond their chronological peers; (b) methods designed to seek out and identify those pupils whose extraordinary capacities require special services and programs; (c) provision for examining a pupil's range of capacities; (d) methods and techniques of identification which generate information as to a pupil's capacities and needs; (e) equal opportunity to be identified in the categories served, and (f) methods designed to seek out and identify gifted and talented pupils from varying linguistic, economic and cultural backgrounds. Evidence for identification needs to be compiled which shows the pupil's capacity for excellence beyond his/her chronological peers. Appropriate data may include school, class and individual records; individual tests; group tests, interviews and questionnaires and data which should be broad 
enough to reveal talents across cultural, economic and linguistic groups. Evidence may also emanate from pupil products, comments from peers and assessments from a professional person. In addition, the evidence should reflect consideration of the economic, cultural and linguistic characteristics of the pupil's background (California Education Code, Sections 33031 and 52203).

Referrals may be made by teachers, staff, students, community, parents and peers. The final determination of eligibility should rest with the superintendent or a designated employee of the school district. The decision should be based on the evaluation of the evidence by the school principal or designee, a classroom teacher and, when appropriate, a credentialled school psychologist. A person recognized as an expert in the gifted and talented category under consideration and/or an individual who has in-depth understanding of the pupil's linguistic or cultural group should participate in the evaluation process.

Using results from a national survey conducted by Yarborough and Johnson (1983), California's method of gifted identification appears to be representative of those used by other districts in the United States. According to the researchers, a combination of IQ, achievement, and behavioral checklist data is used in 78 percent of the programs for the gifted and 85 percent of the programs for the gifted and talented. Yarborough and Johnson found only 17 percent of the districts surveyed used "culture-free" 
tests. This researcher found that none of the seven local districts surveyed used "culture-free" tests to identify minority gifted students. However, as indicated earlier, additional points were added to the identification criteria if a student was considered culturally disadvantaged.

Culturally disadvantaged may mean the use of English as a second language and/or low socioeconomic level. Teacher/ guidance counselor recommendation also added points to the youngster's total score.

\section{Gifted Identification Procedures in San Diego County}

An informal survey of seven school districts in san Diego County revealed the following composite of identification procedures:

Referrals may be made through teacher, parent request, the individual student, a peer, or by attaining a high score on an achievement test (between 70 and 99 percent on the language and math sections) for placement in program for intellectually-gifted students. One school district has employed a "Teacher's Checklist" on which the teacher records observations of the student related to leadership traits, peer relationships, evidence of creative thought and other non-academic attributes. 
An identification form is used which lists the categories examined and on which scores are recorded. For example, a student may receive between 1 and 14 points according to his/her score on an individual or group intelligence test, 1-3 points for a student whose language and culture may have inhibited academic success, $I$ point for economic disadvantage, 3-7 points for achievement test scores and points for a portfolio of work if the student is applying for placement in the visual and performing arts component.

\section{CuIture and Sex-Role Ideology}

Culture has been defined as social heredity transmitted by one generation, learned by another and shared by the particular collectivity which possesses it. Conceptually, culture is a system of symbols which orders experience and guides behavior. These symbols might be translated as values, beliefs and attitudes which members of the culture develop to insure the maintenance of the status quo of the system -- and, in this instance, the culture (Rainwater, 1979). These roles and rules become cultural norms -- ideas about how members of the culture are expected to behave. These norms are used by the members as reference points to measure their behavior with other members of the same culture. The messages about what is appropriate and acceptable behavior are incorporated into the child's 
personal belief system and affects how he/she feels, thinks and acts.

According to Hurlock (1974), "Cultural influences play an important role in the development of interests by controlling learning opportunities. The child is given opportunities to learn the interests the group considers appropriate but is denied or deprived of opportunities to learn interests the group considers inappropriate" (p. 578).

Values have been defined as beliefs about desired end states of existence or preferred modes of conduct. Sex-role beliefs can be represented as instrumental values because the behavior (sex-role) about which the value is held is a mode of conduct. The purpose of Young's study was to examine value differences among adolescent girls who aspired to traditional, innovative or moderate careers. Five hundred ninety lith grade subjects were administered the Rokeach Value Survey (because it measures beliefs specific to modes of conduct) and the Internal-External Locus of Control scale. Significant value differences were found among females who chose innovative or traditional occupations. Females aspiring to traditional occupations ranked the values "clean," "forgiving" and "helpful" as more important than other values; females aspiring toward innovative occupations chose "courageous," "imaginative" and "independent" as more improtant. Young indicated this finding as being similar to Tangri's (1972) in which role innovators described themselves as more unconventional and intellectual. No significant difference was found among the 
three groups on locus of control and career planning. The women who aspired to traditional occupations differentiated themselves by value rankings that are assumed to be traditional sex-role beliefs. Young concluded that while results may not be generalized to all populations of adolescent females, it is appropriate to consider that values serve as adequate and economical representation of sex-role beliefs in choice of occupation.

Kluckhohn and Strodtbeck (in Maestas, 1983) and Arciniega (1971) indicated that values orientations typically vary from culture to culture and that specific cultures allocate values differently. These values have consequences for behavior and affect the performance of children outside the dominant cultural mainstream. Value differences then account for child rearing practices, family structure and belief systems.

Bronfenbrenner (1979) used the term "macrosystem" to refer to the broader cultural or subcultural context. The macrosystem provides "blueprints" or patterns for various cultural institutions, relationship and belief systems which provide a context for the parent-child relationship.

McBroom (1981) explained that most theories of socialization contend that early experiences are associated with the attitudes and orientations people come to hold. Thus, it is widely accepted that significant others as well as the family are of considerable importance in the development of the beliefs, values and attitudes children come to adopt. 
Chetwynd and Harnett (1978) theorized that each society has its own sex-role ideology which dictates a basic family structure. In many cultures, the "family" is determined by the prescription of wife and mother role for women and that of "breadwinner" for the father. This definition of "family", then, is transmitted to the boy and girl and affects the development of their perceptions about what is appropriate for men and women to do (Marion, 1980).

Sex-role attitudes are part of the socialization process acquired by the individual during the early years of the child's life. The attitudes prevalent in the home and the actual behaviors of the parents constitute a critical set of influence factors on the young child (Herzog, 1982).

Societies have been fairly consistent in assigning specific roles to their members, Miller (1981) indicated, and socialization begins the moment the parent knows the sex of the child. At this time, parents form a Gestalt, or global, picture to organize their perceptions of what behaviors they will accept from the infant.

Barry, Bacon and Child (1957) in an analysis of various cultures to determine differences in socialization processes, found that child rearing practices across cultures train girls to be nurturant and boys to be selfreliant; boys to achieve and girls to be responsible and obedient.

Sexual identity is defined as that psychological state in which a person believes he is male or female (Hunsaker, 
1986). "Gender identity is established as the child interacts with and observes his/her signficant caregiver" ( 19). As children grow and develop, they learn to interact with others and through imitation begin to develop sex specific behaviors. By the time preschool years are reached, children not only know what sex they are but know the play preferences and psychological characteristics expected by them. By kindergarten, girls have learned sexrole stereotypes even as they relate to careers" (Wells, 1985; Hoffman, 1972).

Zuckerman and Sayre (1982) conducted a study of 60 middle class children (aged 4-8) to determine the extent to which recently changing cultural mores have influenced children's sex-role concepts. Although children's career choices were not expected to be predictive of adult goals, the questions "What do you want to be when you grow up?" and "If you were the opposite sex, what would you want to be when you grow up?" were asked as a measure of sex-role attitudes. During the interview, each child was also asked, "Do you like being a boy/girl? Why?" aided in coding the question "Why?" by whether the reason given reflected traditional sex-role differences.

The second part of the interview asked about the activities and occupations that most children and adults had previously judged to be appropriate for only one sex. The children were asked, for example, whether it was "all right for a man to be a nurse" and "all right for a woman to be a police officer." 
Results showed a non-stereotypic view of activities and occupations but "extremely traditional career choices." In addition, they apparently assumed these goals would change if they were the opposite sex. The children seemed to perceive the liberal attitudes held by young adults in previous studies, according to the researchers, but these sex-role attitudes were not reflected in their own career expectations. For example, four girls stated that it is appropriate for women to be doctors or nurses, but list nurse as their career choice and doctor as the career they would choose if they were boys. Interestingly, neither mothers' employment status nor mothers' non-traditional careers predicted children's non-traditional sex-role attitudes.

While the data suggested that sex-role attitudes are changing, according to zuckerman and Sayre, parent education level strongly influences the extent to which children accept these attitudes. Children with more highly educated fathers tend to express less stereotypic attitudes toward traditionally male careers; girls with highly educated mothers or homemakers tend to express less stereotypic responses. Boys with homemaker mothers appear to have a more positive attitude toward their sexual identity than do girls. Boys whose mothers are full-time homemakers tend to refuse to consider opposite sex career choices; though this may be an indication that the homemaker role model has a negative influence both on boys' perceptions of women and women's role options. 
It was evident in early as well as later stages of this review, studies pertaining to influences affecting career choice of intellectually gifted Mexican-American, Pan/Asian or black adolescent girls was limited. Also apparent is the fact that studies related to family influence in career/occupational aspirations and choice has been dominated by studies of white, middle-class males (Staples and Mirande, 1980), and/or white college or senior high school aged females. "Much of the current research on majority career behavior fails to include separate analyses of ethnic minority subjects and therefore fails to address the issue of whether the conclusions are equally applicable to black and other minority clients" (Leonard, 1984, p. 103).

However, statistics showed that some ethnic minorities are not attaining an educational level which would prepare them for many careers. The San Diego Evening Tribune (1985) reported that PACE (California Post-Secondary Commission) predicted in 1985 that baccalaureate degrees will be earned from public four-year college or universities by 56 white, 16 black, 14 Hispanics and 176 Asian students out of every 1000 ninth graders in 1980. An average of 25 percent of California ninth graders do not complete high school. Dropout rates for American Indians is 40 percent, 33 percent for blacks and 34 percent for Hispanics.

In terms of eligibility among ethnic groups for entrance to the University of California, the Commission indicated that 3.6 percent of black and 4.9 percent of Hispanic graduating seniors would qualify. It was also 
stated that 6.6 percent of blacks and 10.4 percent of Hispanics were eligible for admission to schools within the California state University System. PACE (Policy Analysis Commission on Education, 1986) indicated that minorities are over represented in California two year colleges as compared to their enrollment in four year institutions.

Rodman (1986) reported that a decline in black college enrollment began in 1976; that between 1976 and 1982, black college enrollment grew by only 6.7 percent; and by 1982 "growth was at a virtual standstill" (p. 1). In addition, the proportion of black students who enroll in college fell from 9.3 percent in 1976 to 8.8 percent in 1982 . Further statistics show that only 58 percent of the 18-19 year old black population had graduated from high school in 1982 compared to 75 percent of the white. More white students enroll in academic programs, while blacks enroll in vocational or technical programs.

The Post Secondary Commission also reported that the primary influences preventing students from attending college include academic achievement, family income, parents' educational and achievement plus cost and admission standards.

In addition, Blackwell (1986) indicated that blacks earned more doctoral degrees in the 1970's than in the previous 100 years, but between 1980-1984 the number of blacks who received doctoral degrees declined from 1100 to 978. Black enrollment in graduate and professional schools has also declined. 
In his book, Mainstreaming Outsiders: The Production of Black Professionals, Blackwell analyzed student enrollment and graduation rates over fifteen years at both traditionally white and traditionally black schools of medicine, dentistry, law, veterinary medicine, optometry, social work and engineering. He found that during the 1970's nearly 7000 blacks received doctoral degrees. This increase, however, came as a result of liberalized financial aid and recruiting and admissions policies affecting Blacks in graduate and professional schools.

The decline occurred in 1978 after the supreme court decision in "University of California Regents vs. Bakke". since then, the author believes, many institutions have lost interest in recruiting and keeping Black students.

The Family as Perpetrators of Attitudes and Values

A child's value system begins in the home and it is in this environment the young child develops abilities and skills to be used in relationships with others. One way to consider these intervening variables in an "economical way yet comprehensive" way, according to Young (1984), is to use human values as the level of analysis.

The gifted child's potential is developed within the parameters of the dominant cultural as well as the specific ehtnic values of both the family and the community in which he or she is raised. 
The family, as part of this system, has been described as a "microcosmic" social system and it is here the culturally defined roles, rules and expectations are taught (Minuchin, 1974) .

According to researchers, the family is the transmitter of the values and beliefs about the role the man and woman are expected to play. Diggs (1974), for example, cited Robinson and Robinson (1965):

The process of molding begins in the family; the mother and father are the first and in many ways the most important socialization agents. In countless interactions each day, the parents communicate to the child their interpretation of the world and the ways they expect him to behave in it. They teach him what to like and what to despise, whom to obey and against whom to rebel, and when to strive actively against circumstances and when to submit to the inevitable. (p. 579)

Entwistle and Baker (1983) discovered in a study of second graders that middle class white parents expected sons to earn higher grades than their daughter in mathematics. In contrast, lower class parents -- black and white -expected higher grades for daughters than they expected from sons in reading and math.

Lynn (1966) suggested that sex-role learning is initially linked to the mother for both boys and girls. In 
time, boys switch to identify with the masculine image of the father and girls with the mother. Yet Biller and Weiss (1970) emphasize that "adequate fathering" is an important factor in the psychosocial development of girls. The authors hypothesize that fathers reinforce the daughter's effort to imitate the mother's behavior. Thus, the sex-role orientations of women are, in part, a function of the father's preferred sex-role stereotype. The man or masculine image influences the feminine role. If the girl has a good relationship with her father, his preference would be accepted by her. If the relationship was not a positive one, she may resist his effort to establish his concept of "appropriate" behavior.

Some researchers believe that men interact differently with children than do women. Hoffman, Tsuneyoshi, Ebina and Fite (1984) designed a study with 24 women and 24 men to determine differences in men's and women's interactions with boys and girls. Men spoke significantly more and used longer MLU's (Meaningful Language Units), showing greater syntactic complexity with boys than girls in unstructured situations. In structured settings, males did not respond differently to boys and girls but did speak significantly more to boys than did females.

The finding of no differences in females' verbal interaction is inconsistent with literature which indicates differences in women's behavior based on the child's sex, according to the authors. However, finding that fathers, to a greater extent than mothers, treat sons and daughters 
differently is in line with the findings of previous studies.

The authors contended that while girls apparently perceive their role as social or relational, boys can be seen as acquiring the need to dominate -- to be more powerful than others. "Despite some indications of an increasing involvement of men with children in our society...our current social milieu continues to encourage females and to discourage males to expect to have significant interaction with children. Females come to see this as entirely appropriate for themselves as part of their role.."(p. 809)

Rubin, Provenzano and Lurie (1974) conducted a study with thirty parents of newborn infants and found that whether they had a boy or girl, sex typing occurred in two ways: (1) parents have different expectations for boys than for girls, and (2) the sex of the parent and the sex of the child interact to produce a different set of expectations. Fathers, for example, were more extreme in their ratings of sons and daughters. Sons were rated firmer, larger featured, better coordinated, more alert, stronger and hardier. Daughters were considered softer, finer featured, more awkward, less attentive, weaker and more delicate. Mothers rated both sexes closer together on the adjective pairs than fathers (who are the stronger sex-typers), but both parents agree on the direction of sex differences in keeping with cultural sex stereotypes. Thus, the attitudes prevalent in the home about expectations for girls and actual parental behavior (in the form of modeling) 
constitute a critical set of influence factors. The girl is encouraged to learn socially correct behavior which may then be reinforced by grandparents and other relatives, friends and teachers. Correct behavior is supported by approval and may take the form of parental love (Herzog and Bachman, 1982) .

In contrast, Shepard (1980) studied a sample of college students to ascertain their perceptions of their parents. One question asked, "Do mothers-fathers, as groups, play different roles?" revealed two areas of perceived difference between mother's and father's treatment of the individual child. One was the difference in nurturant child care activities as performed by mother and the other was that even though there was some division of labor in the home, the division didn't appear to follow one dominant pattern. A second question, "Does parental role division interact with the sex of the child?" sought to explore personal emotional relationship with parents. The researcher concluded that parents are not the major determinants of differential sex-role socialization -- at least in this population. This supports the finding of Maccoby and Jacklin (1974) who pointed out that people simply assume children are treated differently but instead there really is very little in the literature which substantiates this claim.

Shepard did infer that the fathers and mothers of the sample help promote stereotypic views -- mothers were interested in religion, family and marriage while fathers 
showed interest in politics, education and career -- yet neither parent was seen as influencing one specific value. Both parents instead were perceived by the subject sample as placing heavy emphasis on achievement for cinildren of both sexes. However, considering that this was a college population, one could assume a great deal of learning went on before the student reached this age; thus, one cannot tell what kinds of information passed between parents and student before the daughter or son reached college.

Groth (1971) perceived conditions conducive to achievement as being different for girls than for boys. During the first seven years of life, warmth from the opposite sex parent seems to be sufficient for inspiring boys to achieve. Girls, however, need support from both parents. The hypothesis presented is that since achievement in the Anglo culture is usually subsumed under manhood, manhood and achievement are mutually reinforcing. A warm mother helps develop a positive self-concept in the son and inspires him to achieve. A woman must learn to combine womanhood and intellectual achievement. The mother may guide the girl toward womanhood but the daughter also needs the acceptance of her father to validate her concept of womanhood.

Fox (1977) cited studies in which mathematical ability appeared to be related to masculine interests and values and that educators believe that interest in science results, in part, from reinforcements of sex role appropriate behavior. Boys whose father was not present during the early years of 
childhood had lower mathematical aptitude relative to verbal aptitude than did boys whose fathers were living in the home; studies of creative female mathematicians reveal that these women come from homes in which the father is a professional man and a dominant figure in the home. Early identification with the father who is analytic and intellecutal is related to quantitative interests and ability for both boys and girls.

A major factor relating to family influence or socialization is ethnicity (Rosen, 1959). Ethnicity accounts for more variance than social class, economic status or even peer group influence. Rosen wrote that ethnicity relates to achievement, whether by not encouraging a child to strive for success or by rejecting the importance of education as an avenue to higher status.

An extensive review of racial and cultural variation among minority families done by staples and Mirande (1980) indicated that part of the problem in understanding minority families has been that researchers failed to distinguish between factors of culture and class in the family lifestyle. Methodologically, this has represented a flaw since much of the research from 1959-1968 used lower class minority groups as they compared to middle class white families.

Shade (1978), in a review of literature on characteristics of achieving black children, found the families of these black children different from those of non-achievers. These differences were primarily in those 
characteristics often related to middle class membership. Children who were considered achievers had parents who were warm, accepting, supportive and "demanded a better-thanaverage performance from their children."

Foster and Seltzer (1986) cited Bloom (1982) and Sosniak (1981) who interviewed 150 individual achievers and found that during childhood (particularly between ages 3 and 7) participants were encouraged by parents to explore a field of endeavor in depth. If the child's interest continued, parents rewarded the child's efforts with extensive personal and financial support for further development of the performance area. Parents also served as role models for achievement, living lives of commitment and hard work. Bloom added that such early parent interest and guidance is vital to the achievement of excellence in adults.

Yet, the ethnically-diverse girl may face an additional limitation in terms of achievement. Marion (1980) indicated that parents of ethnically-diverse children have not participated in nor can it be assumed that they are comfortable with gifted programs. In fact, gifted programs are viewed with suspicion in some minority cultures and parents are or may be concerned about having a child singled out for such a program.

Wahab (1973) studied poor (if not impoverished) Mexican-American families in California and identified prime characteristics or values of these families as religion, the extended family, "machismo", honor, self-respect and self- 
sufficiency. The sample described family expectations as a hierarchy of respect based on the individual's age and sex -- older males receiving the most respect. Family demands are placed on an individual member economically, in terms of contribution, assigned chores and other family-related physical tasks. Mexican-American parents teach children to conduct themselves with honor and dignity in social interactions.

Mejia (in Powell, 1983) indicated that the most interesting aspect related to child-rearing is that the Mexican-American parent does not describe a successful or educated person in an economic sense but as one possessing education or urbanidad, the individual who has training in human understanding and interpersonal relationship.

Maestas (1983) indicated that it is difficult to relinquish cultural values. Unlike many immigrants, Mexican-Americans have refused to give up their social culture even though encouraged to do so. While desiring social acceptance and the benefits of the dominant social group, the Mexican-American has not been willing to exchange those benefits at the cost of language, customs and cultural values. While some Mexican-Americans may be described as being acculturated or assimilated, others are aware of society's role expectations of them and take positive steps to change the assigned status which the dominant culture has assigned them (Mejia, 1982).

While all members of a particular minority group are not alike, social class differences more than ethnic 
background often determine a minority student's behavior (Henderson, 1979). "Minority group children from middle class oriented families are burdened with the need to succeed in school -- not just for themselves but for all members of their ethnic group. This cultural press for academic success is vividly seen in Japanese-American and Chinese-American families, especially traditionally oriented families with high success orientation" (Henderson, 1979, p. 23).

In 1986, an editorial in the San Diego Evening Tribune was entitled, "The Asian Family: Garden of Values". It stated that Asian-Americans have been called the model minority because of family stability and high income. More members of Asian-American families work long hours to provide the necessary finances for children to obtain a good education. Valentina Chen, a freshman pre-med student commented," 'One of the primary goals of life is to learn and succeed. My parents taught us those values' " (p. B-1). The article also stated that "values matter. And they are inculcated by responsible parents. Intact families can best transmit culture. The importance of the family to the success of individuals cannot be overstated" (p. 33).

In December 1985, a Los Angeles Times' article indicated that the Asian population has "mushroomed" 125 percent in the last ten years and despite language and cultural barriers, Asians are the most likely of all ethnic groups to attain a higher education. Cited was a figure from the U. S. Department of Education which reported that 
35 percent of all adult Asian-Americans have earned college degrees -- more than double any other ethnic group. Asians account for 22 percent of the student body at UC Berkeley, 21 percent at UCLA, 10 percent at Harvard and 34 percent of the freshman class alone at UC Irvine.

Asian-American high school graduates are the most likely of all ethnic groups and twice as likely as whites to gain entry to the University of California system which is mandated to admit the top 12.5 percent of the state's high school graduates, according to The Times.

Nathan Caplan, a researcher at the University of Michigan, conducted a three-year study of the southeast Asian refugees to find out how they were "faring" in American public schools. He found that children of poor farmers, fishermen and laborers were as high achieving as were those Asian students whose parents were well educated.

The Times' article quoted U. S. Education Secretary, William J. Bennett (1985) who believed a key reason for the Asian students' success is "the existence of extraordinarily close ties between parents and children and the willingness of parents to sacrifice for the sake of their children's education" (p. 33). Additionally, Bennett noted that Asians possess a cultural trait of a deep respect for learning. This concept was corroborated by Vy Trac Do, a college counselor, who added that "in Confucian thought, teachers rank above fathers and below only their king in the social hierarchy" (p. 33). 
In a study conducted in 1983 at Northwestern University, eight of nine Asian parents interviewed, "said without hesitation that they would sell their only house if necessary to send their children to college." Only one of the five Anglo parents were willing to do so. AsianAmerican parents carefully define specific career expectations for their children. Anglo parents, on the other hand, usually allowed their children to decide their own futures. Family expectations were found to be higher among first generation Asian-Americans; second generation Asian-Americans have higher educational achievement than third, who may have become more assimilated into the dominant culture.

This strong belief in achievement has a negative counterpart, however. Ron wilson (1985), UC Irvine ombudsman, said that problems related to parental demands among Asian families are escalating. Suicides are related to academic pressure -- meeting parent expectations of obtaining top grades; finishing school quickly and finding a top-paying job to finance siblings' education; and contributing economically. All these fators weigh on the young Asian college student. "The worst thing is the guilt," according to a second generation Filipino college senior. "My parents are into saving face. Their pride is their kids...I'm the oldest. I can't disappoint my parents. I can't be a failure."

Cornell (1984) conducted an extensive study to look at the relationship of family variables and cognitive 
development and achievement. In considering family relationships, it is important to consider the effect of the child's influence on the parents. Bi-directional influence suggests that application of child rearing strategies are influenced by the characteristics and behaviors of the individual child (Laosa, 1982).

In a study of forty-two families who had a gifted child in school, Cornell examined this bi-directional influence on families of gifted children. Data was collected through parental interviews and use of the Family Environment scale and the Children's Personality Questionnaire, as well as measures devised by the author.

The experimental group was from middle to upper middle class and the control group was from a lower socioeconmic area. Data was collected from 168 individuals -- 42 families. Among variables examined were perception of parents regarding closeness in the parent-child relationship between parents who perceived their children as gifted and those who did not. In this case, "perceivers" described a closer parent-child relationship than "non-perceivers." Findings included:

1. Parents of giftd children place strong value on being closely involved with children.

2. Firstborn gifted children were more submissive, more shy, more easily upset and less outgoing than non-gifted.

3. Secondborn gifted were emotionally more 
stable, more controlled and socially precise, less tense or frustrated.

4. The 'content' of family interaction was different. For gifted, there was more order and organization to the family's approach to a task -- qualitatively, there was a difference in the kinds of things the gifted family did.

5. Parents of gifted children are eager to articulate their values to the children.

6. The child not perceived as gifted is in a much less favorable position in the family than the gifted child.

7. The firstborn gifted child is a relatively more powerful influence on the family at the expense of the father. That is, the gifted child has a relatively more favored position in the family. Fathers are less likely to perceive their children as gifted; the child's giftedness was more meaningful to the mother and she was the one who took steps to develop the child's ability.

Surprisingly, because it does not follow from status literature in sociology, according to McBroom, young men seem more responsive to mothers. It was suggested that mothers may well be an important source of values and motivation; however, the negative sign of the regression 
coefficient for mother's education may indicate that the lower the mother's education, the more the son is encouraged to attain higher status.

Ihinger-Tallman (1982) hypothesized that different socialization behavior would be manifest by parents toward children of different sexes. Specifically, the study sought to substantiate that parents will engage in relatively more encouragement of their cross-sex rather than same sex youngsters and the greater the encouragement and parental awareness of opportunities, the greater the attainment value of sons and daughters. Additionally, it was hypothesized that positive family effect would be associated with greater attainment value for sons and negative family affect associated with greater attainment value for daughters.

In this study, mothers and fathers of 12-15 year olds appeared to encourage sons and daughters in similar ways. Parents were more generally involved, at least verbally, in the career planning of daughters as compared to sons. It was suggested that greater verbal activity may reflect more concern (or less assurance) on parents and daughters concerning female career choice -- or that parents talk more to girls.

Even though verbal activity was greater for girls, parent-son interactions were more predictive of attainment value for sons. Sons with a high attainment value sought paternal advice and had fathers who challenged their decisions but did not dominate. Mothers in this sample of 
sons with high attainment value assumed,a low profile, and neither advised, challenged nor solicited their choices.

Two conclusions were drawn by Ihinger-Tallman. Different patterns affecting attainment value are evident in paternal interaction with sons and daughter and more is known about socialization variables affecting adolescent sons' attainment value than adolescent daughters. Parents appear to know more about career planning for sons, but more uncertainty was apparent in planning with daughters. Parents seemed more aware of opportunities for boys in a goal-directed pattern for sons. The researcher concluded that the variables affecting attainment values of young women are still somewhat elusive.

Perino and Male (1981) indicated that as many females near the end of their schooling they persist in selecting occupational categories defined as feminine. They suggested that one of the reasons is that parents usually give less thought to the future of girls than boys and, during adolescence, discuss careers in law, science, and mathematics with boys while gently nudging girls toward something more traditional (Weitzman, Berns, Friend, 1985).

Evans (1985) suggested many women may not plan for a professional career or vocation because, for many of them, traditional sex-roles are still salient -- especially in adolescence and early adulthood. They still see their futures in terms of marriage. Bardwick (1980) was supportive of this notion as well as citing a number of researchers who have attempted to identify factors in a 
woman's background which shape her orientations toward work. Family relationships have been linked to woman's career decisions in that career women are more likely to have had working mothers, had close relationships with the fathers, more freedom while growing up and received rewards for assertiveness (Kahn, 1979; Elder, 1974; Giele, 1982).

Thus, many women feel it is proper to work but only if they fulfill their role as wife and mother. These women may choose less demanding jobs, jobs with lighter educational requirements and jobs in which work can be interrupted when family demands occur. Some women avoid the conflict between the pressure of $a$ career and the needs of the family (Broschart, 1979).

\section{Socioeconomic status}

If one were to use a single variable to predict an individual's future occupational status, according to Schulenberg, Vondracek and Crouter, 1984, it would be the socioeconomic status (SES) of the family. Socioeconomic status usually incorporates paternal and maternal educational attainment, family income and occupational status of father and mother. In addition, values, opportunities and parental encouragement also enhance or limit an individual's potential occupational status.

Schulenberg, Vondracek and Crouter (1984) noted that it has been well documented that background socioeconomic status is positively related to occupational status aspirations. 
This positive association exists for both males and females, though background SES may have less value in terms of influencing females' vocational choices than it does for males. Even inter-generational occupational status mobility has been found to be related to SES background. Cited was a study conducted by Blau and Duncan (1967) employing a sample of over 20,000 men. It was found that occupational mobility upward or downward occurred much more frequently among those with intermediate SES background than among those of either extreme -- high or low.

Family socioeconomic status is also thought to be a powerful factor in intellectual achievement, according to Henderson (1981). While socioeconomic status in itself is not an explanatory variable related to children's performance, it is a better predictor of academic achievement because of behaviors, attitudes, values and physical living conditions of families. That is, the higher the socioeconomic status, the higher are the child's achievements and aspirations (White, 1982).

In 1953, Kahl indicated that the particular SES level of the family is not the decisive factor in achievement, but instead it is parental values. It is the parent's direct encouragement of good work which inspires the son and daughter to achieve. Middle class parents tend to value self-direction in their children and lower sES parents value conformity. Whether this translates into children's vocational aspiration and attainment may also depend on the quality of the relationship between parents and child. 
Achievement is not a class difference, according to kohn (1969), but a difference in the degree to which families retained the values of the culture. The retention of cultural values is as opposed to looking to a higher class as a reference group and encouraging the child to achieve in order to move into that class.

Duran (1983), however, wrote that the educational attainment level of the parents is more important than ethnicity. Hispanic mothers with more educational attainment are more likely to teach their children thinking skills by using praise for approval and inquiry methods in problem solving, as well as reading to their children more frequently than are Hispanic parents of less education. In addition, Laosa (1982) has suggested that the success or failure of Hispanic children in school is directly linked to socialization and learning cognitive skills at home.

Laosa (1982) sought to determine the conceptual and empirical examination of the impact of schooling on the parent-child relationship. The sample consisted of Chicano and non-Hispanic white families. Results showed that mothers in more highly schooled families held higher educational aspirations than did mothers in families who were not highly schooled. In the Chicano families, there was no relationship between maternal aspirations for the child's education and either parent's occupation. In the white, non-Hispanic families, father's occupational status was a significant predictor of maternal aspirations for the education of the child. Laosa (1982) concluded that the 
educational level of the parents is a "preeminant and critical factor in childrens' development of cognitive style" related to cognitive learning requirements.

Wright and Wright (1976) also suggested that the connection between SES of the parents and aspirations of children has to do with value systems. People in different economic strata possess different values related to mobility, orientation, social and cultural values. Implanting these values in the children "equips" the children to remain in the parental stratum once adulthood is reached. Middle class parents are said to value achievement, creativity, deferred gratification; working class parents are said to value mostly the opposite traits, making school performance difficult and upward mobility less likely. Thus, "values" mediate the gap between parents' and children's socioeconomic strata (Kerchkhoff and Huff, 1974; Kohn, 1969).

It has generally been acknowledged that middle class Anglo parents are more likely to set standards in scholastic achievement. They are more likely to teach their children to believe in success and to take active steps to make it possible (Scott-Jones, 1984). Economic status is a forceful determinant in that parents in a higher economic status are able to control the availability of education through the ability to pay for it (Sherer, 1967).

Families with higher SES have greater financial capability to send children to college and a college degree implies higher occupational status (Blau and Duncan, 1967). 
Oppenheimer (1974) indicated that men in professional, managerial and sales occupations reach their peak earnings when their children enter college. Low occupational status job holders have reached their peak -- or earnings may have even dropped off -- by the time children are old enough to attend college. The lower SES families may not only have less money but have less at a time when it is most needed. Karabel and Astin (1975) found that students with lower SES background tend to be in colleges with lower admissions standards and those from high and middle sES backgrounds were more inclined to attend four-year colleges; those from low SES backgrounds attend community colleges. In 1986 (Spring), the Commission for the Review of the Master Plan for Higher Education reported that approximately 80 percent of all underrepresented minority students entered college through the community college system. The commission further indicated that access to post-secondary education is highly dependent on socioeconomic background. In 1982, more than 300,000 students attending community colleges in California came from families with incomes under $\$ 12,000$ or were self-supporting. The income of self-supporting students fell below $\$ 12,000$. As a group, according to the 1986 report, students who attend community colleges are less wealthy than students in other colleges and universities.

Leonard (1984) indicated that census data documents the disproportionate concentration of blacks in blue-collar, service and farm worker classifications. These "lower status and lower pay" careers and occupations are held by 70 
percent of the black work force, as compared to 50 percent of the White work force. Only 30 percent of black workers are employed in professional, managerial and technical fields. The failure of blacks to complete secondary and post-secondary schools is the result of a "complicated enculturation process," -- values, aspirations, perceptions and skills required for educational economic and professional advancement and evolvement. He concluded that research on the impact of the black family on vocational behavior suggests that the interaction between parental occupation, socioeconomic status and the aspirations and achievement of the offspring is complex, and that the expected patterns may also be confounded by affective and perceptive variables.

Fleming and Malone (1983) found that socioeconomic status correlated significantly with three performance measures -- cognitive, achievement and attitudes toward science in a meta-analysis of the characteristics and science performance of children in kindergarten through students in 12th grade. However, the researchers pointed out that socioeconomic status and race could not be correlated because the studies they included in the racial comparisons did not report the subject's socioeconomic status.

The contemporary approach to discussions regarding socioeconomic status-parental status as it related to aspirations and attainment, according to McBroom (1985) has derived from the early essays of Talcott Parsons (1958). 
Parson's thesis is that the family is a unit of stratification, thus all members derive their status from it. Because the American value system stresses achievement, occupation is the important dimension. Traditionally, the father is the one who works, thus the wife and mother and minor children are "status dependents." McBroom (1985) administered a questionnaire to college students which sought to answer:

1. What is the relative importance of mother's as compared to father's status characteristics on the status aspirations of their children?

2. Is it important to consider a variety of status indicators other than traditional objective indicators?

3. Since the influence of mother's characteristics may not be the same for sons and daughters, is it important to identify sexspecific ones?

Using regression analysis to predict the class to which students aspire, McBroom discovered that occupation and education of neither parent was particularly important in determining status aspirations. However, two sex-specific effects were observed. The prediction was more complete for females than males, and status of the mother was more important than that of fathers in men's aspirations. The traditional role of women may justify such an assumption, 
according to McBroom, but males are relatively less influenced by the SES of the parents.

Malone and Shope (1978) found that the vocational expectations of high SES males were higher than expectations of low SES males but no difference appeared for high and low SES females. While some researchers (Almquist and Angrist, 1970) found no correlation between SES and vocational orientation in females, Tangri (1972) and Miyahira (1977) detected a slightly negative relationship between background SES and vocational orientation.

In addition, Tangri's (1972) study indicated that women who had non-traditional career aspirations came from families in which the father was highly educated. Ruhland, in a 1978 study, found that for junior and senior high school women in the sample socioeconomic status was "perhaps the most powerful" factor influencing career aspirations. Daughters of more highly educated parents and of parents with higher status jobs chose less traditional and higher status careers. Income level was weaker than other socioeconomic variables. Education of the father was considered the most powerful predictor of career choice in this study. The author stated that the effect of SES for junior and senior high school girls was found to be a more important factor than it was in Tangri's study. It must be noted, however, that researchers conducting studies on college women are already working with a highly select group, thus the parental education level and job status may 
be an important determinant of whether a young woman decides to go to college at all.

Most research regarding ethnic background as related to vocational choice investigated black/white differences. Blau and Duncan (1967) found that even when SES background, education and career beginnings were controlled, blacks did not attain the same occupational level as whites. In 1975, Treiman and Terrell found that background SES did not correlate with educational or occupational status among blacks. Portes and wilson (1976) found that the most prominent predictors of Anglo educational expectations were parental status, ability and grades; predictors for blacks were self-esteem and educational aspirations. While Blau and Duncan (1967) explained that data for these racial differences were gathered in the early 1960's before equal rights and affirmative action, it is evident that some blacks have attained higher education and higher status careers. Such people have either avoided or overcome the discriminatory practices rampant in some places or the impetus for achievement by blacks may result from a more intrinsic basis rather than from the effect of affirmative action. In addition, Portes and wilson (1976) in a literature review concluded that when background SES and ability were accounted for, black children tended to have higher vocational aspirations than did Anglos.

Kagen and Moss (1962) as cited by Foster and Seltzer (1986) found that (1) an expectancy of later life success was highly correlated with early achievement; (2) an 
individual's intellectual level was closely related to parents' educational level, and (3) family social status served as a strong predictor of the individual's level of occupational attainment (p. 579). While such evidence shows the importance of the quality of early life to the development of mature talent, it is difficult to expect such outcomes when in 1980 forty-four percent of black children under 18 lived in single-parent families headed by women. Ealf of these households were classified as below the poverty level (Gibbs, 1984).

Head (1978), in a study of 1400 black female and male students, found that boys were more influenced by parental background than girls; sex-role orientation and self-esteem have an important influence on educational and occupational plans of both boys and girls; and that the salient influences on girls' sccupational plans are educational expectations, most important adult role, grade level and father positiveness.

In a study conducted by Grevious in (1985) it was predicted that black males' occupational aspirations would be significantly more prestigious than black females' aspirations. This prediction, according to Grevious, followed logically from the results of earlier studies.

The sample in Grevious' 1985 study consisted of 259 juniors and seniors (127 males and 132 females) in college. Subjects were asked to complete a questionnaire requesting demographic data as well as the subject/major area of 
concentration, occupational aspirations and parents' education. Black males' aspirations were indeed significantly more prestigious than females. Students were compared on the frequency of selecting certain fields and although engineering was not included in the Chi square analysis, four males and one female aspired to this profession. In addition, when males and females aspired to the same general fields, they selected different areas of specialization. Seven of the females who chose medicine planned to specialize in pediatrics and psychiatry; in law, females chose criminal and family law. When teaching was chosen as a profession, females mentioned nursery, elementary or secondary teaching. Not one male aspired to teach elementary school.

Grevious concluded that study results were consistent with earlier studies, but these findings, when compared to data from a 1970 study, showed a larger percentage of women considering careers in medicine and law. Corresponding decreases were evident in choices of teaching and social work. Despite this, most women still aspired to careers considered traditional for women and not among the most prestigious.

Hernandez (1973), in a review of the literature on Mexican-American students' achievement, found vocational and educational aspirations of Mexican-American males to be lower than those of white males. She suggested that part of the reason might be that the Mexican-American culture tends to believe that fate controls one's life; therefore, one 
need not plan for the future. Hernandez also cited research in which those Mexican-Americans who had achieved professionally believed less in fate and more in personal efficacy.

Schulenberg, Vondracek, and Crouter (1984) conjectured that in some respects male-female differences related to career aspirations in minorities are similar to male-female difference among Anglos. Head (1978), for example, found that vocational expectations among black males were more influenced by background SES than were black females. Hernandez (1973) noted that vocational expectations were higher among Mexican-American males than among MexicanAmerican females; Mexican-American men still see themselves as the primary economic provider.

Schulenberg, et. al. (1984) in a critical analysis of family effect on vocational development indicated that there is accumulating evidence that human communities and patterns of social interactions are often formed on the basis of region, race, ethnicity as well as social class. Even inter-generational occupational status mobility has been found to be related to SES background. However, if classlinked parental values explain the inter-generational transmission of social status, a requirement must be that children and parents share the same values. Schulenberg, et. al., admits, however, that there is little evidence which confirms that children assimilate the same values as parents. 
McBroom's study in 1981 was designed to identify the influence of SES background and parental influence on young women's sex-role expectations. One hundred forty-eight college women (ages 18-22) were administered a series of items in a questionnaire. Items were designed to measure agreement with traditional and stereotyped ideas and expectations for the domestic role of married women and the perceived relationship with their parents. The assumption was made that social class would be related to sex-role scores but in cross-tabulation with paternal social class, this assumption was not true. There was no systematic relationship across social class for those women with traditional sex-role expectations.

An additional point-of-interest was the lack of relationship between sex-role score and childhood relationship with the mother. However, women from low social class backgrounds showed a substantial relationship with the father. As class status increased, the degree of association with the father decreased. When the childhood relationship with the father had not been a positive one in low, medium and high status classes, women rejected traditional sex-role orientations -- independent of social class. McBroom concluded that lower class background alone produced traditional stereotypes among the women if the father-daughter relationship was good. The conclusion reached by McBroom, then, is that the acceptance of a traditional role for women is both class and parent specific. 
Nielsen (1982) contended that most black girls have to deal with both racism and sexism. Yet black adolescents may be less restricted by their sex roles than are white adolescents. A "woman's self reliance, economic independence and educational advancement are traditionally encouraged by black communities, even though approval of female employment and independence arose from economic necessity and not from dedication to feminist principles" (p. 110). Most black girls do not receive their "fair share" of educational and vocational encouragement -- nearly two-thirds of black women in professional occupations are found in the lower paying careers of teaching, nursing and library work. Female scientists from minority cultures say that teachers and counselors do not encourage minority girls to enter these professions. In addition, they have experienced both racial and sexual prejudice.

Black females are more likely to earn higher grades, graduate from high school and earn a college degree than are black males. Nielsen wrote that the few black women who are highly educated are conspicuous and probably contribute to the myth that being black and female are advantageous. But black females often have difficulty finding work. However, in agencies under edict of affirmative action or any number of "consent decrees," being black and female is advantageous and that is not a myth.

Recognizing that black, female college students have been over-represented in the selection of careers in education, the humanities and the social sciences for the 
past three decades, Thomas (1985) hypothesized that "once black students' family background, academic performance and preparation are controlled, their major field choice would primarily reflect the values, interests, and aspirations they have acquired as a result of past race and sex socialization and their previous family and schooling experiences" (p. 539).

Thomas conducted a study of a sample of 927 black, college juniors and seniors who were enrolled in one of thirteen college majors classified as engineering, natural and technical sciences -- versus education, nursing and social sciences. The subjects were questioned on the following variables: parental education, childhood interests, high school science affinity, high school curriculum, advanced math and science grades performance, high school and college grades performance, educational expectations, college major, reasons for field choice and whether they were enrolled in a public or private college.

The significant finding is that the ascriptive status of sex, based on sex-role socialization, childhood and high school career interests and subsequent occupational expectations expressed by black females and males were considered the most important factors influencing college major field choice. "The traditional sex-oriented expectations and aspirations expressed by Black males and females...were directly translated into the three-to-one representation of Black females in traditional and lower paying majors...relative to Black males" (p. 546). 
Hispanic girls are not well represented in high status careers either, according to Nielsen (1982). Only 4 percent of Hispanic females enter college as compared to 8.6 percent of the males. Many Hispanic females lack role models of successful women and are taught to sacrifice their own needs for those of their men. "Girls from minority cultures are often convinced that their personal advancement will hinder their group by undermining men's progress. Motivated by family pride and cooperation, accustomed to respecting their elders and strictly disciplined, Hispanic youngsters often perceive competition and individual gain as inappropriate" (Nielsen, 1982, p. 112).

Chusmir (1982) indicated that vocational choice is made by the time the girl enters high school and her career options have been reached. These choices are influenced through "cultural barriers, feminine role perceptions, role conflict, fear of career impact on family life and lack of confidence" (p. 44).

McNair and Brown (1983) conducted a study with 259 10th graders -- 54 black females, 80 white females, 38 black males and 87 white males -- the purpose of which was to determine the variables predicting occupational aspirations, occupational expectations and career maturity of black and white males and females. Using the Attitude scale of the Career Maturity Inventory, a multiple regression analysis was used to examine the relationship of several independent variables to each of three dependent variables: socioeconomic status, parental influence and self-concept. 
The results showed that (1) white students scored higher on career maturity than did black students -- females scored higher than males; (2) self-concept was a significant predictor of career maturity for white males only; (3) differences in career maturity were not significant between races but were between sexes; (4) females of both groups had higher aspirations and expectations; (5) parent influence was significant for all but white males; and (6) socioeconomic status had a negative effect on males but a positive effect on females. That is, girls from a high socioeconomic status had lower occupational aspirations and expectations. McNair and Brown noted that previous research cited a positive relationship between socioeconomic status for men and career aspirations; thus, the authors believed the results of this study were surprising. Parental influence added the greatest degree of predictability, thus lending credence to the hypothesis that important models influence career development.

Research conducted by SMPY (Study of Mathematically Precocious Youth) has focused on acceleration in math and only with young people who are mathematically gifted. Fox (1980), in an assessment of the attitudes of seventh and eight grade girls, found that parents of these gifted girls were less likely to view a career in science or mathematics as appropriate than were parents of gifted males.

Casserly's study (in Fox, Brody and Tobin, 1981) of 161 high school women (ages 15-18) who had been or who were currently enrolled in Advanced Placement (AP) classes in 
physics, calculus, chemistry and biology, described interesting home environments. Eighty-six percent of the women were native-born Americans, fourteen percent of whom has spent time in a foreign school system. Seventy-eight percent were Asian and the remaining were English, Dutch, French, Mexican and Hungarian. The educational levels of the parents were high: $\mathbf{8 . 8}$ percent of the mothers had earned doctorates and/or had some graduate study; 30.4 perent or one-third of the mothers had college experience; one-third (29.6 percent) had finished high school while 1.6 percent (two mothers) had not.

of the fathers, 14.4 percent had earned doctorates and 11.2 percent had master's degrees in engineering or business; 24.0 percent had bachelor's degrees and 14.4 percent had some college. Almost one-fourth of the fathers (23.2 percent) had completed high school but one in eight, or 12.8 percent, had not.

That these girls did not come from a socioeconomically elite group of parents was exemplified by the kinds of occupations in which the parents were involved. While just over one-third of the fathers and one-fifth of the mothers were employed in positions requiring college or advanced degrees, one-fifth of the mothers and one-fifth of the fathers had blue collar jobs. Casserly indicated that socioeconomic data were not available for all the women since 35 of them qualified for a federally funded lunch program and these particular girls did not want to be asked about parental incomes. 
Most of the women in McNair and Brown's study (1983) felt their parents were supportive of their general goals. Working class parents, however, lacked understanding of the specific steps necessary to achieve a particular science or math-related career. In addition, they were reluctant to agree to let the daughter go to school away from home. In addition, the women rarely had a role model or significant adult outside of school who was involved in a professional career. Nor did parents in the lower socioeconomic status want to apply for Einancial aid for their daughters to go to college. Rather, they wanted their daughters to go to a local college the parents felt they could afford.

Block, Denker and Tittle (1981) conducted a study to examine responses of eleventh grade students to three sets of sex-role related values and to relate these to educational and occupational aspirations. Students were asked to respond to two open-ended questions: (1) Why they chose a particular career; and (2) what person or experiences were important to that choice of career.

The sample was composed of 600 students and divided equally into three ethnic groups (black, white and Hispanic). Socioeconomic level was established through educational level and occupation. Occupations were described as Professional (doctor, lawyer), Semiprofessional, Business, Clerical, Manual, Protective and Service, as well as job levels in each category. Approximately one-third were bilingual (Spanish and English). Religious affiliations were predominantly Roman 
Catholic (59 percent); Protestant (22 percent); Jewish (11 percent); and others ( 8 percent).

Eighty percent of the fathers and 51 percent of the mothers worked full-time. Only seven percent of the mothers had not worked at all. sixty-three percent of the fathers were the major wage earner; twenty-four percent of the single mothers and thirteen percent of the families were welfare recipients, social security recipients or dependent on relatives.

Educational level showed that 25 percent of the fathers and 23 percent of the mothers had less than a high school education; 42 percent of fathers and 51 percent of the mothers had graduated from high school and had some additional education; 22 percent of fathers and 21 percent of mothers had a college degree with some professional or graduate degrees.

Results regarding an influential person or experience were very similar across groups. A family member (in the profession or not) was mentioned more often than non-family; general academic influence was not subtantial; personal experience (generally work related) was seen as important by 15 percent and media and books were seen as important by less than 10 percent of the sample. Non-family member and teacher influence were regarded as influential by 5.5 percent and 5.3 percent, respectively. While no significant sex or ethnic difference was found, significance was discovered in socioeconomic levels. Middle class students were influenced more than lower class students by non-family 
members in the chosen profession and by family members not in the chosen profession. However, it was suggested that students from middle class homes had more opportunity to meet people in their field of interest than did lower class students.

Enjoyment was the reason for specific career selection; status/prestige and financial aspects were mentioned less frequently. Significant differences related to sex were that a goal-directed reason was mentioned by twice as many females as males. Variables identified as "practical considerations, such as status/prestige and financial aspects" were expressed at least twice as often by males as females. The researchers noted that the differential emphasis on the achievement of social and/or personal goals was largely confined to the middle class, the other three sex differences (practical consideration, status/prestige and financial aspects) appeared in both middle and lower SES groups.

While Endo (1984) indicated that a significant amount of attention has been directed toward the educational ambitions of racial minorities, little empirical research has been conducted with Asian-Americans. Some AsianAmericans have relatively high aggregate levels of education and this has been Iinked to socioeconomic mobility.

Boardman (1984), using Coleman's (1966) data on AsianAmerican 12th graders, found that a composite measure of educational and occupational expectation was affected by endogenous variables (motivation, parental expectations and 
self-esteem) and exogenous variables (teacher and student characteristics) but not sex or socioeconomic status.

Endo cited a study by Centra (1980) who reported that grade point average, Graduate Record Examination, verbal scores and gender affected Asian-American graduate students' degree objectives, but that affluence, selectivity and predominant racial make-up did not.

Endo's (1984) study of 200 Japanese-American and 200 Anglo undergraduates revealed that the academic variables important in distinguishing levels of ambition for JapaneseAmericans were concern over inadequate grades, academic performance, and academic self-confidence. Apprehension over inadequate grades was the most important concern. Gender had no importance in determining the level of educational ambition, but socioeconomic status was slightly important as was field of study, parental expectations and the importance of "connections" in determining educational achievement. The most important variables for the white Americans were academic self-confidence, academic performance, concern over inadequate grades and sex role.

In a separate study conducted in 1982, Endo hypothesized that Japanese students attending medical school in Japan were more likely to come from families with high levels of education and occupational attainment. In addition, he hypothesized that youths from a high social status background often report their parents as a major source of influence in decision-making. Parents would also be cited most frequently as bringing strong pressure to bear 
on students to enter the medical profession.

Endo asked a sample of 194 students enrolled in three medical schools (170 males and 24 females) to respond to a demographic questionnaire. Results revealed that nearly half the fathers of the students (46 percent) were physicians with an additional 3 percent involved in professions related to medicine -- particularly pharmacy. Six percent of the fathers were in other professional occupations; the remaining 30 percent working as "company employees," that is, managers to white collar positions. In addition, high occupational attainment correlated with a high level of educational achievement; with 80 percent of the fathers having an undergraduate degree and 50 percent in possession of a graduate or professional degree (most are medical school degrees). Only 11 percent of the fathers had not graduated from high school. Among the mothers, 39 percent had completed high school, 21 percent obtained undergraduate degrees and 7 percent obtained advanced degrees. Interestingly, evidence showed that medical careers extended over three generations in some families and 20 percent of the students reported grandfathers who had been physicians.

Results of this study supported the hypothesis that these students were most likely to come from families who had obtained high socioeconomic levels of educational and occupational attainment, particularly father's and mother's educational level. The encouragement of fathers, especially those who are physicians, was significant. This resulted in 
a high proportion of students manifesting the pattern of occupational inheritance.

Researchers concluded that the ascriptive characteristics of education and occupation play more critical roles in status attainment among Japanese youth than among their American counterparts. While it was suggested that a larger sample tested longitudinally might prove the status attainment model more applicable, the importance of the parents was not expected. While it was acknowledged that both American and Japanese parents place much emphasis on educational achievement, "the Japanese educational system is more intensely competitive and graduation from one of a handful of top-rated public and private universities is a critical factor in opening doors to the most desirable positions in business, government or the professions" ( $p$. 91). Three points were mentioned regarding the value parents place on occupational attainment: (1) since parents recognize the importance of the amount of education received as well as the prestige of the institution, they willingly finance and encourage children to receive the best education possible; (2) the desire is strong among parents in high status occupations to have at least one child succeed in the father's profession; and (3) strong social pressure is experienced by the Japanese youth to fulfill parental expectations because while his/her achievements enhance the self image, the young person's achievements enhance the public image of the family as well. "Such filial obligation is taken seriously in this group-oriented society" (p. 91). 
Endo (1984) also reported explanatory factors related to the educational ambitions of Japanese-American college students. The sample was composed of 200 Japanese-Americans plus 200 Anglo undergraduates at a west coast state university. The dependent variable was conceptualized as expectation. Students were asked, "As things stand now, how much education do you think you will actually get?" Thirteen explanatory variables were measured; the degree of importance of socioeconomic status when controlling for other variables was significant. However, the researcher indicated that much of the effect of SES would be seen more clearly if the casual ordering of the variables was given. Contrary to the findings of Boardman, Endo et. al. (1978) suggested that the SES status does have an effect on the ambition of Asian-American students.

Komarovsky's (1982) study of college women entering one of the so-called Seven Sisters eastern colleges explored the degree of consistency among various components of gender orientations: perceptions of psychological sex differences, attitudes toward sex roles, ideals of femininity and masculinity, and views about the women's movement.

The sample included Protestants, Catholics and Jews. Ethnically, one-third of the students were black, Asian and Puerto-Rican Americans. The majority of the parents were college graduates, some parents had attended but did not finish college and 25 percent of the fathers and 30 percent of the mothers had 12 or fewer years of schooling. In terms of career prominence, education of father and mother, 
occupational status of father, family income, employment of the mother and occupational status (high, middle, low) had no bearing.

It is important to recognize that the choice of sample cannot be considered as random of the population, since the girls attending a selective women's college would be drawn disproportionately from a higher educational and economic strata according to the author. However, the demographic spread, which included ethnic and religious diversity was considerable. Interviews with first generation college students from lower socioeconomic backgrounds strongly intimated that career motivation was linked to upward mobility. Their emphasis was more on attaining an economically and socially secure status, whereas daughters of professional and economically affluent families emphasized their commitment to work as an avenue of selffulfillment and as an intrinsic component of life.

With whites constituting 69 percent of the sample, race-ethnic differences may not be reliable, according to Komarovsky. The study does not show significant differences, and the figures did not confirm the higher career expectations of black students, as indicated by other studies. Among white students, the proportions of career salients did not vary by religion. Komarovsky noted, for example that other studies have confirmed that careeroriented women were more often Jewish. This study showed that the proportion of career-oriented women were Protestant, though religious differences were not significant. 
Catholic freshmen showed the highest rate of career salience, and this is explained by the high incidence of Latin American Catholics. The fathers of the Latin American students had the fewest years of schooling as compared to the fathers of the other two groups. The desire for upward mobility was considered the clue for career salience among the Latinas. No reason was suggested for the fact that black and Asian-Americans, also from lower socioeconomic backgrounds, exhibited rates of career salience similar to the white majority.

\section{Parental Occupation}

Studies have been reported which have sought to determine the influence of a mother's or father's occupational role on the daughter's career orientation. Baruch, 1976, for example, found that daughters of nonworking mothers were more likely than daughters of working mothers to devalue women's competence. Baruch suggested that the daughters of non-working mothers identified more with their fathers, while daughters of working mothers identified with them.

However, times have changed and more women are entering the working world. Yet, research reviews indicated that the effects of maternal employment on children are not clearly shown (Colangelo, Rosenthal and Dettman, 1984). Gold and Andrus (1978) provide a similar conclusion in their research, stating that maternal employment is a 
heterogeneous concept and its influence on children's development varies depending on the behaviors examined. Dellas, et. al. (1979) contend that maternal employment has various correlations, including the nature of maternal employment, the amount of time spent on the job, child care arrangements, the father's attitude regarding the mother's employment as well as maternal job satisfaction.

In 1972, Burlin explored the relationship of parental education, maternal work and occupational status to occupational aspirations (classified as traditional, moderate or innovative) of adolescent females. Innovative occupations are those in which fewer than 30 percent of the workers are women; moderate occupations are those in which fewer than 30-50 percent of the workers are women; and traditional occupations are those in which more than 50 percent of the workers are women. The sample was composed of 139 women in the 11th grade.

The categories of innovative, moderate and traditional were to be reflected in the participant's responses in both IDEAL and REAL choice of occupational aspirations as well as significantly different selections of occupations in their REAL and IDEAL occupational aspirations. In their IDEAL choices, 57 percent of the women aspired to an innovative occupation. In the REAL occupation choice, only 32 percent aspired to an innovative level. The selection of a traditional occupation increased from 29 percent of the IDEAL choices to 56 percent of the REAL choices. 
In addition, a significant relationship between respondent's REAL choice of an innovative, moderate or traditional occupational level and fathers with graduate or professional degrees and daughters who aspired to an innovative occupation. In addition, there was no significant difference between daughter's choice of a REAL occupational aspiration and the mother's educational level or work status (employed and not employed). The significance in relation to mother was found between occupational status of mother (traditional or nontraditional) and daughter's REAL choice of a traditional, moderate or innovative occupation. Thus, Burlin suggested that much of the relationship may be attributed to the strong association between mothers who work and traditional occupations and daughters who in REAL choice aspire to traditional occupations and between mothers who work in nontraditional occupations and the finding that so many more of the female adolescents aspired to an innovative occupation in their IDEAL choice of occupation may indicate that girls have a desire to pursue a broader range of occupations but that personal and social forces limit their beliefs in their ability to accomplish a goal.

A significant finding by Angrist and Almquist (1970) was that women with non-traditional career choices were more likely to have mothers who had worked while they were growing up and had achieved higher level of education. Burlin (1976) suggested that it is the type of job the 
mother holds that influences the choice of the daughter's career. It was also significant that the women who expressed interest in non-traditional careers had fathers who had attained higher levels of education.

Steven and Boyd (1980) conducted a study involving a subpopulation of 2976 women representing 894,000 married women between the ages of 30-44 who had lived with both parents when 16 years of age. The daughter's occupation in 1973 was more like the mother's than the father's, possibly the product of maternal values as to "what is appropriate." This finding was true even if the mother's occupation had been housework. There was a positive relationship between the mother's labor force status and the daughter's. The daughter whose mother had worked full-time was one and onethird more likely to work than if the mother had been a housewife during elementary and secondary school. The daughter of the employed mother was more likely to be engaged in a white collar occupation. Steven and Boyd suggested that this influence on the daughter was due to having a typical role model and economic advantage attributable to two-parent incomes; but the mother's type of occupation was not entirely inconsequential.

Haber (1980), for example, conducted a study with 50 college seniors from lower and middle class backgrounds in an attempt to determine the effects of mother's employment. Assessment was by questionnaire and tape recorded interviews. Subjects were between 20-24 and unmarried. The major finding of this dissertation study was that the 
encouragement of the parents' and daughters' sex role orientation were critical factors in determining career ... choice and commitment. The daughter's career choice was correlated with perceived attitudes and beliefs of mothers, rather than the mother's actual employment or non-employment status.

It has been suggested that the point is not so much whether the mother is employed outside the home, but the kind of work she does and whether she likes working or whether she works because it is economically necessary. The girl who sees her mother struggling with job and home responsibilities -- putting in long hours at each -- may aspire toward a career because she knows that she does not want to repeat her mother's difficult, possibly unrewarding lifestyle. For example, statistics show that the black female population has made more progress in terms of numbers of women receiving degrees (Romer, 1980). One of the reasons, Romer believed, is that black females are taught by female relatives and indirectly by the observing of black males, that women must take a strong, economically independent and responsible role in the family.

Rosenthal and Hansen (1981) assessed the impact of maternal employment on 555 seventh, eighth and ninth grade students' self-concepts, school achievement, vocational development and the perceptions of their parents. Females comprised 51 percent of the sample. Children in non-intact families were 19 percent of the sample; 42 percent were living in separated or divorced homes, 28 percent in which 
the mother was a widow, 26 percent with remarried mothers and 4 percent with remarried others.

A Multivariate $F$ test indicated no significant perceptual or developmental differences between children from homes with mothers who worked full time and those whose mothers did not work. Rosenthal and Hansen indicated that "the failure to find any differences in young adolescents' perceptions or development...attributed to maternal employment is important" (p. 597). There were no significant differences in children's level of self-esteem; men with working wives were not perceived any differently by children than were men with non-working spouses; no differences were recorded in perceptions of parents' loving, rejecting, demanding of working and non-working mothers. Findings were the same in non-intact homes. Working mothers had no appreciable effect on children's educational or vocational development, school achievement or vocational planning.

\section{Single Parent Homes}

However, social conditions are changing and the number of children living with one parent has increased dramatically (Scott-Jones, 1984). In 1984, it was estimated that between one-third and one-half of all children would live with one parent for some part of the child's life. Two years later, the Los Angeles Times reported that one in two marriages ends in divorce and subsequently more than half of 
all America's children can be expected to spend part of their childhood in a single parent home. In 1984, 14 percent of all white children and 54 percent of all black children were raised in homes headed by a woman. Projections are that by 1990 nearly nine million children will be brought up in such homes and many of them in poverty (Los Angeles Times, May, 1986).

Some women, and a few men, choose single parenthood according to Scott-Jones (1984). However, the increase in one parent homes also comes at a time of economic difficulty in American society. Two parent families may find child rearing a financial challenge, but the income of the single parent (particularly if the single parent is a female) may be barely adequate (Scott-Jones, 1984). This fact takes on additional significance when more than 86 percent of the non-white teen mothers and 40 percent of the white teen mothers in 1983 were unmarried.

Little research is available on the impact of single parenthood on career aspirations and choice (Schulenberg, et. al., 1984). However, Scott-Jones (1984) cited reviews which conclude that children from one parent families show pronounced differences on measure of achievement (grades and teacher evaluations) than on standardized measures of intelligence.

Zajonc (1976) found that children from single parent families had lower intellectual functioning because of fewer adult "teachers" in the home with whom to interact. Schulenberg, et. al. (1984) suggests that this idea is too 
broad to describe the issue since duration and timing of father's absence may differentially influence academic grades. In addition, the father's absence has been related to high occupational success when children reach adulthood, as well as higher IQ scores in middle class children.

Rosenthal and Hansen also found in their 1981 study of seventh, eighth and ninth grade students from single parent and two parent homes, that both males and females perceived absent fathers more negatively than those from two-parent families. This is relevant in light of the fact that vocational aspirations and vocational maturity were correlated with children's positive perceptions of parents. To what extent vocational maturity and aspirations might be affected by the father's absence is not clear. Schulenberg, et. al. (1984) indicated that females' grades and IQ scores were less adversely affected than those of males in homes where there was no father. However, as indicated earlier, little research has been conducted regarding the impact of single parent families on achievement and/or vocational aspirations of young people.

svanum, et. al. (1982) found that when socioeconomic status was controlled, males with a single mother or single father tended toward lower occupational status occupations. If income is very low, the parents may be consumed by work and worry about financial concerns. If income is not an all-consuming problem, one parent may have more time to interact with the child than if there were another adult in the home, svanum contended. Yet, the results of the study 
indicated that with socioeconomic status controlled, one parent families showed no detrimental effects on measures of achievement and intelligence.

The influence of non-intact homes on children is related to age of the child when the family divides, which parent is not living in the home, financial and supportive resources that are available, whether remarriage occurs and whether the single parent home is a result of separation, divorce or death (Schulenberg, et. al., 1984).

\section{Peer Influence}

Little empirical research has been conducted to investigate the role the peer group may play on the career choice of adolescents (Young, 1983). It is common knowledge, however, that the peer group is very influential in the lives of young people in junior and senior high schools. In fact, Spenner and Featherman (1978) wrote, "The encouragement of one's parents and the plans of one's peers appear to shape the ambitions more directly and with greater impact than any other source. Their efforts are stronger than the direct influence of one's scholastic aptitude or previous academic achievement and musch stronger than any other direct influence from one's social origins per se" (p. 392).

Coleman (1961), in the classic The Adolescent Society, investigated ten high schools and 8000 students who attended those schools. He wrote that high school students form a 
small society with a prestige hierarchy rooted in values that often conflict with the schools' academic functions. In addition, patterns suggesting independence from parents and emphasis on athletics and popularity led to decline in achievement. While showing effect for both sexes, the effects of peer pressure seem to affect females more than males and, thus, were considered to be a reason for the supposed decline of achievement by females in high school. In fact, both Coleman and Devereux (1970) argued that peer groups undermine parental values as well as providing a testing ground for moral values.

Lueptow (1984) pointed out that this supposed decline in achievement has been limited to sex-related achievement tests and courses rather than overall graded performance. Discussions of the supposed female decline generally treat it as pervasive rather than specific to sex-typed content and perhaps experience (Hunt, 1980).

A discussion of the specific influence of peers and the influence they may have on the career aspirations and choice by the ethnically-diverse, intellectually-gifted female is difficult because of the interrelatedness of expected behaviors of sex-typing of appropriate sex roles -- a young woman's desire to appear feminine and to be accepted by the peer group as well as to achieve academically.

Results from a study by Davies and Kandel (1981) found that parental influence on their adolescent childrens' aspirations is much stronger than the influence of best friends. Interestingly, however, while parental influence 
is strong, significant and equal for boys and girls, peer effects (though weaker than parental effects) are much stronger for girls than for boys. It appears that friends are relatively unimportant in determining future aspirations of boys but very influential in determining aspirations for girls.

According to Morse and Bruck (1982), sex typing cannot be ignored in a discussion of peer influence because "sex typing brings to the fore the fact that achievement toward eminence by men in the professions is a cultural expectation and, hence, looked on favorably...similar accomplishments by women are regarded as attained at the expense of sex-role expectations...and meet with disapproval" (in Khatena, 1982, p. 229)

Callahan (1979) and Fox (1977) wrote that there is no difference between the sexes in the intellectual process of perception and learning and the only areas in which boys' performance seem to be consistently superior are in visualspatial ability and mathematics. While these differences appear only after adolescence is reached, attitude and environment may be the real reasons for achievement or the lack of achievement (Eccles, 1985).

Girls' lack of achievement usually begins after puberty. It has been found that girls who do not receive grades commensurate with their ability in secondary school had attained grades equal to or superior to those of achievers in the early elementary years (Frazier and Sadker, 1973; Shaw and McCuen, 1960; Fitzpatrick, 1978). Despite 
girls' history of superior grades in elementary school (Dweck, Goetz and Strauss, 1980; Card, Stele, Abeles, 1980; Maccoby and Jacklin, 1974), they possess lower expectations of themselves, particularly when faced with difficulty or heightened evaluative pressure (Dweck, et. al., 1980). Girls are more likely to avoid situations which hold the threat of failure and tend to blame their own lack of ability when they fail at a task. While they may blame their lack of ability (when failure occurs) on a specific task, they also seem to view failure as an indication that they will fail in future academic situations. Studies have shown that females' verbal achievement scores remain superior to males throughout adolescence.

Rodenstein and Glickhauf-Hughes (1979) claimed that gifted girls are caught in a dilemma. That is, throughout adolescence, gifted girls receive conflicting messages: first, they are encouraged to achieve implying leadership and automony ... then to be 'feminine', which implies passivity and dependence. Blackburn and Erickson (1986), in their discussion of "Predictable crises of the Gifted student", imply that adolescence can become the third crisis in adolescent girls" lives. "Irrational mood swings, inconsistent behavior patterns, and tension about biological changes confuse the gifted student" who, heretofore, was skilled in "rational problem solving" (p. 553). The adolescent girl who is also gifted is particularly vulnerable as social and physical development take precedence over intellectual and academic pursuits. 
For example, Groth (1969) devised a cross-sectional study using gifted individuals at different ages who were asked to describe "wishes". These were correlated with Maslow's hierarchy of needs. Results showed that the fourteen year old girl seemed to be in a critical age in which needs for love and belongingness were more important than a need for self-esteem and achievement.

Coleman (1961) noted that girls with high grades receive less prestige than male scholars and the devaluation of female scholars is greater in middle class schools than in schools of working class people. There also seems to be less sex role differentiation in middle class schools where males and females are expected to achieve academically.

Dweck, et. al. (1980) suggested that sex differences in confidence toward seeking challenges may not be more than a desire for women to present themselves in a socially desirable light. Young female adolescents may be responding to a stereotype which depicts women as modestly feminine. Thus, academic performance may be perceived an inappropriate criterion for achievement among young females.

While one of the objectives of education is to internalize success, several studies have indicated that females evaluate themselves on the basis of how a parent, peer or teacher perceives them (Aiken, 1970). Females seem to need overt encouragement indicating that they are correct and/or are proceeding in the right direction. No comment is construed as a negative response. High achieving students 
tend to be more motivated by cues emphasizing grades and academic success. Thus, feedback effects are affected by the relationship the student has with signficant others.

Some studies have shown a positive correlation between academic performance and positive peer acceptance and positive peer interaction (Scott-Jones and Clark, 1986). St. John and Lewis (1974) found that popularity with white girls was a significant predictor of black girls' grade point averages. Martin Patchen (1980) discovered interracial contact to have little effect on the academic performance of black students, however.

In a study regarding person orientation of 848 tenth and eleventh grade students, Schneider and Coutts (1985) speculated that girls would indicate a greater need for affiliation than would boys. They also predicted no sex difference in the total amount of social interaction with friends but that there would be sex differences in the type of interaction; that scholastic success would be less important for boys than girls in the achievement of status and popularity among peers and that boys would be more likely than girls to act independently of adult standards and compromise their principles to gain peer acceptance.

Results showed that while girls did indeed indicate a higher need for affiliation, boys also manifested high affiliative needs. The boys ranked interpersonal friendships as their areas of greatest concern. Grade 10 boys ranked female friendships and male friendships first and third, respectively; grade 12 boys ranked female 
friendships first and second, respectively. Particularly noteworthy, according to the researchers, was that while girls ranked friendships with members of the same sex of greatest concern to them, boys ranked friendships of the opposite sex of greatest concern.

Boys did not consider high grades as being very important in being considered popular by members of their own sex; nor did the girls believe academic success made boys popular. Both sexes were exposed to peer group expectations not especially conducive to academic excellence. Boys were more likely to perceive a negative influence of peers on their achievement -- as wishing they would work harder but do not because of what friends might think. The researchers pointed out that more females indicated they study with friends. Thus, they may be satisfying their affiliative and achievement needs at the same time.

In 1975, Curtis conducted an extensive study examining adolescent orientations toward parents and peers. Using the variables of sex, age and socioeconomic status, 9,056 young people in grades 7-12 were interviewed. Curtis noted that previous research indicated a greater attraction/dependence on friends by female adolescents. In addition, females indicated a preference for the opinions of the mother.

Results of Curtis' study showed that preference for the same sex parent while not discernible for males was for females, and that at each grade level both parents were preferred over friends. Curtis also noted that the study 
showed a growing shift toward independence in opinion formation rather than a shift from parent to peers.

Lee (1985) selected a sample of 68 black adolescents in a southern rural environment to explore factors related to academic and social success. Nominated by teachers in junior and senior high schools, the students were all considered academically and socially successful. The sample of ninth, tenth, eleventh and twelfth grade students were interviewed about family life, interests, personal attitudes and values and plans for the future.

sixty-three students indicated the importance of friendship and 55 indicated they had many friends. Thirtysix of the students stated they had no difficulty in making friends and "best friends" were people who shared common beliefs and interests. While not questioned regarding the influence of friends on career choice, best friends were considered "special" because they "offer encouragement help with homework, Iisten and understand and have the ability to make a person feel special by being attentive" (p. 136) .

Cohen (1983) asserted that there is no single effect of peer influence. There are, instead, "peer influences on college aspirations, peer influence on occupational aspirations, peer influences on drug use" and so on ( $p$. 733). In other words, peers may influence some parts of an individual's life but not others.

While this may be true for many adolescents, Barnett (1978) and Blackburn and Erickson (1986) noted that adolescence is a particularly stressful time for gifted 
girls. Resulting from reinforced cultural stereotypes, adolescent girls may no longer be rewarded for academic accomplishments. Approval of others, popularity and marriage may become the girls' perception of success (Heilbrun, 1969; Slee, 1968; Horner, 1972; Haven, 1972).

Blackburn and Erickson (1986) and Schneider and Coutts (1985) explained that gifted adolescent girls are "particularly vulnerable to the trials of adolescence including irrational mood swings, inconsistent behavior patterns and tension about biological changes." While boys continue to receive encouragement to achieve and compete for grades, the girl is encouraged to adopt values such as marriageability, femininity, poise, modesty, dependence, unselfishness, physical beauty, and flexibility. "Many researchers believe that academic and career achievement is a negative, painful, rejecting, isolating experience" (Blackburn and Erickson, 1986, p. 553). Many gifted women fail to develop their intellectual abilities to the fullest professional attainment. Instead, they respond to pressures to conform to specific sex roles (Broverman, Vogel, Broverman, Clarkson and Rosenkrantz, 1972).

In a comprehensive study of 241 junior and senior high schools, John Goodlad (1984), in A Place Called School, revealed some cogent points regarding the effect of the peer group on the high school student. Dr. Goodlad made a point of not assuming that every finding is generalizable to every population. That is, while schools have much in common, they also have much that is unique to a particular community 
and specific school. Students know that planning to go to college and demonstrating the ability to do so is important. At the same time, they are surrounded by a youth culture which promotes other values -- mediated and reinforced by the media, commercial interests and major elements of the adult culture.

Junior and senior high school students were asked to select from six classifications the students they perceived to be the most popular. "Smart students" was chosen by only 14 percent of the junior high population and 7 percent by the students in senior high school. "Good looking students" and "athletes" accounted for 79 percent of the choices by junior and senior high students. "My friends" was the top choice $(37$ percent and 34 percent in the senior high schools) when asked "What is the one best thing about this school?"

Many students feel less than good about themselves academically, yet take great satisfaction from athletic ability and peer relationships. "Perhaps the educational aspect of school life simply declines in significance for large numbers of students as they feel less than able to succeed in what the school sees as most important, and as they move into adolescence" (p. 77).

Giftedness may place an additional burden on the girl, particularly during adolescence. Austin and Draper (1981) indicated that during the preschool years bright children do not enjoy a definitive popularity because of intellect. When the child moves into the elementary grades, however, a 
positive correlation between intelligence and social acceptance begins to be apparent. During adolescence, status changes once again. Gifted boys and girls tend to lose status until later in high school when boys seem to regain acceptance -- particularly those who become high school athletes. Girls who are academically talented do not enjoy the same kind of popularity because other kinds of behaviors and abilities in areas other than academics are more acceptable by the peer groups and more highly valued (Karamessinis, 1980).

Role definition is publically rewarded and fathers often vicariously gain "macho points" for their son's accomplishments. Also, in minority communities, being an athlete has more chance of financial reward and scholarships. Thus, the status of the star athlete was higher than that of the intellectually-gifted boy. Still, boys seemed more apt to acknowledge their intellect than did girls (Perino and Male, 1981).

Monks and Ferguson (1983) developed a model for viewing adolescent psychosocial development. Assumptions of the model are that basic changes in adolescents' biological, cognitive and social capacities reciprocally interct with the social settings of the family, peer group and school or work to influence change sin sex areas of psychosocial development. These include attachment, friendship, sexuality, achievement, autonomy and identity. usig the model as a framework, the authors reviewed literature pertinent to the psychosocial adjustment of the gifted adolescents. 
It was determined that peer relationships are strengthened as the adolescent's detachment from the family grows. Adolescents tend to rely less on physical or fact constructs and more on psychological constructs to define friendships. The authors cite Duck (1975), La Gaipa (1979) and Selman (1980) who indicate the number of reported friendship relations increase until the age of 15 , at which time the number of reported friendship relations decreases. Friendship continues to be defined as sharing of experiences, coping with problems together and someone to exchange ideas with about solutions to problems. Friendship also provides a learning environmenmt for the regulation and integration of aggressive behavior, value orientations and sexuality.

Vidulich (1978) found the size of the high school to be an important factor in the decision of the intellectuallygifted girl's decision to enter the fields of science and mathematics, for example. People choose their peers and there are more opportunities for a girl in a large school to find other girls with similar goals. Thus, in such an environment the selection of a non-traditional career might not be perceived as particularly unusual by age-mates. High school size might also mean that more programs are available to the students. Enrichment programs are more apt to be in place with qualified and experienced teachers, counselors and personnel.

Casserly (in Fox, Brody and Tobin, 1980) found in a 
study of 161 high school girls that gifted girls repeatedly spoke of the importance of girlfriends who had like interests and abilities and who provided encouragement, particularly in dealing with teasing and disapproval of boys. When asked whether their social group outside of school was the same as the school academic group, the majority of girls preferred to date boys outside their Advanced Placement classes in math and science. For girls who were not tracked into Advanced Placement earlier, eighth grade algebra placement was the most traumatic. The girls reported that other girls rejected the placement because of lack of parental awareness or support, as well as lack of support from guidance counselors.

Many guidance counselors are a poor source of encouragement for girls interested in science and mathematics, according to Casserly (1981). Through interviews she learned that girls in Advanced Placement classes credited older girls with encouraging their interest in science or mathematics. Encouragement was particularly important at the eighth grade level when girls had to choose whether to take Alegbra. The second difficult time was in high school when girls had to choose between college, preparatory classes or the Advanced Placement Program. Apparently, for the particular girls in the study, adult support was lacking.

Emmerick (1978) replicated a study conducted by
Brittain in 1963-1966. Girls were presented with


hypothetical situations in which one situation was favored by parents and another by peers. The subjects were asked who the person in conflict would follow. Emmerick's study used 49 boys and 49 girls in ninth and twelfth grades. Results showed that in both studies, the situation itself was the determining factor of who the student favored. In addition, the sex of the student made a difference. Boys tended to switch responses to parent and peer pressures from 9-12th grades, while girls' responses remained stable. Ninth grade boys relied more on parents than older boys or ninth grade girls, both on important as well as unimportant issues. It was concluded, as were the conclusions of the earlier studies, that: (1) adolescents are influenced by parents on long range situations when important and difficult choices are involved, and (2) peers exert more influence when short range, less difficult or less important choices are involved.

June and Fooks (1980) reported that previous research and theoretical evidence asserts that a person's career development is strongly influenced by role models, significant others, key influencers and key figures. A key influencer is generally defined as a person or persons the responder identifies as having the most significant single greatest impact on career choice. It may be a parent, a relative, a teacher or a friend.

studies cited by June and Fooks included an investigation by Pallone (1970) who assessed 161 black and 
218 white high school males and females from working class families. The finding was that regardless of race or sex the most influential person was the same sexed parent in conjunction with the person who held the preferred occupation.

In 1973, Pallone replicated the study with 73 Puerto Rican females, 211 black females and 200 white females in grades 11 and 12. Some of the results were the same as the 1970 study in that black females most frequently named their mother as key influence; father was ranked ninth.

June and Fooks (1980) administered the Vocational Preference Inventory to 25 black males and 25 black females who were staff members or faculty members at a large predominantly white university. Five of the respondents held bachelor's degrees, 23 master's degrees, 14 had PhD.s or EdD.s and five had professional degrees (law, medicine, veterinary medicine). Males and females listed a person who held the job as well as the mother as key influencers. Females ranked mother as the most influential and a close friend or buddy and person who holds the job tied for second. Males' responses indicated that the father and the techer were equally influential. The father and the teacher were ranked as third in importance. Across sex, females influenced males at a higher rate (44 percent) than males influenced females ( 32 percent), but both sexes tended to be influenced more by persons of the same sex. The researchers emphasized the need for additional studies related to key 
influencers because the role played by the key influencers may have implications for "either perpetuating or helping to eliminate the 'traditionality' of black career choice.

\section{SUMMARY}

The first part of the review cited identification practices which have historically excluded ethnicallydiverse children from participation in gifted programs. Inappropriate use of tests, traditional definitions of giftedness which favor the traits found in white middle class students, and the cultural bias of standardized tests were among the reasons discussed. Alexander and Muia (1983) also indicated that areas, or categories, of giftedness which will be recognized as "gifted" are determined by the dominant culture. The culturally different child, who may possess exceptional abilities not recognized as important by the dominant culture, may be regarded as intellectually inferior and function in an environment which regards them as disadvantaged or as learning disabled (Alexander and Muia, 1983).

Methods of identification in California are representative of those procedures used in other states, according to the research. These methods include a combination of a score of $130+$ or above on an intelligence test, ranking in the 95 th percentile or above on an achievement test and/or teacher/counselor checklists of attributes the child possesses. For example, these 
attributes may include evidence of leadership ability, creativity and/or evidence of skill in cognitive problem solving ability.

It is evident, from the literature review, that there is still a narrow definition of giftedness. It is also obvious that assessment of giftedness in culturally-diverse young people is often limited to an intellectual level, through standardized intelligence or achievement tests, academic performance as exemplified through grades or through non-creative measures. "If educators and psychologists would broaden their concept of giftedness and recognize the complexity and multiplicity of giftedness, greater numbers of minority students could be included in gifted classes (Marland, 1972; Khatena, 1982; Masten, 1985; p. 84).

Despite a vast amount of literature related to occupational aspirations and choice, the studies have focused on white Anglo males or white Anglo college-aged women or conducted comparison studies of Anglo young people and ethnically-diverse young people. An extensive review of conducted and reported research revealed no studies specifically related to influences affecting life planning/career selection of intellectually-gifted adolescent girls from black, Pan/Asian or Hispanic backgrounds.

However, statistics show that women from ethnicallydiverse cultures are underrepresented in high status careers. One reason hypothesized for this underrepresentation is that cultural values, attitudes and 
expectations held by parents and peers within the subculture may be strongly affecting the career/occupational selection of women from some ethnically-diverse cultures. While some ethnic cultures may be encouraging women to select a life plan other than that of the traditional role of wife and mother, women as a group, and ethnically-diverse women in particular, are not seeking careers in non-traditional areas (Young, 1983).

While Callahan (1981) noted that it is impossible to control heredity and environmental factors influencing the ethnically-diverse gifted female, the literature indicates certain factors within the environment which do impact the gifted girl in general.

In a number of studies, some type of cognitive variable has been identified as contributing to achievement or success as represented by career choice or aspiration (Young, 1984). These variables have been identified differently and, in some cases, ascribed an intervening role between such variables as parental modeling, social class, academic achievement and a typical occupational choice for females.

Traditional feminine role values are dictated by an external authority that supplies simple, morally proper definitions of what is required in a given situation. Sexrole identification is acquired through societal modeling. The child is encouraged by parents to learn a specific behavior and reinforced by others outside the home. When women do pursue a career and achieve success, Perino and 
Male (1981) suggest that it is because they have had parents who supnorted them in their role choices and gave them the options of choosing activities identified with either sex.

Traditional sex roles that have been developed and reinforced by a culture are difficult to ignore, according to Diggs (1974). Without parental and societal support, the gifted, ethnically-diverse female who aspires toward a nontraditional career may select one that is more traditional, such as nursing and teaching, because she perceives it as the acceptable thing to do (McBroom, 1981; Herzog, 1982).

Perino and Male (1981) suggested that females do not aspire or achieve high status careers in greater number because the requirements for a woman to be considered feminine are not the same as the requirements for successful achievement. Successful achievement requires aggressiveness and competitiveness -- attributes not in agreement with society's expectations for women (Wells, 1980; Hoffman, 1972) .

Part of the task of teachers, parents and counselors involved in providing vocational counseling is to be aware of and to understand the effects of the culture -- how it aids or inhibits aspirations and future plans of the ethnically-diverse gifted girl. It is important that each young woman understand that she does not have to abandon the values of her culture but that she ought to select a career or occupation commensurate with her abilities. 
CHAPTER III

RESEARCH DESIGN AND METHODOLOGY

The primary purpose of this case study was to examine and assess cultural influences, as transmitted by the parents and as perceived by the ethnically-diverse, intellectually-gifted adolescent girl on her life planning aspirations. The secondary purpose was to examine and assess influences the adolescent, intellectually-gifted, ethnically-diverse girl perceives as being transmitted by the community. These findings are to provide parents, teachers, career counselors and gifted coordinators with an increased understanding of the perceptions the ethnicallydiverse gifted girl perceives as affecting her future plans.

A comprehensive review of reported studies revealed a paucity of research regarding this topic: Influences Affecting the Life Planning of Ethnically-Diverse, Intellectually Gifted, Adolescent Girls. Because of a lack of reported data related to career and occupational choices of Hispanic-American, black-American and Asian-American girls, a case study was designed.

The research tried to examine and assess perceived cultural influences affecting the future life planning of ethnically-diverse, intellectually-gifted adolescent girls. A quantitative examination of perceptions was accomplished 
perceptions was accomplished through use of a survey instrument to which 51 girls responded. A qualitative exploration of the adolescent girls' perceptions was obtained through use of three group interviews in which nine girls participated.

The case study, according to Borg and Gall(1983), is well established as a qualitative approach to research in the behavioral sciences. In the case study, the investigator looks at a social situation to study relationships among attitudes, values and perceptions of individuals. Lutz and Ramsey(1974) emphasize the importance of the case study as a method of research to handle particular problems of education in which certain information could not be attained in any other way.

Mason and Bramble (1978) indicate that the case study contrasts "sharply" with other research methods used in behavioral sciences:

- The attempt is made to study a multitude of factors by limiting the number of cases observed.

- Studies of phenomena are investigated as they exist in the natural setting.

- The case study is useful in bringing to light relationships which can be further studied in other ways.

- Suggestions from case studies, for example, may be used to conduct more tightly controlled research. 
Conversely, findings from tightly controlled, quantitative research can be subjected to indepth case or field studies.

As used in social sciences, case study results may be classified as a descriptive narrative and may include opinions, attitudes and perceptions of the individuals or "cases" being studied (Patton, 1980). This method of qualitative research is advantageous, according to Mason and Bramble (1978), because it is useful in bringing to light relationships that can be further studies in other ways. On the other hand, the information gathered from tightly controlled circumstances can be used to design case studies.

Additionally, the case study may provide new insights, help to modify pre-existing conditions or assist in pointing out gaps in knowledge (McMillan and Schumacher, 1984).

In a case study design, the focus of the research is one unit of analysis. "The researcher defines or designates a single unit of analysis regardless of the number of events, participants or phases of a process" (McMillan and Schumacher, 1984; p. 322 ).

The single unit may be an individual person, a clique or a class of students. The numbers in a unit may range from one to thirty. Thus, the case study is to probe deeply in order to analyze the unit with a veiw of establishing generalizations to a wide population to which the unit may belong (Cohen and Mason, 1985). 
Selection of subject Sample

In order to accomplish the purposes of this study, perceptions regarding influences affecting occupational aspirations/choices of intellectually-gifted, ethnicallydiverse, adolescent girls, the original proposal was designed to include fifteen black, fifteen, Hispanic and fifteen Asian eighth grade girls.

Girls between the ages of 12 and 14 were selected for the study because it is at this point that adolescents begin thinking seriously about their future. The selection and preparation for a vocation is one of the key development needs of adolescence (Lindgren, 1980). "Exploration of self in relation to careers and work is the principal task of career education at this stage" (Evans, Hoyt and Mangum, 1973, p. 30).

A telephone survey of secondary schools in San Diego County was conducted to find these subjects. Nine secondary or unified school districts were contacted. Five districts had at least one identified gifted girl of ethnic origin for the researcher to contact. of these five districts, one denied permission for the researcher to conduct the study in that district. Two districts had a sufficient number of Hispanic girls; four districts had no black identified gifted eighth grade girls. Within four districts, the researcher found the subjects needed for the Asian sample. In an attempt to find additional gifted girls from the black population, the researcher contacted the 
President of the San Diego Urban League, a consultant who works in the black community and an administrator at the San Diego County Department of Education. A survey was conducted among the faculty at the school of Education at the University of San Diego. Finding no more eighth grade black girls, permission was received to use two seventh grade black girls since their ages fit in the age range of 12 to 14. In order to balance the lower age range, two Hispanic and two Asian subjects in the seventh grade were included among the participants.

The final sample consisted of 51 female students in grades 7 and 8 . The subjects had been identified as belonging to a particular ethnic population by the Racial/Ethnic Survey conducted by individual school districts. The three racial groups were identified: Pan/Asian-American ( $N=17)$, which included Japanese $(\mathrm{N}=4)$, Guamanian $(\mathrm{N}=1)$, Filipino $(\mathrm{N}=10)$, Korean $(\mathrm{N}=1)$, and Vietnamese $(\mathrm{N}=1)$; black-American $(\mathrm{N}=14)$ and HispanicAmerican $(\mathrm{N}=20)$. The predominance of Filipino girls participating in this study occurred because, as mentioned earlier, the school district allowing the researcher access to the girls had more Filipino gifted girls than any other Pan/Asian population. The mean age of the subjects was 13 years, 1 month, varying from $12-14$ years. No attempt was made to randomly sample the subjects because of the few girls available.

The reason for selecting San Dieo County Schools was 
because of the racial/ethnic diversity. The 1984 Fall Racial/Ethnic Survey from the San Diego County Department or Education revealed that out of 317,154 students in public, elementary, secondary or unified school districts,59.9 percent are white non-Hispanic. The percentages for racial/ethnic representation is as follows:

.6 - 1,903 students: American Indian or Alaskan native

$5.3-16,809$ students: Asian or Pacific Islander

4.6 - 14,584 students: Filipino

21.7 - 68,822 students: Hispanic

7.9 - 25,055 students: Black, Non-Hispanic

The Office of Gifted Education at the San Diego County Department of Education indicated that out of 43 elementary and secondary districts, 26 receive state funding for education of gifted students. Districts which do not receive state funding either do not have special programs for gifted education or provide funding through their district budgets.

Each girl in this study was eligible for the school's enrichment program for gifted students as a result of achieving a score in the 98th percentile on a standardized achievement test or at least a score of 126 on an individual or group intelligence test. Additional evidence used by some districts included teacher or counselor recommendations that the student is functioning in a very superior range or exhibits the potential for such functioning. In some instances, teachers made special assessments of 
manifestations of giftedness by completing a checklist of acceptable criteria. The students in the study were taken from the groups of black, Asian and Hispanic girls who participated in the schools' enrichment program.

\section{Development of Instrument}

The questionnaire items in this study were designed by the researcher. Following an examination of the research questions, the researcher looked at existing instruments for one that could be used in its present state. Finding none, the researcher extracted certain items from the following: A study conducted at the University of MissouriRolla in 1978 entitled, Determinants of Career Goals in Junior and Senior High School Women, the Career Determinants of Gifted Women (A questionnaire from the study, 1980); the Rotter Incomplete Sentences Blank -High School Form; and a dissertation entitled, Gifted Female Adolescents' Perceptions of Career and Lifestyle Aspirations (CrayAndrews, 1983).

The questionnaire used in this case study consisted of 50 items. These items investigated the intellectuallygifted, ethnically-diverse adolescent girl's perception regarding:

1. Support and understanding from parents as related to future goals. 
2. A sense of autonomy - feeling somewhat independent to make her own decisions.

3. Satisfaction with self, academically.

4. How the girl perceives she compares, academically, with her peers.

5. Influence of peers regarding future life goals.

6. Impressions the girl has about placement in the gifted program as well as the length of time she has been in it.

7. Ideas concerning additional help she would like to receive about her future goals, e.g., career counseling.

8. School subject strengths, preferences, most difficult subjects.

Eight of the questionnaire items asked for demographic information about the girl's family. These questions asked the girl the educational level of both mother and father, the occupations of both parents, the number of siblings in the family, the level of income of the parents, the ethnic background of the parents, the country from which relatives came, the religious preference of the parents and the girl, and the country in which she was born.

The sixteen family-related questions asked the girl her perception of her relationship with her parents, whether her parents encouraged independent decision-making by her, how well she feels her parents understand her and her future 
plans and whether she perceives her parents as being supportive of her achievement in school. One question asked whether the girl discussed her future plans with other adults. Also included were ten peer influence questions, ten school-related questions and five future life questions. The questions related to perceptions of parental influence were Likert-type in which four choices were offered for answering For example;

How well do you feel your mother understands you and what you want to do with your life?

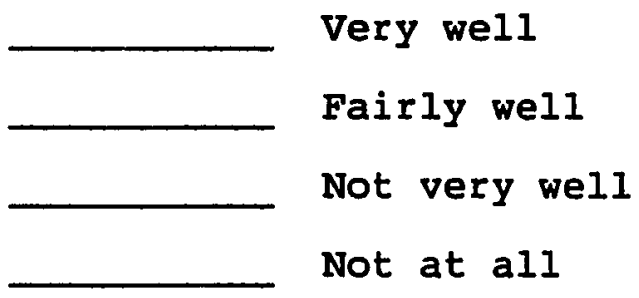

Questions related to peer influence were Likert-type in which three choices were offered. For example:

How often have you taked about the following with your friends and other $\mathrm{kids}$ in your neighborhood and school?

Your educational and career plans?

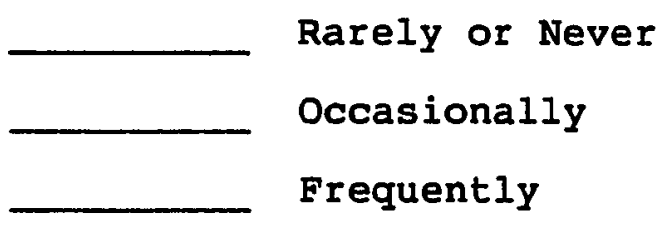

In both parent and peer influence questions, the most positive response choices (i.e., "Very well", "Extremely", "Frequently") were alternated randomly to prevent a response 
set on the part of the participant. Questions related to schooling were open-ended, asking the subject to name a favorite and least favorite subject, suggestions for perceived needs about career choice and questions about gifted program placement.

\section{The Pilot Study}

Content validity of the instrument was determined by having a pilot group of six girls not involved in the study answer the questionnaire. Each girl was asked to critique the questions for clarity of the instructions and for clarity of the questions. Four adult educators were asked to analyze the questionnaire for clarity of item construction and the directions. In addition, they were asked to evaluate the appropriateness of the items by comparing them to the questions underlying the study. Two educators who are members of a minority culture were asked to examine questionnaire items for detection of bias in item design.

In April, 1986, the pilot instrument was administered to a second group of six girls not involved in the study. Two weeks later, the questionnaire was administered to the same group of girls. Reliability and validity of the instrument was determined by calculations from the testing by the students. 
Suggestions made were used to make final revisions on the instrument. Comments from the pilot group included:

1. Directions and questions are clearly written.

2. Question No. 17 regarding parental income might be a problem because the girls may not know the answer or may be reluctant to answer even if they do know the answer. The answer choice "Don't Know" was added.

3. Question No. 50 regarding schooling after high school was revised in part "b" to add the word "only."

4. Question No. 13 was amended to include "other" to the list of religious preferences.

Reliability was established through use of the testretest procedure. Less than 5 percent of the total number of questions showed change. To calculate the stability coefficient or test-retest reliability, five adolescent girls were administered the questionnaire at a two-week interval. The scores of the five responses were correlated and in agreement $(+.77)$, indicating answers were consistent in measuring items over a two-week period.

One question which showed change by three of the five pilot subjects was "How close do you feel to your father?" One pilot subject changed from "Fairly close" to "Extremely Close"; one subject changed from "Quite close" to "Fairly close"; and one subject changed from "Fairly close" to 
"Quite close." The reasons for the change are unknown. One might conjecture that the girls simply felt differently two weeks after the first take. The question just before the father closeness questions asked the same perceptions in relation to the mother. The answers related to the mother did not change for these girls. It could be that the mother-daughter relationship is more stable or that the girls had not thought about their relationship with their father until the questionnaire appeared.

The other question which showed change asked about world unrest and peers --- "How often have you talked about world unrest or threat of war (with your friends)? Three pilot subjects changed from answering "Occasionally" the first time the questionnaire was answered to "Rarely or Never" the second time. It may be the questionnaire was read more carefully the second time since the answers to Question \#36 about world unrest were in a different order from the previous three questions. That is, the prior three questions listed answer choices in the order of "Rarely or Never, Occasionally and Frequently." Question \#36 listed the choices as "Occasionally, Rarely or Never and Frequently."

As none of the questionnaires used in the reliability and validity studies revealed missing data or responses, and because no ambiguity or lack of clarity had been revealed after the initial pilot study corrections, it was determined the final questionnaire reliable and valid and should be utilized as the final instrument (See Appendix B). 
Interview Schedule

The interview schedule used in this case study was designed by the researcher based on questions from the questionnaire.

One reason for the interview was to provide an opportunity for the researcher to gain additional information which would enhance the answers from the questionnaire. It was not the intent of the researcher to identify specific responses as coming from particular girls. Instead, data collected was be discussed in the dissertation as the oral answers relate to those given in the questionnaire itself.

The fundamental principle of qualitative interviewing is to provide a framework within which respondents can express their own understandings in their own terms (Mason, 1978). It is an opportunity for interviewees to express opinions and/or perceptions.

The interview has both strengths and weaknesses according to Yin (1984). Interviews can provide for less misunderstanding as well as increased clarification of responses for an in-depth picture. Weaknesses may lie in the skill required by the interviewer and the possibility of interviewer bias. The researcher, who was also the interviewer, is a professional educator who has also been trained as a counselor with experience in the interviewing process. The skills of sensitivity and active listening, 
along with the awareness of bias, will help insure accurate recording of responses. In addition, each interview was taped and reviewed by an objective examiner who also typed the interviews. Two professional researchers verified the interview data as being recorded accurately and that the interview was conducted in an unbiased manner. The professional researcher's verification was also used as a cross-check to examine the researcher's accuracy in recording interviewees' responses during the interview.

While the interview may be open to problems of validity and reliability, the answers given during the interview were in the form of each girl's affective perceptions. It was the intent of the researcher to learn about the opinions and perceptions of each subject and there was no guarantee of what was factual.

\section{Procedure}

When planning a study in an administrative hierarchy such as a school district, it is important to follow the channels of authority (Borg and Gall, 1979). In the current situation, the researcher planned to obtain participants from more than one school; thus, the coordinator of gifted education in a specific school district was contacted first. If the school district coordinator could not be reached and/or could not obtain permission for the study, the superintendent was contacted. 
During the initial meeting with the administrator, the researcher :

1. Explained the purpose of the study and the kinds of information being sought.

2. How the results of the study might assist parents, counselors, gifted education coordinators, and teachers in understanding the kinds of variables influencing the Asian, black and Hispanic girl planning for her future.

3. Assured the administrator of anonymity of the subjects, the individual school and the school district unless requested otherwise.

4. Assured the administrator that results of the study, if requested, would be available to the school district following completion of the study.

If permission to conduct the study was obtained, the researcher was directed to the school site principal or the school counselor. In one instance, the researcher was given the names of guidance counselors at each of three shcools. In addition, the gifted coordinator sent a letter to the counselors explaining that the researcher would be contacting them.

At the meeting with the school contact person, the researcher followed the same procedure as with the district administrator and answered any questions. It was explained 
that a letter of informed consent had been prepared for parents to sign. Two meetings with the girls were requested, one for the purpose of explaining the study to the girls and handing out the parent permission letters, and the second for administration of the questionnaire. The length of time for the first meeting was expected to be 15 minutes and the length of the second to be 20-25 minutes. In two schools, dates were set for interviews.

The parent letter of informed consent (See Appendix A) was necessary because the subjects were minor girls. As defined by Borg and Gall (1979), "Informed consent emphasizes the need for a voluntary, uncoerced consent and provides for the freedom of the research participants to withdraw without prejudice (p. 82).

At the first meeting with the subjects, the purpose of the study and how results might help adults plan career counseling for students was explained. It was also emphasized that no girl had to participate and that, to protect anonymity, real names would not be used and all answers would be confidential. The parent letter was read aloud and an opportunity provided for questions. Parent consent forms were returned by all but one girl.

During the second meeting, the questionnaire was administered. Girls were asked to write their middle name, their mother's name or a name they particularly liked on the instrument. Directions were read aloud and girls were assured that the researcher would explain an item if it 
seemed unclear. One student asked what to answer if her father was not in the home and the girl saw him infrequently. The researcher suggested answering it as best she could. If she could not or did not spend enough time with him to know an answer, she should leave it blank. The second $k$ ind of question pertained to the lack of knowledge about the meaning of "technical and vocational" school. All responses were made on the instrument in order to simplify the process for subjects. A candy bar, lollipop or gum was distributed following completion of the instrument.

A total of 51 subjects answered the questionnaire: 17 Pan/Asian-Americans; 13 black-American; 20 Hispanic-American from seven schools and four school districts. Four schools were from the South Bay, one from East county and two from North County.

Two weeks after the administration of the questionnaire, the researcher met with one group of three Hispanic-Americans, one group of three Pan/Asian-Americans and one group of three black-Americans. These groups were from South County and North County --- a total of 9 girls or 20 percent of the total number of girls. Interview subjects were randomly selected. The interview was taped and lasted about one hour. The size of each group was set so that each of the three girls would have an opportunity to respond to the questions. 
Research Questions:

To guide in the analysis of data relative to perceptions of black, Pan/Asian and Hispanic intellectuallygifted adolescent girls, the following research questions were designed.

1. What is the extent of the ethnically-diverse, intellectually-gifted adolescent girl's relationship with her parents?

Questionnaire items: 2-5, 8-9, 29-34

2. What is the extent of the ethnically-diverse, intellectually-gifted adolescent girl's interaction with each parent relative to career choice/future life planning? Questionnaire items: $6-8,9-10,28$

3. What influences, as related to the family's sociological environment affect the career choice/future life planning of the ethnically-diverse, intellectually-gifted adolescent girl?

Questionnaire items: $1,11,14-17,19$

4. Are occupational choice/life planning goals clearly defined by the ethnically-diverse, intellectuallygifted adolescent girl?

Questionnaire items: $46,47,49$

5. What is the ethnically-diverse, intellectuallygifted girl's perception of herself and her ability to pursue a career/occupation commensurate with her ability?? Questionnaire items: $35-39,41-44,48,50$ 
6. Who else does the girl perceive as influencing her future life plans?

Questionnaire items: 7

7. Does the ethnically-diverse, intellectually-gifted adolescent girl perceive that the life planning of her peers influence her own life planning?

Questionnaire items: $18,20,40$

8. To what extent do the perceptions regarding cultural/parental influences vary for the intellectuallygifted adolescent girls between each of the three ethnic groups? 


\section{Data Analysis}

The analysis of the data was accomplished through the use of the University of San Diego's VAX $11 / 780$ computer and The Statistical Package for the Social Sciences (SPSS-X).

Differences in the responses between the three ethnic groups were tested by the use of the chi-square. Chi-square was used to analyze specific questions which were important of themselves or which were important to the understanding of a general topic. The .05 level of significance was employed.

Qualitative data obtained from the interview were used to compare questionnaire data with comments given by the girls when peers were present. It was also the intent of the researcher that the interviews provide an opportunity for the subjects to express opinions, attitudes and perceptions not available from the survey instrument. Data from the interviews were analyzed according to themes as they related to questionnaire items. 
CHAPTER IV

ANALYSIS OF DATA

The primary purpose of this case study was to examine and assess cultural influences as transmitted by the parents, which the intellectually-gifted, ethnically-diverse adolescent girl perceives as influencing her future life planning. The secondary purpose was to examine and assess community influences the intellectually-gifted, ethnicallydiverse adolescent girl perceives as influencing her future plans.

Findings from this study will assist teachers, parents, guidance counselors and those who work with gifted black, Asian and Hispanic girls to gain additional insight and understanding of how the family and the community affect the aspirations of girls from ethnically-diverse cultures. It is expected that the awareness of and understanding by those who work with the gifted will translate into developing strategies to assist these girls in the development of plans for their future lives which will utilize their talents and gifts.

Data were obtained from a 50 question survey designed by the researcher, and from three interviews with asample from this study which comprised a total of 51 intellectually-gifted, adolescent black (N=14), Pan/Asian $(\mathrm{N}=17)$ and Hispanic $(\mathrm{N}=20)$ females. 
The questionnaire was administered to all 51 girls and all answered questionnaires were used for data analyses. An interview was conducted by the researcher with nine girls in groups of three. Each interview was about one hour in length. The purpose of the interview was to gain additional insight into the variables affecting these girls' future life plans. It was also the intent of the researcher to compare answers from the questionnaires, with answers given during the interview. The purpose of this comparison was to see whether any issues emerged other than those asked for in the questionnaire. This qualitative exploration offered the opportunity for the girls to discuss their ideas, perceptions and feelings in their own words. The interview data served to enrich and enhance the quantitative data. The chi-square statistical analysis was used to analyze and determine the significance of differences on selected questionnaire items. While statistical analysis allows a more precise examination of data, it was not possible on all questionnaire items because of the small sample and inadequate cell size. In these instances, a qualitative discussion of results was used.

Research Question 1: What is the extent of the ethnically-diverse, intellectually-gifted adolescent girl's relationship with her parents?

The questionnaire item relative to the research question asked the girls which parent they felt they were 
most like. The number of girls who believed they were equally similar to or like both parents was 20 girls 139 percent), while seventeen girls ( 33 percent) believed they were more like the mother. Out of fourteen girls whose parents were divorced or separated, six girls (40 percent) believed they were more like the mother; three girls 120 percent) believed they were more similar to the father and five girls (22 percent) felt they were equally like both parents. Fewer Pan/Asian girls believed they were more similar to the mother (12 percent) as compared to the Hispanic girls (40 percent) and black girls (50 percent).

Table 1 shows that 40 percent of the girls believed they were more similar to both parents, while 33 percent felt more similar to the mother. Previous research (McBroom, 1981) has indicated that young women who identify with fathers tend to select less traditional careers. As can be seen in Table 1, Questionnaire Item 46 , of the thirty-two girls who selected non-traditional careers, the majority felt more similar to the mother or to both parents.

Question three asked the girls whether they felt their mother understood them and what they wanted out of life. "Fairly well" or "very well" was the perception of thirtynine (77 percent) girls, and while there was little difference across the three ethnic groups, 80 percent of the Hispanic girls believed the mother understood them. 
TABLE 1

Questionnaire item 2: Which of your parents do you feel you are most like?

Number of Responses

\begin{tabular}{lccccccc}
\cline { 2 - 7 } GROUP & $\mathrm{n}$ & $\mathrm{F}$ & $\mathrm{M}$ & $\mathrm{B}$ & $\mathrm{N}$ & $\mathrm{nr}$ & $\underline{x}^{2}$ \\
\hline Black & 14 & 3 & 7 & 3 & 1 & & \\
Hispanic & 20 & 1 & 8 & 8 & 3 & & \\
Pan/Asian & 17 & $\underline{3}$ & $\underline{2}$ & $\underline{9}$ & $\underline{3}$ & & \\
Total & 51 & 7 & 17 & 20 & 7 & & 8.31 \\
\hline
\end{tabular}

Questionnaire item 46: What career/occupation would you like to pursue? (Responses of girls who selected nontraditional careers.)

\begin{tabular}{lrrrrr}
\hline Black & 8 & 1 & 5 & 1 & 1 \\
Hispanic & 11 & 1 & 5 & 3 & 2 \\
Pan/Asian & 13 & $\underline{2}$ & $\underline{3}$ & $\underline{6}$ & $\underline{2}$ \\
Total & 32 & 4 & 13 & 10 & 5 \\
\hline
\end{tabular}

Note:

$$
\begin{aligned}
& \mathbf{F}=\text { Father } \\
& \mathbf{M}=\text { Mother } \\
& \mathbf{B}=\text { Both } \\
& \mathbf{N}=\text { Neither }
\end{aligned}
$$

* $\mathrm{p}<.05$

(When asterisk appears next to chi-square statistic, results are significant at the .05 level.) 
TABLE 2

Questionnaire item 3: How well do you feel your natural mother understands you and what you want out of life?

\begin{tabular}{|c|c|c|c|c|c|c|c|}
\hline \multirow[b]{2}{*}{ GROUP } & \multicolumn{7}{|c|}{ Number of Responses } \\
\hline & $\mathrm{n}$ & A & B & C & D & $\mathrm{nr}$ & $\underline{x}^{2}$ \\
\hline Black & 14 & 7 & 4 & 3 & 0 & & \\
\hline Hispanic & 20 & 7 & 9 & 3 & 1 & & \\
\hline Pan/Asian & $\underline{17}$ & $\underline{4}$ & $\underline{8}$ & $\underline{5}$ & $\underline{0}$ & & \\
\hline Total & 51 & 18 & 21 & 11 & 1 & & 4.7 \\
\hline
\end{tabular}

TABLE 3

Questionnaire item 4: How well do you feel your natural father understands you and what you want out of life?

\begin{tabular}{|c|c|c|c|c|c|c|c|}
\hline \multirow[b]{2}{*}{ GROUP } & \multicolumn{7}{|c|}{ Number of Responses } \\
\hline & $\mathbf{n}$ & $\mathbf{A}$ & B & c & D & $\mathrm{nr}$ & $x^{2}$ \\
\hline Black & 14 & 4 & 5 & 3 & 1 & 1 & \\
\hline Hispanic & 20 & 3 & 10 & 5 & 2 & & \\
\hline Pan/Asian & 17 & $\underline{3}$ & 10 & $\underline{3}$ & 1 & $\underline{-}$ & \\
\hline Total & 51 & 10 & 25 & 11 & 4 & 1 & 2.1 \\
\hline
\end{tabular}

Note:
$A=$ Very well
$B=$ Fairly well
C $=$ Not too well
$\mathrm{D}=$ Not at all

$\star \quad \mathrm{p}<.05$ 
Question four asked whether the father understood them and what they wanted out of life. As can be seen in table 3, the number of girls who believed the father understood them "very well" or "fairly well" was thirty-five 170 percent). Among the families in which mother and father did not live together, six girls thought their father understood them "very well" or "fairly well", while eight perceived their fathers as not under-standing them at all.

Results of question five showed that a "close" or "extremely close" relationship between the daughter and the mother was perceived by 38 girls (74 percent) in two parent families. Table 4 reflects that a "close" or "extremely close" relationship to the father was perceived by 26 girls (53 percent), while 23 (478) said they were not very close to the father. Among the fourteen single parent families, six girls felt "fairly close" to the father and eight indicated "not very close" to the father.

Question eight asked the girls how much the parents encouraged them "to do things for yourself as you were growing up." Table 5 shows nearly all of the girls (98 percent) believed their mother had given them "a lot of encouragement" or "some encouragement," while 82 percent believed their father had given them "a lot of encouragement" or "some encouragement." The fourteen girls who lived with only one parent believed their father had given them "a lot" or "some" encouragement, while three girls believed they had received "very little" or "no" encouragement from the father. 
TABLE 4

Questionnaire item 5: How close do you feel to your mother and father?

Number of Responses

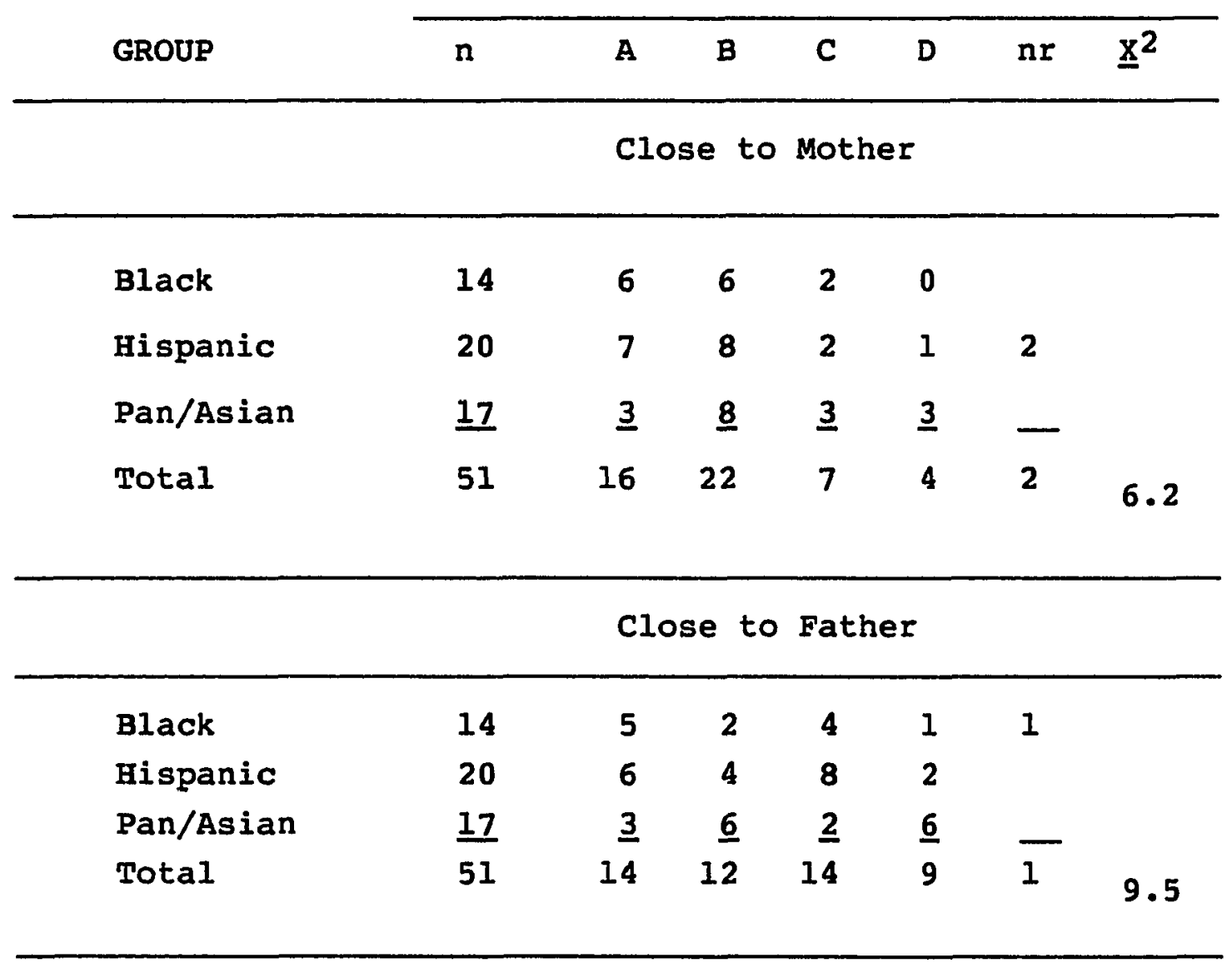

Note:
$A=$ Extremely close
$B=$ Quite close
C = Fairly close
$D=$ Not very close

* $\mathrm{p}<.05$ 
TABLE 5

Questionnaire item 8: As you were growing up, how much did your parents encourage you to do things for yourself?

\begin{tabular}{|c|c|c|c|c|c|c|c|}
\hline \multirow[b]{2}{*}{ GROUP } & \multicolumn{7}{|c|}{ Number of Responses } \\
\hline & $\mathbf{n}$ & A & B & $\mathrm{C}$ & $\mathrm{D}$ & $\mathrm{nr}$ & $\underline{x}^{2}$ \\
\hline \multicolumn{8}{|c|}{ Mother Encourage } \\
\hline Black & 14 & 11 & 2 & 0 & 0 & 1 & \\
\hline Hispanic & 20 & 14 & 5 & 1 & 0 & & \\
\hline Pan/Asian & $\underline{17}$ & 10 & $\underline{Z}$ & $\underline{0}$ & $\underline{0}$ & - & \\
\hline Total & 51 & 35 & 14 & 1 & 0 & 1 & 4.1 \\
\hline \multicolumn{8}{|c|}{ Father Encourage } \\
\hline Black & 14 & 7 & 4 & 2 & 0 & 1 & \\
\hline Hispanic & 20 & 7 & 9 & 1 & 3 & & \\
\hline Pan/Asian & 17 & $\underline{9}$ & $\underline{5}$ & $\underline{2}$ & $\underline{1}$ & - & \\
\hline Total & 51 & 23 & 18 & $\mathbf{5}$ & 4 & 1 & 5.0 \\
\hline
\end{tabular}

Note:
$A=A$ lot of encouragement
B = Some encouragement
$C=$ Very little encouragement
$D=$ No encouragement

$\star \mathrm{p} \leftarrow .05$ 
In question nine, the girls were asked "how much freedom the parents gave them to make their own decisions while the girls were growing up". Table 6 shows again that the majority of girls $(94$ percent and 80 percent, respectively) believed both their mother and father had given them "a lot of freedom" or "some freedom" in making their own decisions. In looking at questions eight and nine, the girls perceive themselves as being independent and free to make their own decisions.

The girls who do not live with their natural father perceive their relationships generally the same as the girls with two natural parents at home. A number of reasons may account for this: a) the father lives nearby and the girl has frequent interaction with him: "He doesn't live with us but I see him every day"; bi the girls were not asked how long their parents had not lived together; c) if the parents had been divorced a long time, the daughter may not have known the father at all and, thus, has no relationship with him.

Questions 29-34 were designed in an attempt to discover whether, in fact, the girls talk to parents about personal values, television, world unrest, news, science or books read. A chi-square analysis was completed for items 29-34. However, due to the small sample and inadequate cell size, these items had a number of empty cells. There were no significant differences between the groups. When the cells were collapsed into "Rarely" and "Frequently", significant 
TABLE 6

Questionnaire item 9: As you were growing up, how much freedom did your parents give you in making your own decisions?

\begin{tabular}{|c|c|c|c|c|c|c|c|}
\hline \multirow[b]{2}{*}{ GROUP } & \multicolumn{7}{|c|}{ Number of Responses } \\
\hline & $\mathbf{n}$ & $\mathbf{A}$ & $\mathbf{B}$ & c & $D$ & nr & $\underline{x}^{2}$ \\
\hline \multicolumn{8}{|c|}{ Mother } \\
\hline Black & 14 & 5 & 7 & 2 & $\mathbf{0}$ & & \\
\hline Hispanic & 20 & 4 & 15 & 1 & $\mathbf{0}$ & & \\
\hline Pan/Asian & 17 & $\underline{2}$ & 15 & $\underline{0}$ & $\underline{0}$ & & \\
\hline Total & 51 & 11 & 37 & 3 & 0 & & 6.4 \\
\hline \multicolumn{8}{|c|}{ Father } \\
\hline Black & 14 & 4 & 7 & 1 & 1 & 1 & \\
\hline Hispanic & 20 & 4 & 12 & 3 & 1 & & \\
\hline Pan/Asian & $\underline{17}$ & $\underline{4}$ & $\underline{10}$ & $\underline{2}$ & $\underline{1}$ & - & \\
\hline Total & 51 & 11 & 29 & 6 & 3 & 1 & 0.9 \\
\hline
\end{tabular}

Note:
$A=A$ lot of freedom
$\mathrm{B}=$ Some freedom
$C=$ Very little freedom
$D=$ No freedom

* $\mathrm{p}<.05$ 
results appeared. As can be seen in Table 7, there were significant differences on items $29,30,33$ and 34 . It appears that the black girls tend to talk more frequently with their parents about these items than do the other two groups of girls. However, the significance of the chisquare values on these items is that the three groups of girls rarely talk to parents about TV, sports, movies, science, books or even personal values.

TABLE 7

Questionnaire items 29-34: Report of intellectually-gifted, ethnically-diverse, adolescent girls' discussions with parents.

\begin{tabular}{|c|c|c|c|c|c|c|c|c|}
\hline & & \multicolumn{2}{|c|}{$\begin{array}{l}\text { Black } \\
(N=14)\end{array}$} & \multicolumn{2}{|c|}{$\begin{array}{l}\text { Hispanic } \\
(\mathrm{N}=20)\end{array}$} & \multicolumn{2}{|c|}{$\begin{array}{l}\text { Asian } \\
(N=17)\end{array}$} & \multirow[t]{2}{*}{$\underline{x}^{2}$} \\
\hline \multicolumn{2}{|c|}{ Questionnaire Item } & $\mathbf{R}$ & $\mathbf{F}$ & $\mathbf{R}$ & $\mathbf{F}$ & $\mathbf{R}$ & $\mathbf{F}$ & \\
\hline 29 & TV, Sports, Movies & 9 & 5 & 19 & 1 & 14 & 3 & $5 \cdot 34 *$ \\
\hline 30 & Personal Values & 7 & 7 & 16 & 4 & 16 & 1 & $8.53 *$ \\
\hline 31 & World Unrest & 10 & 4 & 16 & 4 & 15 & 2 & 1.37 \\
\hline 32 & News Events & 8 & 6 & 16 & 4 & 13 & 4 & 2.36 \\
\hline 33 & Science & 11 & 3 & 20 & 0 & 17 & 0 & $8.42 *$ \\
\hline 34 & Books & 9 & 5 & 19 & 1 & 14 & 3 & $5.34 *$ \\
\hline
\end{tabular}

Note:

$$
\begin{aligned}
& \mathbf{R}=\text { Rarely } \\
& \mathbf{F}=\text { Frequently } \\
& \star \mathrm{p}<.05
\end{aligned}
$$


A review of the parent-daughter relationship indicates that overall: a) more girls perceived they were similar to both parents, though nearly half the girls felt they were more similar to the mother; b) the majority of girls believed both parents understood them and what they wanted out of life; c) more girls felt closer to the mother than to the father; d) more girls perceived their mother had given them a lot of encouragement to do things for themselves than did their fathers; e) the majority of girls believed their mother had given them freedom to make their own decision. Few topics other than values are discussed with parents, except for parents of black girls who frequently talk to their daughters about values, behavior, respect for others and/or religion in addition to values.

Research question 2: What is the extent of the ethnically-diverse, intellectually-gifted adolescent girl's interaction with the parents relative to discussion of career plans?

Three questionnaire items were designed to answer this question. Item six asked the girls how much they and their parents agree about their future plans. As can be seen from Table 8, forty-two girls (82 percent) believed they and their mother agreed "very much" or shared "some" agreement about their future plans. Out of twenty Hispanic girls, six reported disagreement with their mothers regarding career plans. 
TABLE 8

Questionnaire item 6: How much do you and your parents agree about your plans for the future?

\begin{tabular}{|c|c|c|c|c|c|c|c|}
\hline \multirow[b]{2}{*}{ GROUP } & \multicolumn{7}{|c|}{ Number of Responses } \\
\hline & $\mathrm{n}$ & $\mathbf{A}$ & $\mathbf{B}$ & C & $\mathrm{D}$ & nr & $\underline{x}^{2}$ \\
\hline \multicolumn{8}{|c|}{ Mother } \\
\hline Black & 14 & 11 & 1 & 2 & 0 & & \\
\hline Hispanic & 20 & 12 & 5 & 1 & 1 & 1 & \\
\hline Pan/Asian & $\underline{17}$ & 7 & $\underline{0}$ & $\underline{9}$ & $\underline{I}$ & - & \\
\hline Total & 51 & 30 & 6 & 12 & 2 & 1 & $17.4 *$ \\
\hline \multicolumn{8}{|c|}{ Father } \\
\hline Black & 14 & 8 & 1 & 3 & 0 & 2 & \\
\hline Hispanic & 20 & 8 & 8 & 1 & 2 & 1 & \\
\hline Pan/Asian & $\underline{17}$ & $\underline{7}$ & $\underline{1}$ & $\underline{7}$ & $\underline{I}$ & $\underline{I}$ & \\
\hline Total & 51 & 23 & 10 & 11 & 3 & 4 & $14 \cdot 3^{*}$ \\
\hline
\end{tabular}

Note:
$A=$ Very much in agreement
$B=$ Some disagreement
$\mathrm{C}=$ Some agreement
$D=$ Major disagreement

* $\mathbf{p}<.05$ 
However, the interview revealed very different types of "agreement." The black girls' mothers stress the use of intellect. However, a double message appears in that the mothers also say they want the daughter to "have something to fall back on." A double message appears among the Filipino girls as well. The mothers encourage the daughters to achieve and develop financial security. At the same time, the mothers are telling the girls that when they get married and have children they need to stay home and take care of them. In addition, the girls are expected to Iive at home after marriage -- or at least nearby and look after the aging parents. The Hispanic girls say their mothers "agree" with future plans, but there is no direction given. The mother is more affiliative -- "whatever you want to do is all right."

Interviewer: If your mother could choose a lifestyle for you what do you think it would be? What would she choose for you to do?

P/A student I: I don't know what she wants for me. She says I better learn to cook in case I become a housewife. And then she says, "When you grow up, go to work so you can support your whole family and us." She says I've got to find a job I fit perfectly into, not a job that makes you work overtime. She doesn't want me to be a normal housewife. 
B1. Student 1: She never says anything to influence me, but she says she knows I'm smart. My grades right now aren't up to her standards. She says if $I$ were $a$ dumb $k i d$ and $I$ got those grades and she knows I'd gone as far as I could go, then she wouldn't be mad. But she knows I'm not dumb. All my life she's been telling me I'm not stupid so I should work up to my full potential.

B1. Student 2: That's what my father says, too. He tells me, "Don't go to school and just sit there" 'cause that's what I want to do.

Interviewer: You want to go to school and just sit there?

Bl. Student 2: I don't really like school. They tell me it's only a few more years and you'll be glad you stayed with it.

Interviewer: You don't like school but you've set up a long time to go to school if you're going to be an engineer.

Bl. Student 2: Well, I'm not stupid. I don't like it but I know I'm going to have to put up with it.

B1. Student 3: She said I was smart and I should be using my brains.

Interviewer: Why is that?

Bl. Student 3: Because when they're not there, I 
can make my own decisions.

BI. Student 1: So you can get somewhere in life. Our parents want us to have a better life. There are a lot of parents who never got what they really should have gotten and they're trying to get their kids to get exactly what they didn't get, and they want their kids to be real smart and have things that they didn't have when they were little.

My dad says, "Oh, I didn't get this when I was little so I want to give it to you," and you're all well, what if I don't want it?

Interviewer: I guess parents want their children to have a better life.

B1. Student 1: But we will! Even if we don't go to school. I have a feeling we will because life is better, everything is progressing. Everything in this world is progressing. Everything is advancing. So whatever happened thirty years ago isn't going to happen anymore. Some things are going to happen but not the same things. What happened in the depression is a lot of the reason why parents didn't get what they wanted.

B1. Student 2: She wants me to become somebody and then get married and, if I get a divorce I can support myself and don't need welfare. She says she doesn't care if I get married on the day I get 
my diploma. Just in case $I$ get into a bad marriage, I can get out and support myself.

While all three groups of girls believed parents to be generally supportive of whatever they chose to do, the Hispanic parents were probably the least directive.

H Student 1: Well, I'm supposed to go to school whenever I want to. Like she's a secretary and I help her sometimes with typing. She says if I want to go for my secretarial courses, I'll do good.

E Student 2: She just says whatever I have to do to be a model.

One girl's mother, for example, wanted the daughter to be a teacher because she had planned to be a teacher and dropped out when she got married. She also wanted the daughter to be a teacher and a part-time nurse -- reasoning that the mother felt her daughter would not make enough money being a teacher only.

The responses of the girls on the second part of question six show that thirty-four girls (66 percent) believe they and their fathers were "very much in agreement" or shared "some agreement" about the girls' future plans. A small number (thirteen girls or 25 percent) of the girls believed they and their fathers were not in agreement. However, only the three interviewed Pan/Asian girls and one Hispanic girl commented about the kinds of disagreement they were experiencing. 
Another motive for the father's high aspiration for his daughter is the financial security he perceived necessary for taking care of the aging parents. "They want us to earn a lot of money so we can take care of them," responded one girl.

During he interview, the Asian girls responded that the father encouraged them to "be a doctor" or "get into computers." In both instances, financial reward was cited as the reason. This suggests two culturally-related attitudes, one of which was reviewed in the literature. That is, the Asian parent looks at the child's achievements as enhancing the family's public image. secondly, at least among the Filipino family, according to santos (1983), the children are expected to assume responsibility for aging parents.

Interviewer: If you think your father could choose a lifestyle for you what do you think it would be? What would he choose for you to do? P/A Student 2: Probably make me a brain surgeon. (Laughter) I can't imagine cutting into someone's head.

Interviewer: Really? A brain surgeon?

P/A Student 2: Well, no but they keep saying, "Doctor, doctor."

Interviewer: Why is that?

P/A student 2: I don't know. It's like the Filipino family dream. They want their kids to be 
doctors to have a better 1ife. But, if you aren't happy with what you got, what's the difference? If you're a doctor and you don't like it, you might mess someone up.

H Student 1: My dad wants me to be something other than a secretary. He thinks that a secretary won't get me far. He wants me to travel and see other places.

P/A Student 3: My dad wants me to learn everything; he wants to put me in special things and he tells me to work hard and go to college and support myself when I'm older.

This girl's mother was a housewife. The father did not want his wife to work because, as the daughter said, "...she only had a fifth grade education and "even though she worked in the Philippines, he says she wouldn't know how to work here."

P/A Student 1: My dad wants me to be either a Navy nurse or doctor.

P/A Student 3: My dad wants me to go to a military academy but he really wants me to be a mechanical engineer. He doesn't want me to be a doctor. He wants me to learn about computers because he says that's the future and that I should know how.

P/A Student 3: If something breaks down, they say, "Why can't you fix this?" Mechanics earn a lot of money. My dad says he'll buy me all those 
little things like he did for my brother so I can learn how to fix things. But generally, they want any career I want to be. They'll accept anything I want to do.

P/A Student 1: When my parents asked me what I wanted to be I told them a schoolteacher. They said, "No, you shouldn't be that. It's not good for you. You're going to be an old maid. Be a doctor in the Navy. You'll get more money that way and then you can support us." And then my dad says, "You've got to get a scholarship and we'll pay half your subaru." And I tell them I hate the inside of bodies and my dad says, "That's not good enough. Be a nurse then."

Questionnaire item 10 asked the girl how much her parents had encouraged her to do well in school. As can be seen from Table 9, all of the girls (mothers, 98 percent; fathers, 92 percent) believed their parents had encouraged them to do well in school.

Questionnaire item 28 asked the girls how often they talked to parents about career plans. A chi-square analysis was completed for item 28 but, again, because of the small sample and inadequate cell size, there were empty cells. When these cells were collapsed, significant differences between the groups appeared. 
TABLE 9

Questionnaire item 10: How much have your parents encouraged you to do well in school?

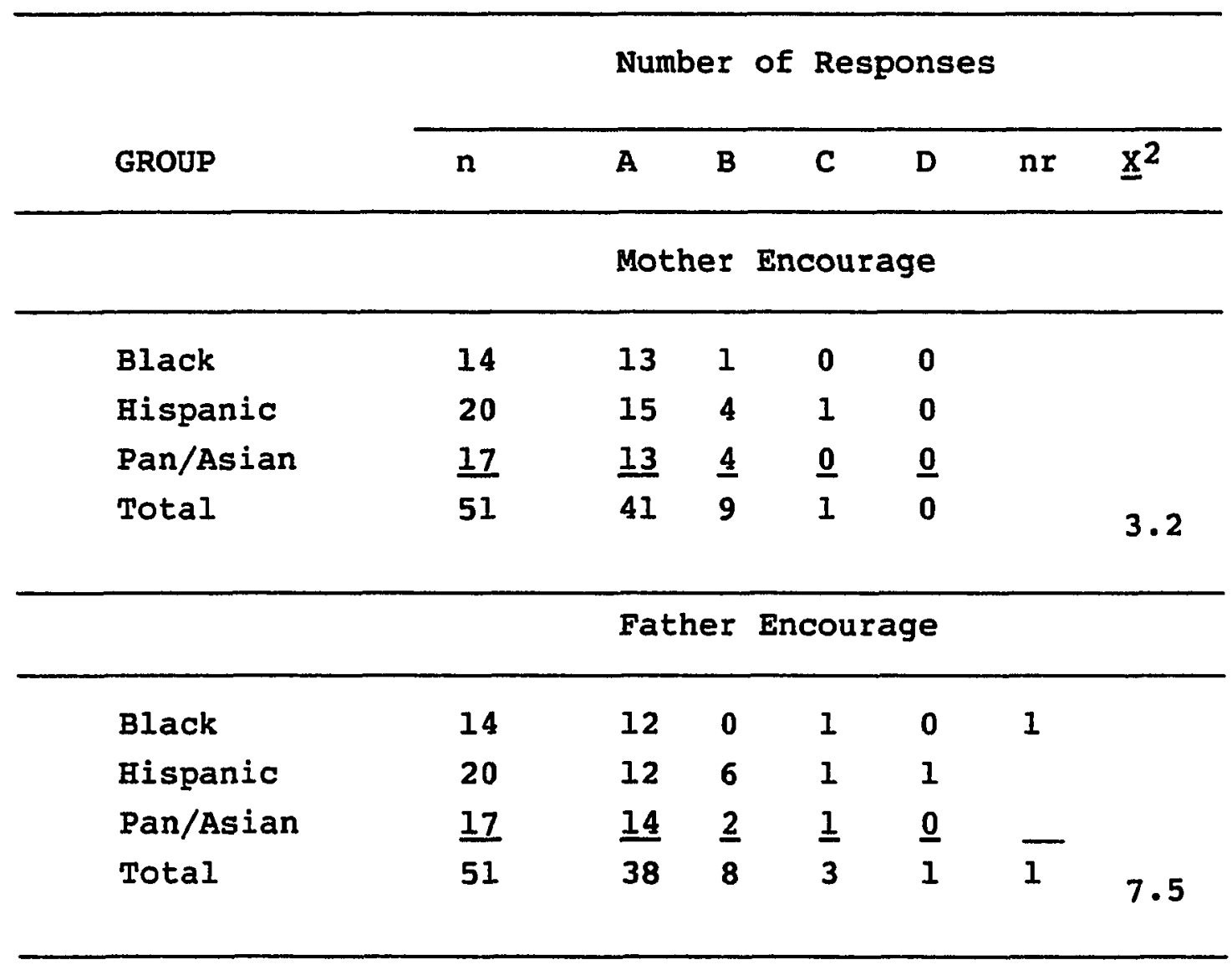

Note:
$A=A$ lot of encouragement
$B=$ Some encouragement
C $=$ Very little encouragement
$D=$ No encouragement

* $\underline{p}<.05$ 
Table 10 reveals that Pan/Asian girls reported talking less to parents about educational plans than did the black or Hispanic girls. However, the three Pan/Asian girls interviewed revealed that they at least had talked to parents. Thus, it may be that no conclusions can be drawn since the three groups of girls may have interpreted the questionnaire item differently. The kinds of discussion may be the explanation for the discrepancy. The interview with the three Pan/Asian girls revealed that parents were transmitting their opinions rather than discussing particular educational plans.

The interview discussion with the girls appeared to be in the context of "taking care of us" or "making a lot of money" rather than specific educational plans.

TABLE 10

Questionnaire item 28: Report of intellectually-gifted, ethnically-diverse, adolescent girls' discussions with parents and educational and career plans.

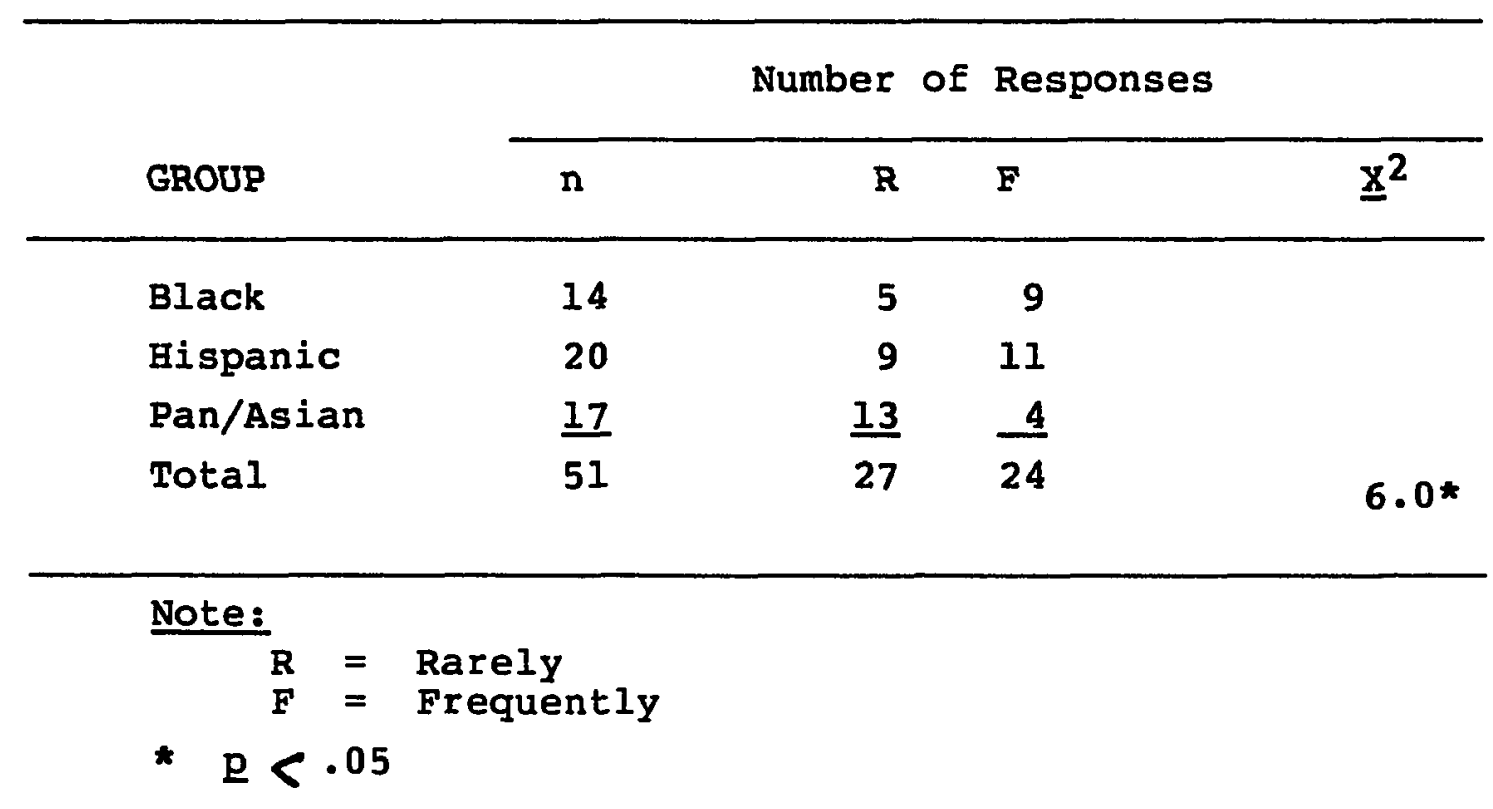


Research Question 3: What influences as related to the family's sociological environment affect the career choice/future life planning of the ethnically-diverse, intellectually-gifted adolescent girl?

The first results in table 11 show that out of the 14 black girls, eleven ( 78 percent) lived with both parents. Among the twenty Hispanic girls, twelve (60 percent) lived with both parents. In the Pan/Asian sample, twelve $(71$ percent) out of the seventeen girls lived with both parents. Fourteen girls ( 27 percent) lived in homes in which the parents were divorced or separated. Among those who did not live with both parents, one girl's father was deceased and one girl had never lived with her father.

TABLE 11

Questionnaire item 1: Are your natural parents living together, divorced or separated, one or both parents deceased?

\begin{tabular}{lllllll} 
& \multicolumn{5}{c}{ Number of Responses } \\
\cline { 2 - 6 } GROUP & $\mathrm{n}$ & A & B & C & $\underline{x}^{2}$ \\
\hline Black & 14 & 11 & 3 & 0 & \\
Hispanic & 20 & 12 & 8 & 0 & \\
Pan/Asian & 17 & 12 & $\frac{3}{14}$ & $\frac{2}{2}$ & \\
Total & 51 & 35 & 14 & 2 & 6.3 \\
\hline
\end{tabular}

Note:
$A=$ Parents living together
$B=$ Divorced or separated
$C=$ One or both deceased

* $\mathrm{p}<.05$ 
Question 11 asked the girl about the education level of each parent. Again, because of the small sample and inadequate cell size, there were empty cells. By collapsing the empty cells, significant differences were revealed. Table 12 shows that 30 percent of the mothers had less than a high school education and 55 percent of these are Hispanic mothers. Two of the Hispanic interviewees' mothers, according to the girls, had not gone farther in school than the fifth grade. One Pan/Asian girl reported that her mother had not advanced past the fifth grade.

The table shows that the Hispanic fathers were also the least educated among the three groups of fathers. It was noted in the literature review that parents who have little formal education may not recognize the importance of education beyond high school nor know how to assist their children in pursujng higher education. The lack of education by parents then may have rather particular implications for the daughter who wants to pursue a career requiring a college degree. It appears that overall, more Pan/Asian mothers (14 out of 15) have achieved a higher level of education proportionately to their number in the sample than have the black or Hispanic mothers. 
TABLE 12

Questionnaire item 11: How far did your parents go in school?

\begin{tabular}{|c|c|c|c|c|c|c|}
\hline \multirow[b]{2}{*}{ GROUP } & \multicolumn{6}{|c|}{ Number of Responses } \\
\hline & $\mathrm{n}$ & $\mathbf{A}$ & B & C & $\mathrm{nr}$ & $\underline{x}^{2}$ \\
\hline \multicolumn{7}{|c|}{ Mother Schooling } \\
\hline Black & 14 & 4 & 4 & 6 & & \\
\hline Hispanic & 20 & 16 & 2 & 2 & & \\
\hline Pan/Asian & 17 & 1 & $\underline{9}$ & $\underline{5}$ & $\underline{2}$ & \\
\hline \multirow[t]{2}{*}{ Total } & 51 & 21 & 15 & 13 & 2 & 22.4 \\
\hline & \multicolumn{6}{|c|}{ Father Schooling } \\
\hline Black & 14 & 1 & 7 & 5 & 1 & \\
\hline Hispanic & 20 & 15 & 2 & 3 & & \\
\hline Pan/Asian & 17 & 1 & 11 & $\underline{3}$ & $\underline{2}$ & \\
\hline Total & 51 & 17 & 20 & 11 & 3 & 26.0 \\
\hline
\end{tabular}

Note:
$A=$ Less than high school
$B=$ Some college
$\mathrm{C}=\mathrm{BA}+$

* $\mathrm{p}<.05$ 
In order to analyze parent occupations, the girls responses to parent occupations were coded according to categories as found in Occupational Projections and Training (1982). These occupational categories included professional (law, medicine, education, engineering, computer technology); laborers, managers, clerical, service, sales and transportation. The additional category of homemaker was added for mother's occupation. As Table 13 shows, nine of the Hispanic girls' mothers were homemakers as compared to two of the Pan/Asian mothers and two black mothers. Educationally, the Hispanic mothers also had the least amount of education. Those Hispanic mothers who worked were employed as seamstresses, teacher aides, factory workers or in secretarial positions. The one professional Hispanic woman was a teacher.

The Pan/Asian mothers were employed in nursing, as nurses' aides, in food service jobs and technological occupations. More black mothers were employed in professional occupations which included teaching, medicine, and education administration than were the Hispanic or Pan/Asian mothers.

Three of the black fathers were in a civilian professional career and three were Marine Corps career officers. The larger percentage (38 percent) of the fathers were employed in service-related fields. These included non-professional occupations -- truck driver, Navy enlisted, custodian, gardener and farmer (see Table 13). 
TABLE 13

Questionnaire item 14: What is your natural mother's occupation?

Number of Responses

GROUP

$\begin{array}{lllllllllllll}n & A & B & C & D & E & F & G & H & I & n r & \underline{x}^{2}\end{array}$

\begin{tabular}{lrlllllllll}
\hline Black & 14 & 3 & 1 & 0 & 0 & 2 & 2 & 1 & 2 & 2 \\
Hispanic & 20 & 1 & 0 & 1 & 0 & 4 & 2 & 2 & 1 & 9 \\
Pan/Asian & $\underline{17}$ & $\underline{5}$ & $\underline{0}$ & $\underline{0}$ & $\underline{1}$ & $\underline{5}$ & $\underline{2}$ & $\underline{1}$ & $\underline{1}$ & $\underline{2}$ \\
Total & 51 & 9 & 1 & 1 & 1 & 11 & 6 & 4 & 4 & 13
\end{tabular}

19.2

Questionnaire item 15: What is your natural father's occupation?

\begin{tabular}{lllllllllllll}
\hline Black & 14 & 2 & 3 & 0 & 0 & 6 & 0 & 0 & 2 & 0 & 1 \\
Hispanic & 20 & 1 & 1 & 3 & 4 & 2 & 1 & 1 & 6 & 1 & \\
Pan/Asian & $\underline{17}$ & $\underline{2}$ & $\underline{1}$ & $\underline{1}$ & $\underline{1}$ & $\underline{8}$ & $\underline{1}$ & $\underline{0}$ & $\underline{3}$ & $\underline{0}$ & - \\
Total & 51 & 5 & 5 & 4 & 5 & 16 & 2 & 1 & 11 & 1 & 1 & \\
& & & & & & & & & & & & 2.20 \\
\hline
\end{tabular}

Note:

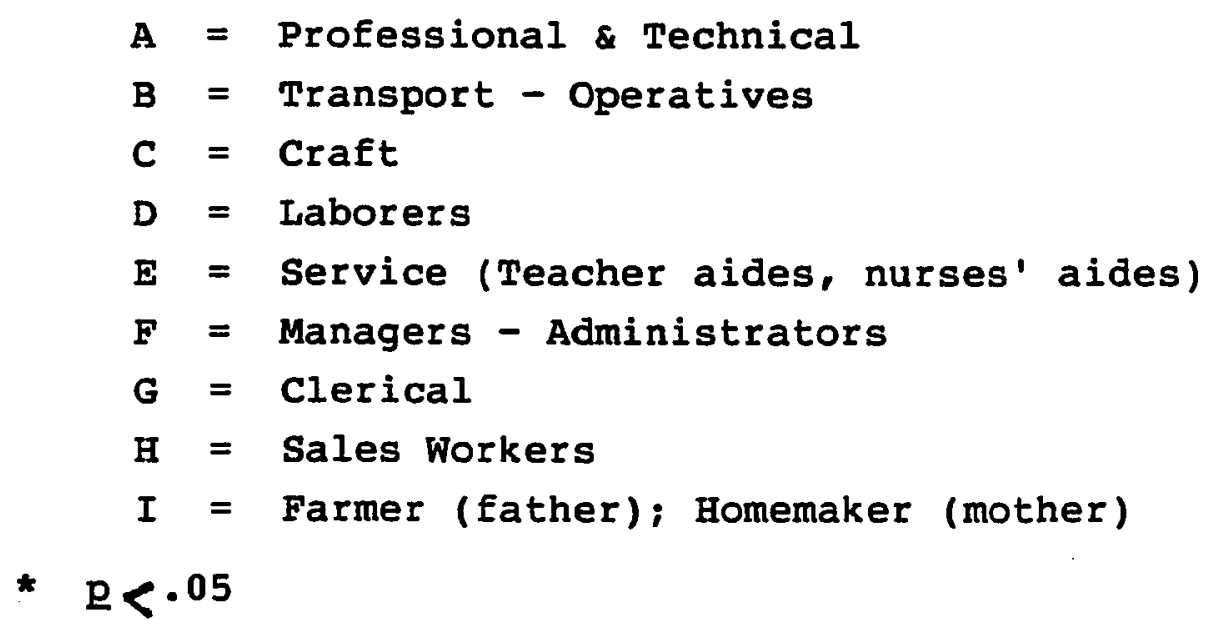


A chi-square analysis was completed for questionnaire items 14 and 15, but again there were empty cells, While collapsing these cells did not reveal significant differences between the groups, the results did show the general occupational areas in which most of the parents were employed. These results can be seen in Table 14 .

TABLE 14

\begin{tabular}{|c|c|c|c|c|c|c|}
\hline \multirow[b]{2}{*}{ GROUP } & \multicolumn{6}{|c|}{ Number of Responses } \\
\hline & $\mathbf{n}$ & $\begin{array}{l}\text { Profes- } \\
\text { sional }\end{array}$ & Service & $\begin{array}{l}\text { Tech- } \\
\text { nical }\end{array}$ & nr & $\underline{x}^{2}$ \\
\hline & \multicolumn{6}{|c|}{ Mother's Occupation } \\
\hline Black & 14 & 3 & 8 & 2 & 1 & \\
\hline Hispanic & 20 & 1 & 16 & 3 & & \\
\hline Pan/Asian & 17 & $\underline{5}$ & 10 & $\underline{2}$ & 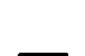 & \\
\hline \multirow[t]{3}{*}{ Total } & 51 & 9 & 34 & 7 & 1 & \\
\hline & & & & & & 4.1 \\
\hline & \multicolumn{6}{|c|}{ Father's Occupation } \\
\hline Black & 14 & 2 & 11 & 0 & 1 & \\
\hline Hispanic & 20 & 1 & 14 & 4 & 1 & \\
\hline Pan/Asian & 17 & $\underline{2}$ & 13 & 2 & $\underline{-}$ & \\
\hline \multirow[t]{2}{*}{ Total } & 51 & 5 & 38 & 6 & 2 & \\
\hline & & & & & & 3.7 \\
\hline
\end{tabular}


Question 16 asked about the number of children in the family and the birth order of each. The data, as recorded in table 15, show that 80 percent of the Hispanic families had three or more children, 75 percent of the Pan/Asian families had three or more children, and 46 percent of the black families had three or more children.

of the sample subjects twenty-three (45 percent) were the youngest, and thirteen (26 percent) were the oldest. The significance of birth order and number of children in the family may clearly affect educational aspirations, as indicated in the literature review, particularly in a low socioeconomic family. Parent income for lower status job holders may have peaked or begun to drop off by the time even the first child is ready for college.

Question 17 asked the girls about the level of parent income. Table 16 shows that while 50 percent of the black girls knew what the family income was, only 20 percent of the Hispanic girls and 18 percent of the Pan/Asian girls knew. By virtue of level of education as well as kind of occupation in which the parent is employed, it appears the Hispanic girls are in a lower socioeconomic level than the other two groups. Fewer Hispanic fathers had a high school diploma and fewer were employed in managenent or supervisorial positions. 
TABLE 15

Questionnaire item 16: How many children are in your family, and what are their ages?

\begin{tabular}{lllllllll}
\hline & \multicolumn{7}{c}{ Number of Responses } \\
\cline { 2 - 7 } GROUP & $\mathrm{n}$ & $1-2$ & $3-4$ & $5-7$ & $\mathrm{nr}$ & $\underline{x}^{2}$ \\
\hline Black & 14 & 7 & 4 & 2 & 1 & \\
Hispanic & 20 & 4 & 9 & 7 & & \\
Pan/Asian & $\frac{17}{11}$ & $\frac{4}{15}$ & $\underline{12}$ & $\underline{0}$ & $\underline{1}$ & \\
Total & 51 & & 25 & 9 & 2 & 17.5 \\
& & & & & & &
\end{tabular}

Birth Order

\begin{tabular}{lrrrrr}
\hline & & Oldest & Middle & Youngest & $\underline{\underline{x}}^{2}$ \\
\hline Black & 14 & 5 & 5 & 4 & \\
Hispanic & 20 & 5 & 6 & 9 & \\
Pan/Asian & $\frac{17}{51}$ & $\frac{3}{13}$ & $\frac{4}{15}$ & $\frac{10}{23}$ & \\
Total & 5.93 \\
\hline
\end{tabular}

* $\mathrm{p}<.05$

A chi-square analysis was completed for Item 17, but again empty cells appeared. In an attempt to find a significant difference between the groups, the empty cells were collapsed into "know" and "don't know" level of income. As can be seen in Table 16, few girls knew the income level. The girls of professional parents did know, however, and 
listed their parent incomes as between $\$ 20,000$ and $\$ 40,000$. By looking at the kinds of parent occupations cited by the girls and comparing them to salaries listed for commensurate positions in the San Diego papers, one could surmise that the majority of parents were in the $\$ 10,000$ to $\$ 19,000$ income level.

TABLE 16

Questionnaire item 17: About what total income do your parents earn every year?

Number of Responses

\begin{tabular}{llccc}
\cline { 2 - 5 } GROUP & $\mathrm{n}$ & Know & Don't know & $\underline{x}^{2}$ \\
\hline Black & 14 & 7 & 7 & \\
Hispanic & 20 & 4 & 16 & \\
Pan/Asian & 17 & $\underline{3}$ & 37 & $4.95 *$ \\
Total & 51 & 14 & & \\
& & & &
\end{tabular}

Schulenberg et. al. (1984) and Henderson (1981) were two researchers who documented the relationship of SES to occupational aspirations and intellectual achievement. According to the researchers, socioeconomic status incorporates paternal and maternal educational attainment, family income and occupational status of the parents. Thus, 
values, parental encouragement and opportunities have also been found to influence a youngster's potential occupational status.

Money was not mentioned in the interview as a reason the girl might not pursue a career but it was mentioned by seven girls in questionnaire item 48 (five Hispanics and two Pan/Asians). Money may be available for girls in small families (0-4 siblings) or families in which siblings are considerably older than the respondents (5+ years). For families in which the births of children are closer together and/or the SES is lower, the financial support simply may not be available and, thus, future aspirations would clearly be affected.

Sibling rivalry was mentioned in two of the families -both Hispanic.

Interviewer: How many people in your family?

Hispanic Student 2: Four kids

Interviewer: Are you the oldest?

Hispanic Student 2: No, there is one who is 17, then 15, then me and a younger sister.

Interviewer: What grade is your sister in?

Hispanic student 2: Third, but I always get better grades. My brothers get Ds and Fs.

Interviewer: Why do you think that is?

Hispanic Student 2: Like my older brother, they say he's smart but he wants to act dumb. So they send him to a psychiatrist for that. They say 
he's jealous of me and he gets bad grades and wants to act dumb.

Hispanic Student 1: My brother is jealous, too. He thinks because I'm the oldest I get everything and because my other brother is the youngest he gets everything. He's in the middle and feels neglected.

Interviewer: What you your parents do about that? Hispanic student 1: They try to show him that we're all equal, but he doesn't believe my mom. My little brother is starting to slack off school, also. I'm trying to help him.

Interviewer: How do you do that?

Eispanic Student 1: Like after school when I'm finished with my homework and he doesn't understand something, I try to tutor him, but my brother thinks it's not important. We think my little brother is taking after my older brother and might drop out of school also. My little brother sees my older brother and he's trying to copy him. My mom is trying not to let this happen.

Interviewer: What happens when you bring home a report card?

Hispanic student 1: They give me $\$ 5.00$. If we get As and Bs my mom's happy -- to my brothers she gets mad. My father says that's too childish and 
he does not want her to get mad. If they bring C's, he says that's a good try. Whoever brings the best grades he gives us money.

Question 19 asked the girls whether they were born in the United States and how old they were when they came to the United States (see table 17). Thirty-six of the girls were born in the United States, fifteen having been born elsewhere. Eight of the Hispanic girls had been born in Mexico, and two Pan/Asian girls had been born in the Philippines. Eight of the sixteen born elsewhere came to the United States between the ages of $1-5$ years and five after the age of five years.

The importance of asking about the country of birth is to determine whether the girls have spent the majority of their lives in the United States or in another country. It was conjectured that girls who had attended school in the United States might have a different perception of what women could do or that they might be more encouraged to at least finish high school given the laws of the state. It might also be conjectured that since these girls are bright and since they are in schools which recognize that talent, they will be encouraged to achieve beyond the high school level. 
TABLE 17

Questionnaire item 19: Were you born in the United States? If not, where were you born and at what age did you come to the United States?

\begin{tabular}{|c|c|c|c|c|c|c|c|}
\hline \multirow[b]{2}{*}{ GROUP } & \multicolumn{7}{|c|}{ Number of Responses } \\
\hline & $\mathbf{n}$ & $\begin{array}{l}\text { Born } \\
\text { Yes }\end{array}$ & in & $\begin{array}{l}\text { U.S. } \\
\text { No }\end{array}$ & $\begin{array}{c}\text { Age } \\
0-1\end{array}$ & $\underset{1-5}{\text { came to }}$ & $\begin{array}{l}\text { U.S. } \\
5+\end{array}$ \\
\hline Black & 14 & 12 & & 2 & 0 & 2 & 0 \\
\hline Hispanic & 20 & 12 & & 8 & 1 & 5 & 2 \\
\hline Pan/Asian & 17 & $\underline{12}$ & & $\underline{5}$ & $\underline{2}$ & $\underline{1}$ & $\underline{2}$ \\
\hline \multirow[t]{3}{*}{ Total } & 51 & 36 & & 15 & 3 & 8 & 4 \\
\hline & & & & $\underline{x}^{2}$ & & & $\underline{x}^{2}$ \\
\hline & & & & 2.62 & & & 3.47 \\
\hline
\end{tabular}

Research Question 4: Are occupational choice/lifestyle goals clearly defined by ethnically-diverse, intellectuallygifted adolescent girls?

Questionnaire item 46 asked the girls what career/occupation they would like to pursue. Table 18 shows that the majority of girls (forty-three or 84 percent) selected a career in a professional field. For instance, one fifth (eleven girls) chose law. Medicine was the second choice followed by teaching and computer technology. When responding to this item concerning career choice, approximately one-third of all the respondents (seventeen girls) designated a specific career (i.e., pediatrician, 
obstetrician, math teacher, free-lance writer, school secretary). The rest of the girls (thirty-four) were nonspecific in their choice (i.e., teacher, scientist, designer).

TABLE 18

Questionnaire item 46: What career/occupation would you like to pursue?

Number of Responses

\begin{tabular}{|c|c|c|c|c|c|}
\hline GROUP & $\mathrm{n}$ & $\begin{array}{l}\text { Profes- } \\
\text { sional }\end{array}$ & Service & $\begin{array}{l}\text { Tech- } \\
\text { nical }\end{array}$ & $\underline{x}^{2}$ \\
\hline Black & 14 & 13 & 1 & 0 & \\
\hline Hispanic & 20 & 16 & 1 & 3 & \\
\hline Pan/Asian & 17 & 14 & $\underline{2}$ & $\underline{1}$ & \\
\hline \multirow[t]{2}{*}{ Total } & 51 & 43 & 4 & 4 & \\
\hline & & & & & 3.20 \\
\hline
\end{tabular}

Questionnaire item 47 asked the girl what career/occupation she would probably pursue. of the fortythree girls who selected a professional field (as seen in Table 18), thirty-eight girls retained their original choice. As can be seen in Table 19, six girls changed the type of occupation named in questionnaire item 46 -- five went from professional to service and one changed from technical to service. For example, such changes as fashion designer - psychologist; dancer - law; law -secretary were indicated. One girl indicated she would be "a secretary, a dancer on the side and a housewife." There were some 
changes with the categories as well. For instance, model cashier; architecture - advertising; secretary - computer programming; and psychiatrist - model.

TABLE 19

Questionnaire item 47: What career/occupation will you probably pursue?

\begin{tabular}{llllll}
\hline & \multicolumn{5}{c}{ Number of Responses } \\
\cline { 2 - 6 } GROUP & $\mathrm{n}$ & $\begin{array}{c}\text { Profes- } \\
\text { sional }\end{array}$ & Service & $\begin{array}{c}\text { Tech- } \\
\text { nical }\end{array}$ & $\underline{x}^{2}$ \\
\hline Black & 14 & 12 & 2 & 0 & \\
Hispanic & 20 & 15 & 3 & $\underline{1}$ & \\
Pan/Asian & 17 & $\underline{11}$ & $\underline{5}$ & 3 & \\
Total & 51 & 38 & 10 & &
\end{tabular}


TABLE 20

Desired Career by Occupational Category

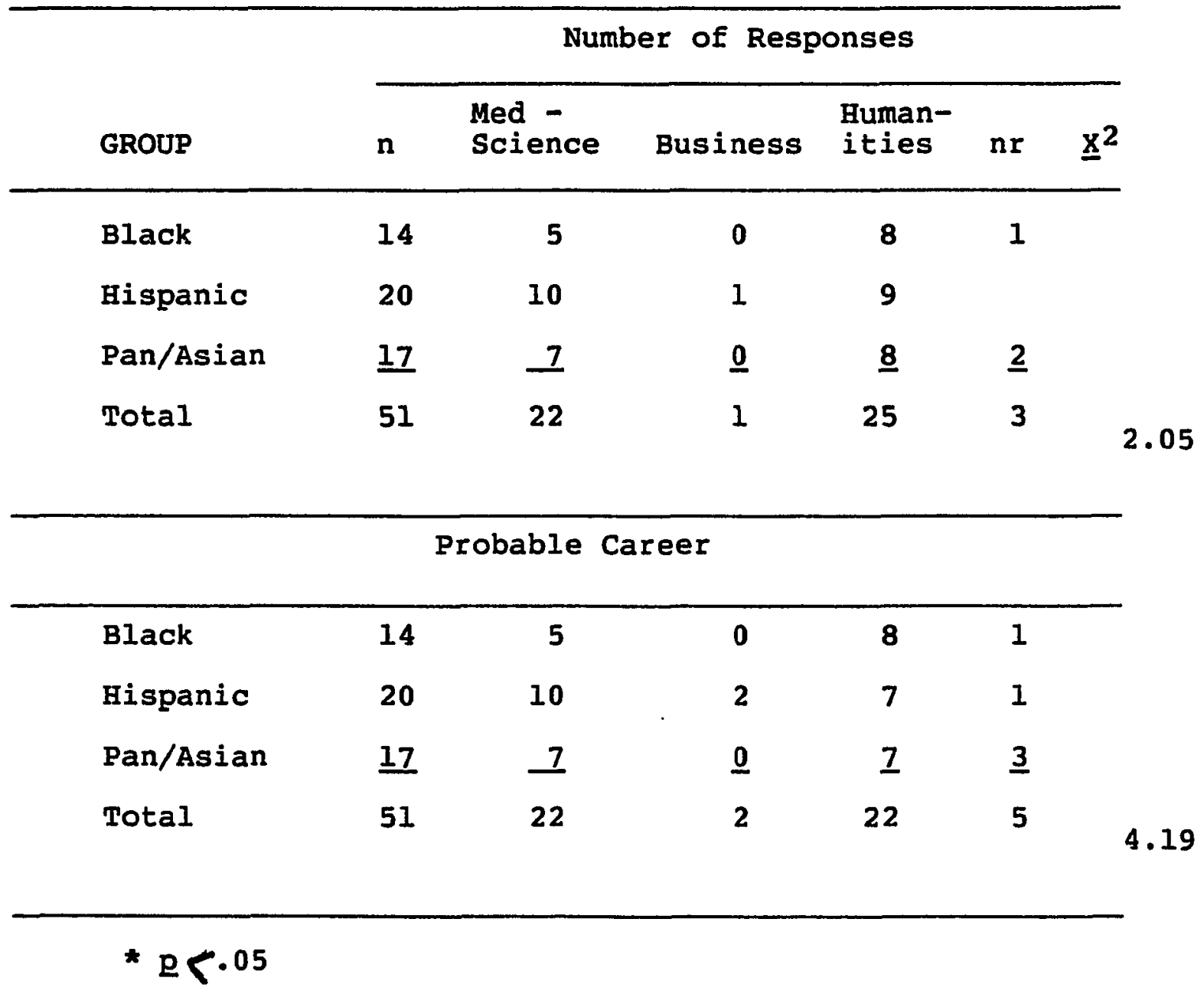

Interviewer: Think about the career choice or occupation you indicated you wanted to be doing 10 years from now. What are some of the reasons you have chosen that career?

P/A Student 2: I chose to be a free-lance writer because I like writing. 
P/A Student 1: I want to be a teacher. I thought that since I worked with my brother, I think I work better working with kids, teaching them how to learn.

P/A Student 3: I want to be a lawyer or an Air Force pilot because I like flying. I would like to fly when I'm older and to be a good lawyer. It earns a lot of money and it's a good career.

E Student 1: I don't know.

H Student 2: I want to be teacher and help kids learn.

H Student 3: I want to be a teacher and a parttime nurse.

Bl Student 2: I want to be an aeronautical engineer. I like to fly and build things. I don't want to stay on the ground even though the space shuttle blew up. I'm not sure I can be an astronaut. I'm just going to start to be a pilot and see how far I get.

Bl Student 1: Right now I'm torn between being a lawyer and a pediatrician. The reason is a lawyer works with all those criminals and how they help them. I want to do that but I'm kind of afraid to be that. What if you had to work with people who knew they did wrong and what if you don't defend them right and they get mad and come back and shoot you? At least that's what my mom says. 
Bl Student 3: I want to be a pediatrician because it pays a lot of money and because I like working with little kids.

Questionnaire item 49 related to future life choices and asked the girls to rank five options in order of importance to their future. Table 21 show that 90 percent of the girls indicated that having a career was the most important option, while three girls indicated marriage as most important.

TABLE 21

Questionnaire item 49: What do you think will be most important to you as an adult?

\begin{tabular}{|c|c|c|c|c|c|}
\hline \multirow[b]{2}{*}{ GROUP } & \multicolumn{5}{|c|}{ Number of Responses } \\
\hline & $\mathbf{n}$ & $\begin{array}{l}\text { Marriage/ } \\
\text { Children }\end{array}$ & Career & $\mathrm{nr}$ & $\underline{x}^{2}$ \\
\hline Black & 14 & 1 & 12 & 1 & \\
\hline Hispanic & 20 & 0 & 19 & 1 & \\
\hline Pan/Asian & 17 & 2 & $\underline{15}$ & - & \\
\hline Total & 51 & 3 & 46 & 2 & 2.23 \\
\hline
\end{tabular}

However, to some of the girls career - occupation - job appeared to be synonymous. As, for example, "I want to get a career and a job and then get married." 
The main objective in considering a career/occupation which was apparent in the questionnaire responses and, to some degree, among some of the interviewed girls, was selfsupport so that they could live comfortably. "To earn a high salary" was selected as the second option in importance by thirty-five girls and as first choice by two girls. One girl selecting a career as a fashion designer ranked "to be well-known" first and "to earn a high salary" second. One girl ranked all options as "ones" except to become wellknown, which she ranked second. Eleven of the Pan/Asian girls ranked marriage as third; four of the black girls ranked marriage as fourth or fifth in order of importance. It appears, then, that while most of the girls expect to marry, they expect to work first and to be self-supporting.

The following, however, is an example of the confusion the Pan/Asian girls are feeling relative to the career choices they see open to them.

Pan/Asian Student 1: Intelligence is used in war and a woman can't go to war unless she's a nurse. They don't let you fight. They really don't suspect that women can do the things that men can do. We're created equal but..... But a woman has to do easy things. We're created equal but told not to be so. Interviewer: What do you mean by that? 
Pan/Asian Student 1: Well, because the guys think they get to go fight. We can fight. We can do anything we want to. And then girls....

They aren't supposed to. They're all acting real ladylike, not real tough.

The guy thinks that their wife has to listen to every single thing they say.

Men think a wife has to listen to every single thing they say. That's how it usually is.

I know my mom isn't as smart as my dad but still she could do certain things that maybe he couldn't do.

A woman knows what meat to buy. A guy has to look at all the tags but a woman knows. It comes to a woman. But my dad does most of the buying. Mostly here all the men cook.

Interviewer: But why do you think men want to control? You say that men wanted to be in charge or wanted to control and now you're saying that your fathers help around the house or cook or take care of the kids.

Pan/Asian Student 1: Well, we're talking about these certain kinds of people but other husbands they don't let their wives do anything. They make their wives stay home and take care of the kids. They're treating them like a dog. Get my slippers, get me something to eat. 
You could see that. Maybe the fathers will help out with cooking but you tell them to vacuum and they go 'are you kidding?'

Pan/Asian Student 2: I know, you barely see your dad vacuum the Iug or wash the dishes.

Pan/Asian Student 2: And you're astonished!

Interviewer: But he'll cook.

Pan/Asian Student 2: He'll cook. Because before he was married he was single and he had to cook.

Research Question 5: What is the ethnically-diverse, intellectually-gifted adolescent girl's perception of herself and her ability to pursue a career commensurate with her ability?

Research question 5 was answered through questionnaire items 35-38. An analysis was conducted by examining the match between the classes the girls described as their favorites and types of careers chosen. For example, if a girl answered that she wanted to be a doctor, then math and science would be subjects she should list as favorites. Likewise, if she selects law as a career, it would be expected that she would select language arts as a favorite subject. Students were then categorized as having symmetry between what they see as a future career and their favorite subjects or as being symmetrical. Table 22 presents an analysis between matching and non-matching of career selection and favorite subjects. 
TABLE 22

Questionnaire item 35: What are your favorite subjects in school?

Number of Responses

\begin{tabular}{|c|c|c|c|c|c|c|c|c|c|}
\hline \multirow[b]{2}{*}{ GROUP } & \multicolumn{9}{|c|}{ Favorite Subjects } \\
\hline & $\mathrm{n}$ & $\mathbf{A}$ & B & $\mathrm{C}$ & $D$ & $\mathbf{E}$ & $\mathbf{F}$ & $\mathrm{nr}$ & $\underline{x}^{2}$ \\
\hline Black & 14 & 4 & 3 & 0 & 1 & 4 & 1 & 1 & \\
\hline Hispanic & 20 & 10 & 6 & 1 & 1 & 1 & 1 & & \\
\hline Pan/Asian & 17 & $\underline{3}$ & 13 & $\underline{0}$ & 1 & $\underline{0}$ & $\underline{0}$ & - & \\
\hline Total & 51 & 17 & 22 & 1 & 3 & 5 & 2 & 1 & \\
\hline
\end{tabular}

Least Favorite Subjects

\begin{tabular}{lrrrrrrrr}
\hline Black & 14 & 4 & 2 & 3 & 4 & 0 & 0 & 1 \\
Hispanic & 20 & 2 & 3 & 11 & 3 & 0 & 1 & \\
Pan/Asian & 17 & 1 & $\underline{0}$ & $\underline{3}$ & $\underline{0}$ & $\underline{0}$ & $\frac{3}{7}$ & $\underline{4}$ \\
Total & 51 & 13 & 5 & 17 & 7 & 0 & 4 & 5
\end{tabular}

\begin{tabular}{|c|c|c|c|c|c|c|}
\hline & & & tching & Non-Matching & & \\
\hline Black & & 14 & 3 & 4 & 7 & \\
\hline Hispanic & & 20 & 10 & 8 & 2 & \\
\hline Pan/Asian & & $\underline{17}$ & 8 & 7 & $\underline{2}$ & \\
\hline Total & & 51 & 21 & 19 & 11 & 0.33 \\
\hline Note: & & & & & $\star p$ & \\
\hline $\mathbf{A}$ & $=$ & Math & & & & \\
\hline B & $=$ & Language & Arts, & Reading & & \\
\hline C & $=$ & History & & & & \\
\hline D & $=$ & Science & & & & \\
\hline $\mathbf{E}$ & $=$ & Fine Arts & S, P.E. & & & \\
\hline$F$ & $=$ & None & & & & \\
\hline
\end{tabular}


Nearly 22 percent of the black girls, nearly 50 percent of the Hispanic girls and 47 percent of the Pan/Asian girls have a match between what they selected as favorite subjects and the career they see themselves as pursuing. Overall, 41 percent of the girls showed a match between favorite subjects and career choice, while 37 percent indicated a non-match. All the interviewed girls appeared to lack specific information about the process necessary to achieve a specific career.

It might appear that the black girls have selected careers in subject areas analogous to what they like and don't like. However, no real significance can be drawn here for all the girls because eleven girls are not included in the totals. The omitted girls are those who said they had no "favorite" or "least favorite" subject in school. Some of the same eleven girls also responded in answer to the question: In what subjects do you receive the best grades? -- "I do well in all my subjects (classes)." And, as might be assumed, in response to the question: In what subjects do you have the most difficulty? The answer was, "None"

Comments related to favorite subjects were not scheduled into the interview, but the black girls talked about problems they had and the following discussion ensued:

Interviewer: If you think you're going to be an engineer, what kinds of subjects will you need to be good at? 
Bl Student 2: I'm taking math all four years. I'm taking English all year, too. Even though I don't need P.E., I'm taking P.E. all year. I'm taking Auto Shop because I don't want to get stuck on the freeway some morning and not know what to do. Math is the only one I'm worried about because $I$ know I'm going to need it as an engineer and I'm good at it, but sometimes I tend to wander and then I don't know what's happening.

Interviewer: What do you think you need to be good at to get through college and medical school? Bl student 1: I do not like science. Here in junior high you don't do experiments. They sit there and you read out of your science book.

Bl student 2: A lot of written work. And you don't do experiments. Last year we did all kinds of experiments and I happen to like cutting up things. So, I was great at that.

Bl student 3: That's the thing about high school that's going to be better because you do a lot of lab work.

Twenty-four percent (eleven girls) of the students received their best grades in math and science, while 61 percent (twenty-eight girls) got their best grades in Language Arts.

Math and science were listed as most difficult by twenty-seven girls or 60 percent. Eleven Pan/Asian girls 
believed math and science to be most difficult. Nine Hispanic girls found math and science, and nine indicated Language Arts to be the most difficult. sixty-three percent of the black girls found math and science to be the most difficult.

While math and science seemed to be difficult for 60 percent of the girls, the interviews indicated boredom with science or having a teacher who didn't "know how to teach math very well." six girls responded that they had no difficulty with any subject.

Comments regarding ability included:

I want to be a psychologist but I lack confidence in myself.

I want to be a secretary but I'm not very good at typing.

I want to be a singer but I'm not sure I have enough talent.

I want to be a teacher and I'm pretty sure I can do it.

I want to be an engineer and an astronaut. I'm not sure I can but I'm going to go as far as I can.

Questionnaire item 39 asked the girls whether they believed they were doing as well in school academically as they wanted to. Table 23 shows the results of responses to this question. 
TABLE 23

Questionnaire item 39: Are you doing as well in school academically as you want to? If not, why not?

Number of Responses

\begin{tabular}{lccccc}
\cline { 2 - 5 } GROUP & $\mathrm{n}$ & No & Yes & $\mathrm{nr}$ & $\underline{x}^{2}$ \\
\hline Black & 14 & 6 & 8 & & \\
Hispanic & 20 & 7 & 13 & & \\
Pan/Asian & $\underline{17}$ & $\underline{8}$ & $\underline{8}$ & $\underline{1}$ & \\
Total & 51 & 21 & 29 & 1 & 0.82
\end{tabular}

* $\mathrm{p}<.05$

It appears that the majority of the girls are satisfied with their grades. Reasons they thought they might not be doing as well as they wanted to be doing included: "I am too lazy," "I want all A's," "I don't try hard enough," and "I don't know."

Questionnaire item 50 asked, "How likely is it that you will do each of the following after high school? Four choices were offered in which the girls were asked to select one option. Education level included technical or vocational school, attend a two-year college only, graduate from a four-year college, attend a graduate school. 
Table 24 contains the responses of the adolescent girls to the question about their future educational goals. As seen in this table, over 86 percent have plans to attend a four-year college. Nearly 29 percent (fifteen) of the Pan/ Asian girls, 25 percent (thirteen) of the black girls, and 31 percent (sixteen) of the Hispanic girls have plans to attend four-year institutions.

The questionnaire answers for item 47 (Table 19) showed that while 75 percent (thirty-eight girls) planned professional careers, 86 percent (forty-four girls) responded that they would attend a four-year college. In addition, 76 percent (thirty-nine girls) indicated they would attend a graduate school.

The data reported cannot, however, be construed as totally representative of the girls' plans. It was evident from the questionnaire responses that some Hispanic and Pan/Asian girls did not know the distinction between the schools. For example, some girls did not know what a vocational or technical school was. Three girls responded that they would "definitely" attend all four schools and five girls selected a professional career in law or medicine but answered "probably not" when asked whether they would attend graduate school. In addition, some girls were not sure whether they would attend a two-year college only or prior to enrolling in a four-year college. Thus, it can be surmised that at least in some of the girls' minds the preparation for certain careers was not clear. 
TABLE 24

Questionnaire item 50: How likely is it that you will do each of the following things after high school?

\begin{tabular}{lcrcccc}
\hline & \multicolumn{5}{c}{ Number of Responses } \\
\cline { 2 - 7 } Group & n & A & B & C & D \\
\hline Black & 14 & 4 & 4 & 13 & 14 \\
Hispanic & 20 & 7 & 10 & 16 & 13 \\
Pan/Asian & $\underline{17}$ & $\underline{8}$ & $\underline{2}$ & $\underline{15}$ & $\underline{12}$ \\
Total & 51 & 19 & 16 & 44 & 39 \\
\hline
\end{tabular}

Note:

Probably will or definitely will attend:
$A=$ Vocational school
$\mathrm{B}=2$-year college
$C=4$-year college
$\mathrm{D}=$ Graduate school 
Research Question 6: Who else does the ethnically-diverse, intellectually-gifted girl perceive as influencing her life planning decisions?

As part of cultural influence, other adults can be significant in a young person's life as role models and/or in helping to inculcate the acceptable attitudes and beliefs of the particular culture. Questionnaire item 7 asked the girl about other adults in her life she felt she could talk to about her future plans. As can be seen in Table 26, older siblings and friends were mentioned most often, followed by aunts, uncles, cousins and, lastly, grandparents. Three girls' questionnaire responses indicated they had talked to a school counselor or teacher. Only five Pan/Asian girls indicated they discussed their future with anyone other than parents and then only four girls indicated they did.

When a chi-square analysis was completed, questionnaire item 7 had empty cells and no significant differences were found. By collapsing the empty cells, as in Table 26, significant differences appeared between the groups. 
TABLE 25

Questionnaire item 7: Are there other adults with whom you discuss your future plans?

\begin{tabular}{|c|c|c|c|c|}
\hline \multirow[b]{2}{*}{ GROUP } & \multicolumn{4}{|c|}{ Number of Responses } \\
\hline & $\mathbf{n}$ & No & Yes & $\underline{x}^{2}$ \\
\hline Black & 14 & 3 & 11 & \\
\hline Hispanic & 20 & 3 & 17 & \\
\hline Pan/Asian & 17 & 12 & 5 & \\
\hline Total & 51 & 18 & 23 & $1406:$ \\
\hline
\end{tabular}

TABLE 26

\begin{tabular}{lcccccccc}
\hline & \multicolumn{7}{c}{ Number of Responses } \\
\cline { 2 - 8 } GROUP & n & A & B & C & D & nr & $\underline{x}^{2}$ \\
\hline Black & 14 & 5 & 1 & 3 & 2 & 3 & \\
Hispanic & 20 & 7 & 3 & 5 & 2 & 3 & \\
Pan/Asian & 17 & $\underline{1}$ & $\underline{0}$ & $\frac{2}{10}$ & $\frac{2}{6}$ & $\frac{12}{18}$ & \\
Total & 51 & 13 & 4 & 10 & 6 & 18 & 3.59 \\
\hline
\end{tabular}

Note:
$A=$ sibling
$B=$ Grandparent
$C=$ Friend
$D=$ Aunt, Uncle, Cousin

* $\mathrm{p}<.05$ 
Interviewer: Who else do you see influencing your life plans?

P/A Student 3: My sister. She talks to me about the future. She says that being a teenager is the hardest stage of life because you have to choose a career. She says, "Do what's right for you and don't listen to the things your parents want you to be. It's your life and you are the one who is going to live it, so be what you want to be and not what your parents want you to be."

B Student 1: My grandparents and my dad influence me. They want me to be a computer operator. They say, "Get a job that ycu'll earn a lot of money so you can support us and buy yourself a car and have good clothes."

H Student 1: My uncle says what I do is okay as long as I like what I am doing and not get bored with the job or something.

BI Student 1: My grandmother and my uncle. He talks about jobs that make a lot of money and then he says be a doctor. He talks to me about the kind of doctor I can be.

B1 student 2: My brother tells me all the time I'm not stupid and that I should do something with my life. I told him I wanted to be a doctor and he said that was a good idea. He really wants me to be in computers because it brings a lot of money. 
Research Question 7: Does the ethnically-diverse, intellectually-gifted adolescent girl perceive that the life planning of her peers influence her own life planning?

Question 20 asked whether the girl talked to peers and friends about career plans. Table 27 reports the data related to peer discussions. It appears that, at least at this age, peers are not considered influential regarding school achievement or future life planning.

Spenner and Featherman (1978) emphasized the importance of the peer group in the life of the adolescent and Davies and Kandel (1981) found that girls are more influenced by friends than are boys, particularly regarding future aspirations. As indicated earlier, however, most of the studies relative to peer influence have been conducted with senior high school students and/or college students, as opposed to junior high school students..

The girls conceded that they would do better in school if they had friends who were also interested in getting good grades.

"You see, I've got some friends who get straight A's all the time and then I've got friends who don't and $I$ 'm kind of in the middle of all of them. But then, some of them are smarter than me, but just they're stuck in Algebra, so they don't get as good of grades as I do." 
TABLE 27

Report of intellectually-gifted, ethnically-diverse, adolescent girls' discussions with peers.

\begin{tabular}{|c|c|c|c|c|c|c|c|c|}
\hline & & \multicolumn{2}{|c|}{$\begin{array}{l}\text { Black } \\
(\mathrm{N}=14)\end{array}$} & \multicolumn{2}{|c|}{$\begin{array}{l}\text { Hispanic } \\
(\mathrm{N}=20)\end{array}$} & \multicolumn{2}{|c|}{$\begin{array}{l}\text { Asian } \\
(N=17)\end{array}$} & \multirow[b]{2}{*}{$\underline{x}^{2}$} \\
\hline \multicolumn{2}{|c|}{ Questionnaire Item } & $\mathbf{R}$ & $\mathbf{F}$ & $\mathbf{R}$ & $\mathbf{F}$ & $\mathbf{R}$ & $\mathbf{F}$ & \\
\hline 18 & Future Goals & 11 & 2 & 14 & 6 & 13 & 4 & 3.55 \\
\hline 20 & Educ/Career Plans & 9 & 4 & 17 & 3 & 14 & 3 & 1.31 \\
\hline 21 & TV, Sports, Movies & 4 & 10 & 5 & 15 & 2 & 15 & 1.51 \\
\hline 22 & Personal Values & 5 & 9 & 13 & 7 & 10 & 7 & 3.01 \\
\hline 23 & World Unrest & 12 & 2 & 17 & 3 & 15 & 2 & .08 \\
\hline 24 & News Events & 12 & 2 & 11 & 9 & 14 & 3 & $5.13^{\circ}$ \\
\hline 25 & Religious Beliefs & 13 & 1 & 19 & 1 & 17 & $\mathbf{0}$ & 1.14 \\
\hline 26 & Science & 14 & 0 & 19 & 1 & 17 & 0 & 1.58 \\
\hline 27 & Books & 11 & 3 & 18 & 2 & 13 & 4 & 1.34 \\
\hline
\end{tabular}

Note:

$$
\begin{aligned}
& \mathbf{R}=\text { Rarely } \\
& \mathbf{F}=\text { Frequently } \\
& \star \mathrm{D}<.05
\end{aligned}
$$


Peer influence for the black girls was considered supportive, at least among the girls who were interviewed. B1 Student 1: Most of my friends know that if they don't do good they're going to be stuck somewhere on welfare or something. So, most of them pretty much know what they want to do. B1 Student 2: They don't want to end up living in the slum.

Bl Student 1: Most of my friends just tell me whatever you're going to do, just get in there and find out how hard it is and don't back out. Bl Student 3: My two girlfriends and I talk about what we're going to do. What college we want to go to and what hospital we want to work at.

The Hispanic girls, however, saw peers as not being particularly supportive. For example, they said they had to make up an excuse if they wanted to study and their friends wanted them to do something else. Otherwise, they call us "schoolgirl" or "nerd."

They also indicated during the interview, that they felt, as did the other two groups, that their friends could get good grades if they wanted to work at it. They also agreed that they would get better grades if they hung around other people who were interested in studying. It might be that once in high school their perceptions will change or they will find others like themselves to be friends with. 
The families of all three girls were close, however, and parent influence appeared strong, at least at this age.

H Student 1: I don't care if other kids don't get good grades.

H Student 2: Boys should be smarter. Interviewer: How do you determine smartness? H student 2: How they act tells them. Bl student 1: I think they can do the same things that I can; it will just take them longer. Bl student 3: They're really smart and everything up here. But they don't turn in their homework.

Thus, the black interview participants told of the support of their friends and did not see much difference between their aspirations and those of their friends. However, the girls did have a preconceived notion that "all kids rebel at sixteen, at least that's what I hear." While peer influence on their future life planning was not discussed, two of the girls were very impatient about getting a job while they were fourteen because when they were sixteen they were quite sure they would not want to work .

Bl. Student 2: "No one wants to work at sixteen, since they're into cars and women. We want to work now so we save up for a car."

One of the black girls told of her boyfriend's attempt to get her to join the debating team rather than to be a 
cheerleader. She saw that as being supportive and thought he just wanted her to use her intellect, but she felt she needed to do fun things too:

Bl. Student 1: "After all, he was on the football team."

Interviewer: What is the most significant reason preventing you from reaching your goal?

This question corresponded to the questionnaire item: Are there reasons you might not be able to pursue the career/occupation you have chosen?

Questionnaire responses, as shown in table 28 , indicated that twenty-eight girls (56 percent) said there were no reasons preventing their pursuit of a career, twenty-two (44 percent) indicated that there were. Fewer black (5) girls perceived any barriers than either the Hispanic (9) or Pan/Asian girls (8). Barriers listed by the girls included money -- either not enough money to go to college or that they did not think they would make enough money at their chosen occupation; lack of talent; few women in the field; and lack of motivation. 
TABLE 28

Questionnaire item 48: Are there reasons you may not be able to pursue the career/occupation you have chosen?

\begin{tabular}{|c|c|c|c|c|c|}
\hline \multirow[b]{2}{*}{ GROUP } & \multicolumn{5}{|c|}{ Number of Responses } \\
\hline & $\mathbf{n}$ & No & Yes & nr & $\underline{x}^{2}$ \\
\hline Black & 14 & 5 & 9 & & \\
\hline Hispanic & 20 & 9 & 11 & & \\
\hline Pan/Asian & $\underline{17}$ & 8 & 8 & $\underline{1}$ & \\
\hline Total & 51 & 22 & 28 & 1 & 0.63 \\
\hline
\end{tabular}

The girls' comments during the interview clearly indicated there were additional barriers. The black girls, however, were quite sure there was no reason they would not pursue their chosen career other than "death."

H/A Student 1: Having children.

E/A Student 2: Getting married.

Interviewer: Why would that get in your way?

H/A Student 2: Because when you want to go out, it costs money to get a babysitter. And they get in your way from doing something. H/A student 2: When you have children, you have to stay home and take care of them.

H/A Student 1: No, you can always go to work and have someone take care of them. 
While the Hispanic girls acknowledged that they sometimes felt they were expected to help their parents out when the girls grew up, there was certainly no indication that this was a foregone conclusion, as it was with the Filipino girls. It appeared among the Hispanic girls that if parents need help, then the girl would help them.

Interviewer: What might be the most significant reason preventing you from reaching that goal?

P/A Student 1: I don't know. Probably more problems in the Philippines.

P/A Student 2: That's doesn't stop me from being a teacher.

P/A Student 1: It will because then you'll be one that will be supporting your parents by then, right?

P/A student 1: What if you were teaching and your parents went to the Philippines and there were problems there?

Interviewer: How would that affect you?

P/A Student 1: I think I might go to the Philippines and try to help them out like my dad does. Interviewer: You think your parents are going to move to the Philippines?

P/A Student 1: Yes. They said, "Why don't we go back to the Philippines?"

P/A student 2: Mine, too. Because they say, "You don't want us to be with you." 
Interviewer: Do you expect to support them the rest of your lives?

P/A student 3: Yes. I think that's how it will be. That's how it usually is. Like the grandmother would be a nanny or something. Like taking care of the house while the parents work. Much like it is in Filipino families.

P/A Student 2: Even if it isn't your own grandmother. If her family doesn't have time for her, then she moves in with another family. But usually the whole family lives together or at least in the same town.

Santos (1983) noted that among many Filipino families there is a "very marked sojourner's mentality" (p. 145). Psychologically, this mentality lessens the pain of having left forever the home country, the relatives and friends. In times of failure, this mentality becomes a rationale. They can rationalize that disappointment has little signficance since they will be going "home" again someday anyway. "Although America is the place to be for economic and material gain, some immigrants look back to the old country as where they really belong psychologically, socially and culturally" (p. 145).

P/A Student 1: They want us to take care of them because that's what my mom keeps asking me. "When I get older, are you going to put me in an old 
folks' home or are you going to let me take care of you? If I still live at their house or move away, she'll say, "Will you be sending money to me when you have a husband?" I'm like, don't look at me.

P/A Student 1: When you're younger, they're telling you, "Oh, I can't wait until you get out of the house." Well, my brother's gone and whenever he calls they all run to the phone and my mother's saying "Don't leave." She tells us, "I can't wait until you grow up," and later on she says, "Well, when you're older are you going to take care of me?

P/A Student 3: My parents come up to me and say "When you grow up you're just going to forget about us, aren't you? When you're married if your husband doesn't like us, you're not going to have us, are you?

P/A Student 2: It's like the kids don't really need their parents but you don't know what to say because you don't know how it's going to be. P/A Student 3: The problem $I$ have is that right now I'm picking a career but I want to get married and when I'm older I might change my mind about a career. I might want to be a doctor instead of a lawyer or get married. 
Interviewer: You think marriage affects your career?

P/A student 3: Yeah, if you have babies.

$\underline{P / A}$ Student 2: Until it's older. But it depends. If you had a sitter.

P/A student 1: If you don't finish college, you'd have to go back to finish. It would look weird -a 30-year old woman in college.

P/A student 2: It's almost like they don't want their grandchildren to be raised like their kids were -- without a mother. They want their grandchildren raised in a normal way.

H/A Student 1: Having children you have to stay home until they are at least three. It costs money to get a sitter. And children get in your way from doing something.

H/A Student 1: We had a sitter once and I used to cry and cry until my mom came home. Our sitter didn't care what we did.

H/A Student 2: My mom says if I have a baby not to go to work. I ask her, "What about a sitter?" She says, "sitters don't take good care of little babies."

Interviewer: How do you figure out what to do? Have you talked to them about what you are telling me? It sounds like you want me to have a career and be self-supporting, but then $I$ should stay 
home and take care of the children when I have them.

P/A Student 1: I know. They give you all these double things to do.

P/A Student 2: Like right now, I'm Michelle Brain and stuff like that brain quack.

P/A Student 2: And then when you talk to them they say don't talk to me right now. Like it's too hard to explain. They tell me not to have a boyfriend until after high school. And then I'm going, "Oh God, I'm going to be so old." And then like two days later she says, "How come no one calls?"

\section{P/A Student 1: I know.}

One of the Pan/Asian girls responded that writers don't make it that far (to make a living of $i t$ ).

"It's all luck depending on who your agent is and what prople like at the time you brought it out." This girl, having done some writing, was aware of the internal problems associated with being a writer.

"(My counselor's) roommate read over my poem and she said it was really good and even though I'm still in school I could do it (write) in my free time. But you really have to concentrate -- you really get into it sometimes and sometimes ... so when I write I have to really concentrate so I can't have anything else on my mind." 


\section{Gifted Program Participation}

All of the schools the sample subjects attended provided enrichment and/or special programs in which the girls could participate. In some schools, girls can enroll in Honors classes in which students are taught at an accelerated rate. Additional opportunities for gifted students may include study trips outside the school site, speakers, and/or independent study projects. Students gifted in music, art or dance can elect to attend a "Fine Arts Magnet" for part of a day. Career awareness presentations were being carried out in some schools. In one school, the principal told the researcher, "Well, now that you've reminded me, I'm going to set up a career awareness program for the gifted students."

Participation in a program for bright students was perceived as valuable by most girls. They responded that it offered a chance to take harder courses and to get a better education.

"It teaches you what can happen to you if you don't go to school. If you don't go to school, like the taxi driver probably didn't have a good education, so he had to be a taxi driver."

In addition, they liked the Honors classes, the field trips and the chance to learn about computers and special projects.

Questionnaire item 41 was an open-ended question from which the following comments were extracted: 
Student: It puts me on a level that I can work at and learn something new.

It has opened up opportunities to do different fun things like field trips and speakers. It is very informative and may contain useful information for the future.

Participation in a gifted program would create a better chance of getting into college.

Teachers treat us like adults.

Additional comments:

It doesn't matter whether you're in a gifted program. Because if you're gifted or not, you can always go for your goal.

I learn more but I also have more hard work.

In regular classes, we did work I already know. Now I get the chance to learn something new and different. I have experienced many different things.

Learning things I could care less about and will never need to know.

The following comments were made during the interview:

Interviewer: Tell me something about your participation in a gifted and talented program. Bl student 1: It doesn't seem that gifted to me. And they don't give us anything special. Bl student 2: I didn't even know I was in the gifted program. They like didn't tell me. And I'm like, oh, okay. 
Bl student 1: One thing that's weird about the gifted is that we have different books than anybody else.

B1 Student 2: I think that if we were in a regular class our parents wouldn't expect as much. Because I know our parents know that. When I first came here in January, I was in pre-Algebra and it was like my parents didn't expect me to get straight As. Now that $I$ 'm in Algebra, they think that now she's smart enough so she can get straight As.

Interviewer: Are there ways you think the school could help in career planning?

Student: Just get programs. Job programs for summer jobs. And career management classes or something that gives you some kind of push on what you want to do in life or something that helps you decide. Right now we don't even talk about careers.

Student: Help us in finding the right courses in high school. We heed help in planning a career. We need somebody to help us decide what we really want to do for a career. I don't know what I'd really like to do. 
Being in a special program for gifted students was considered a good experience for most of the Pan/Asian and Hispanic girls.

P/A Student 1: The different projects let you figure what you're good at and what you like. Except last year I took typing and $I$ ended up filing. I got no typing at all. At least I found out being a secretary is not for me.

They enjoyed participating in the gifted program which included field trips and assembly programs. They wanted more assistance in career counseling to find out what colleges they could attend as well as what classes they needed to take to get into college. They also did not think that they should have to work harder just because they were gifted. "It's hard because people treat you differently, even though you are just like everyone else."

In addition, the questionnaire answers indicated that 50 percent of the girls requested career counseling. The responses in the questionnaires indicated they wanted help in signing up for high school courses, help in finding out what requirements they would need for a specific career and some help in deciding what they "ought" to do. They also requested people to talk about colleges and college costs and what they would have to do to qualify. "I just need somebody to tell me what's going on and how I can decide what to do." 
Research Question 8: To what extent do the perceptions regarding cultural/parental influences vary for the intellectually-gifted adolescent girls between each of the three ethnic groups?

Through the use of the questionnaire and the interview data it is possible to develop a composite of the Hispanic, Pan/Asian and black girl. This composite is in no way meant to imply that all ethnically-diverse girls are the same. The Pan/Asian geographic area, for example, is vast -encompassing the Philippine Islands as well as many Asian nations. Hispanic communities, while possessing some sameness, also possess individual characteristics. It cannot be construed that all black families are similar. In fact, the black girls, because of the educational level of their parents and their socioeconomic status, were very atypical of many black people. It must be emphasized then, that the following is a composite of the Hispanic, black and Pan/Asian girls who participated in this particular study.

\section{The Black Adolescent Girl}

The black gifted female in this case study is from a socioeconomically middle class or upper middle class home. She lives in a home with two parents and between one and three other siblings. She is as likely to be a Roman Catholic as she is a protestant. Both her parents have either had some college or have a bachelor's degree. Both 
parents work; fathers are career military personnel, in sales work or have a professional civilian career. Mothers are in professional careers -- a physician, educator or administrator. Family income is between $\$ 20,000$ and $\$ 40,000$ per year.

The black female believes she is more similar to her mother, is close to her mother and fairly close to her dad. Her parents have encouraged her to be independent and they support the plans she has for her future. Her parents stress the importance of using her intellect and to "be somebody."

Her career aspirations are high and she sees no reason she will not reach her goal. Her parents want her to have a college degree "to have something to fall back on" and also because they want her to have a better life than they have. Marriage is an eventuality but does not appear to be a viable alternative to a career. She may be a physician, a lawyer, an engineer or a pilot and financial reward is a strong factor. She plans to go to a private college.

She talks to older siblings and grandparents who encourage her to do something she likes and in which she will make a lot of money. She also talks to her friends who, like her, want to achieve and earn a lot of money. They see having an education and good professional career as a means of attaining financial security.

School is not particularly difficult for her and she attributes difficulties in math and English grammar to poor 
teachers. However, while she knows she is smart, she also knows she has to work harder at some things more than at others. This did not temper her confidence, nor does she think she couldn't do just about anything she set her mind to do.

She is involved in extracurricular activities and likes music and dancing. She is very articulate, enthusiastic and has a wry sense of humor. She is flexible in terms of demands on her time because there are so many things she wants to do. She resents being only fourteen because she wants to work to buy clothes and save money for a car. Her greatest problem, at least in her own mind, is that it is taking too long to grow up. She is impatient. Time is going too slowly for her and there is much to do. Pacing herself will be important so that she will be able to share her talents and abilities as $a$ leader and valuable contributor to her profession.

\section{The Hispanic Adolescent Girl}

The gifted Hispanic female in this case study belongs to a family with two parents and to have three or four brothers and/or sisters. She is as likely to be the oldest child as she is to be the youngest. Both parents have less than a high school education. Her mother is a housewife and her father is a blue collar worker. He is a laborer, a truck driver or custodian. The family income is between $\$ 10,000$ and $\$ 19,000$ per year. 
She feels closer to her mother but is fairly close to her father. Both parents have encouraged her to do things for herself and have given her the freedom to make her own decisions. She has received encouragement from both parents to do well in school and they are proud that she is in a program for gifted students.

While she discusses her future plans with her parents, a sibling or a friend, they have not suggested any specific career goal. They want her to do whatever she wants to do. The main objective is that she earn enough money to support herself and buy the things she needs. A career is the most important goal. Yet, she also wants to get married and have children even though she believes that if she has children she will need to stay home and take care of them. To her, marriage seems somewhat inevitable. While she aspires to a "career," this word equates more to a job than a career for which college would be a prerequisite.

In school she generally does as well as she would like. She regards languages, reading and spelling as favorite subjects. Math is considered a least favorite as is physical science. While she has some ideas about her future life planning, goals are not clearly defined. She is interested in law, medicine, computers and teaching. She is rather vague about future plans. She does not give the impression that she is the one who will make the decision about her future life. She is not sure, for example, whether there will be enough money for college. She is not 
sure what subjects she will need to take in high school but wants to go to the high school that is known for excellence. She also sees money as the main barrier preventing a college education.

She likes the program at school for gifted students because she gets to assume responsibility which she enjoys. She has the opportunity to work with computers and also tutors other students. There are problems with the boys in her family, however. She has second thoughts about getting better grades in school than they do. She is not unhappy about being able to do well in school, but it appears to create more of a problem. More is expected of her in terms of responsibility and maturity.

She has not developed long-range goals for her future, which perhaps is due to a number of variables. She would probably be the first person in her family to go to college, for example. She is also quite young and hasn't really thought much about higher education. The desire seems to be there, she just doesn't seem sure that (a) a career is really what she wants, and (b) that it is a realistic possibility. The decision then seems to totally rest on her own inner resources and the opportunities available when the time comes. 
The Pan/Asian Adolescent Girl

Because of a lack of a variety of Pan/Asian females in gifted programs, a large number of girls for this case study were Filipino girls. These were the girls selected for the interview because of the availability of three girls at one school. The other Pan/Asian girls were found at three other schools. Other than Filipino females, there was one Guamanian female, one Korean girl, three Japanese girls and one vietnamese girl. The questionnaire data included responses from all these girls.

It is not the intent of the researcher to obscure the diversity of a particular Asian culture but to address the life planning issues facing an intellectually-gifted Pan/Asian adolescent girl.

The Pan/Asian female lives with both parents and two or three siblings. She is probably the youngest. She was born in the United States but her parents may not have been. She and her parents may be Roman Catholic, Protestant or Buddhist. Both parents have graduated from high school and have attended college. They are likely to have a bachelor's degree.

Her father is in the military or recently retired. Her mother may be employed in health care services, an office worker or in a technical field.

She feels fairly close: to both parents and does not feel she is more similar to one parent than the other. Her 
parents encourage her to do well in school and she thinks both parents understand and support whatever she wants to do with her life. She has had some encouragement in doing things for herself and some freedom in making her own decisions.

She likes school and favorite subjects are language arts and reading. Least favorite subjects are math and science and they are also the most difficult. She finds participation in a gifted program challenging and likes working with other people at her ability level. She sometimes feels, however, that people expect more from her because she is in a special program when "you're not very much different from others."

Her Filipino parents want her to "be a doctor" because "it's the Filipino dream". The Japanese girls also indicated an interest in medicine and other Pan/Asian girls selected careers in clothing design or fine arts. While her career plans are somewhat vague, she aspires toward a career and to earn a "high salary". She wants to get married and have children but not until she has achieved her career goal. She thinks she might work toward a career in medicine; but she is also interested in the law. She is fairly confident that she has the ability to achieve her goal. The dilemma, however, is whether she does what she wants to do or what her parents want her to do regarding career plans.

The patterns of background, parental and peer influence 
on career choice in this case study were used to develop a summary of characteristics and influences affecting the lives of the black, Pan/Asian and Hispanic adolescent. It is important to note that this description cannot be assumed to describe all black, Pan/Asian and Hispanic young women. As noted in the review (Baca, 1980), while individuals may belong to a particular ethnic culture, it must be assumed that every family or community, while retaining cultural values, is unique. Even though there may be parallels with girls from the same ethnic group, there may also be significant differences. Also, it is imperative that "culturally different" or "ethnically-diverse" be equated with culturally disadvantaged or socioeconomically disadvantaged. As indicated, some of the girls in this group did not come from low sEs homes. 
There is no question of the crucial part the family plays in the socialization of the young girl. It is the family who teaches her the culturally-defined roles, rules and expectations she will need to live within the culture. It is in the family the young female first learns what role she is to play as an adult woman. She may learn that women can pursue whatever career/occupation they prefer or she may learn that there are roles which are considered more appropriate for women who belong to her culture.

It is well-known that historically women, particularly women from ethnic cultures, have been underrepresented in high status careers. Much has been written in explanation of their lack of representation. Cross (1983) suggested that the ethnically-diverse female may encounter discrepancies between the expectations of her culture and those of the dominant culture. She may also internalize traditional gender and racial stereotypes and respond by selecting traditional careers and occupations which she perceives as being socially acceptable.

Chusmir (1983) explained that career choice starts with a combination of four variables: a) environmental stimuli; b) education; c) reference groups, and d) personal 
characteristics. These factors form a person's perception of self which, in turn, influences one's career aspirations.

The development of a career is a personal one and can be made using knowledge of one's interests and abilities. It is the responsibility of parents, teachers, counselors and gifted coordinators to assist the gifted adolescent, ethnically-diverse female to identify her unique talents to create a full enriching life for herself.

\section{Study objectives}

The primary purpose of this case study was to examine and assess influences affecting the career choice/life planning goals of the black, Hispanic and Pan/Asian intellectually-gifted adolescent girl. The secondary purpose was to examine and assess community influences the intellectually-gifted adolescent black, Hispanic and Pan/Asian girl perceives as influencing her career choice/life planning goals. In order to guide this research, eight questions were designed:

1. What is the extent of the ethnically-diverse, intellectually-gifted adolescent girl's relationship with her parents?

2. What is the extent of the ethnically-diverse, intellectually-gifted adolescent girl's interaction with each parent relative to career choice/future life planning? 
3. What influences, as related to the family's sociological environment affect the career choice/future life planning of the ethnically-diverse, intellectually-gifted adolescent girl?

4. Are occupational choice/life planning goals clearly defined by the ethnically-diverse, intellectuallygifted adolescent girl?

5. What is the ethnically-diverse, intellectuallygifted adolescent girl's perception of herself and her ability to pursue a career/occupation commensurate with her ability?

6. Who else does the girl perceive as influencing her future life plans?

7. Does the ethnically-diverse, intellectually-gifted adolescent girl perceive that the life planning of her peers influence her own life planning?

8. To what extent do the perceptions regarding cultural/parental influences vary for the intellectuallygifted adolescent girls between each of the three ethnic groups?

\section{Research Design and Instrumentation}

The design for this research was a case study. In order to obtain data for the study, a 50-item questionnaire was designed by the researcher. The selection of items was 
based on the variables the literature and existing instruments have found to be pertinent to career/occupation choice.

The questionnaire included sixteen items exploring the girl's perception of the parent-daughter relationship; nine demographic questions about the family; nine questions relating to her perception of peer influence on her future plans; and fifteen items about school subjects (favorite and least favorite), her career aspirations and suggestions for ways she thought the school could help in selecting a life plan/career.

The interview was designed to elicit information about the girls' perceptions, attitudes, beliefs and opinions which would enhance the data from the questionnaire. Selected questions from the questionnaire were chosen for the interview schedule. It was also the intent of the researcher to see whether, in fact, the girls responded differently (when peers were present) from the way the subjects answered the questionnaire overall.

The subject sample was composed of 51 girls from the black, Hispanic and Pan/Asian gifted populations in San Diego County. The sample included 13 black girls, 20 Hispanic girls and 17 Pan/Asian. The Pan/Asian sample included Korean, Vietnamese, Japanese and Filipino girls. The mean age was thirteen years, one month and they were in the seventh or eighth grades. No attempt was made to randomly sample the subjects because of the dearth of 
ethnically-diverse identified intellectually-gifted girls, particularly black girls.

The questionnaire was administered to a pilot group of six girls not associated with the study. Each girl was asked to critique the questions for clarity. Four adult educators were asked to read the questionnaire to evaluate the items by comparing them to the eight research questions underlying the study and for detection of bias in item construction.

Reliability was established through use of the testretest procedure. Less than five percent of the total number of questions showed change. To calculate the stability of coefficient or test-retest reliability, five adolescent girls were administered the questionnaire at a two-week interval. The scores of the five responses were correlated and in agreement $(+.77)$ indicating answers were consistent in measuring items over a two-week period.

To analyze the data, Chi-square analyses were performed on certain questionnaire items. In addition, interview data and select questionnaire items were discussed qualitatively.

\section{Findings and Implications}

One of the first problems the researcher faced was the difficulty in finding identified academically-gifted black, Pan/Asian and Hispanic girls for use as subjects. It was noted in the literature review that the culturally diverse 
youngster is often overlooked in the gifted identification process. While these young people may possess particular talents, their intellectual ability may be neglected, obscured by cultural bias or completely dismissed. These youngsters may not meet the prescribed identification standards because they are assessed by instruments which have been normed on the dominant culture. Expectations for achievement for children from minority cultures have been traditionally low. In addition, ignorance of the general characteristics of giftedness by educators may mean the culturally-diverse bright child is never identified. It is the opinion of this researcher that there needs to be a continued effort to develop specialized testing measures which will allow for a more accurate identification of the intellectually-gifted child who belongs to a minority culture.

This case study's findings indicated that the girls, while different from each other culturally, possess some similar perceptions. In terms of family relationships, for example, they believed they were more similar to and felt closest to the mother. Responses regarding development of independence by the mother (items concerning encouragement to do things for self; make own decisions; do well in school) have been found to relate to young women's selection of non-traditional career. In this study, the majority of girls aspired toward non-traditional careers and indicated that mothers had encouraged independence, but they also felt 
both parents had given them "some freedom" in decisionmaking. The girls are young, however, and are still quite dependent on and influenced by parents. Thus, career choice, at this point, is still in an exploratory stage. The girls are listening to and intuiting what they hear from their parents and in that light, then, their future decisions will be made.

The researcher noted that there were distinct differences between the three groups of girls. The Hispanic girls appeared more mature in their behavior but less in control of their lives. They appeared to be waiting to see how things turned out regarding their futures. They received little direction from parents -- only that the parents want the girls to do whatever they need to do to be whatever they want to be.

The black girls appeared less mature and viewed the future as an opportunity to gain material possessions. Their biggest concern was that they wanted to work but they did not qualify for any of the special programs aimed at minority populations because their parents made too much money. Since they were all under age 16, they had not been able to find work in any commercial establishments. Their parents emphasized the importance of at least getting a college degree. Marriage and family were not a concern.

The Pan/Asian girls exhibited the view that men are the decision-makers and have more options regarding career choice. These girls received direct encouragement to attend 
college and attain a high status career, although they were expected to remain at home if they married and had a family. In any event, the expectations were that the girls would live with their parents or at least nearby whether they married or not.

The responses indicated a need for career counseling. For example, the girls want to know what the requirements are for specific careers, how to go about fulfilling those requirements, where the best schools would be to pursue a particular occupation and what relationship there is between individual talents or strengths and a chosen career.

The literature review revealed that gifted girls often feel lonely as they progress through school. The aloneness results not so much from a lack of friends but lack of support from teachers and parents. Evidence from this case study indicates that few girls talk to people outside the immediate family about their future plans. In addition, the Hispanic girls believed it was really no one else's business. Studies reviewed and reported in the literature stress the importance of significant others who can provide support, encouragement and mutual understanding to the adolescent girl planning for her future. For the Hispanic girl, at least an attempt needs to be made to help her understand that only by expressing her desires for her future can assistance and support become available.

Fewer opportunities are available for the ethnicallydiverse, intellectually-gifted female to see same-sex role 
models in non-traditional careers than are available for her male counterparts. Traditionally, there has been less interest and investment in ethnically-diverse women's academic and professional interests.

Given the socioeconomic level of the Pan/Asian and Hispanic girls, the opportunities available to meet highly successful women in the girls' aspired careers are minimal. The implication is clear then -- attempts need to be made through the school and the community to find and make available opportunities for these girls to develop relationships with ethnically-diverse women who have achieved success in a professional career.

The black girls gave no indications of obstacles to career pursuit. Their implied objective was to remain in the middle class, retain the middle class values of their parents and avoid falling into the morass of ever being dependent on social welfare.

Clearly, the Hispanic girls' parents are the ones who need to be educated and encouraged to recognize the importance of their role in the future life planning of their daughters. Of the three ethnic groups, these parents were the least educated themselves as well as being less financially secure. A harmonious and complementary relationship must be developed between school and parents. This might best be accomplished by bringing the parents into the school and the school into the home through development of parent-teacher relationships. In this way, both teachers 
and parents could become aware of each others' concern for the particular daughter's education. It might be that teachers, counselors and others who work with gifted education could enter into a partnership to develop ways in which the gifted daughter can attain a goal commensurate with her ability.

There is no question that adolescence is a difficult time for young people. While the black, Hispanic or Asian girl may aspire to a professional career, if she does not receive adult reinforcement to pursue that aspiration she may settle for something far less than her abilities would indicate. If she comes from a low SES family, her chances of going to college are small. It is the responsibility of adults who work with her on a daily basis to recognize her abilities and to encourage, support, counsel with and help her achieve. Counselors need to help these youngsters and their families understand that maintaining ethnic identity and developing academic and artistic gifts are compatible.

It was also revealed that among the difficulties the girls in this study have encountered is the conflict with siblings who are not gifted. The Hispanic girls, in particular, noted the negative reactions from their brothers who were competing with the girl by not achieving. A second concern cited was the apparent confusion in the minds of the girls who wanted to achieve but appeared reluctant to follow their own aspirations because of eventual responsibility for aging parents. Solutions need to be forthcoming to enable 
girls to render this family support and achieve the goal toward which they aspire.

It would be helpful for gifted girls to meet together on a regular basis as a support group. While girls from ethnically-diverse cultures may not need to be segregated in such groups, it is important that they feel free to share the unique needs and concerns. The purpose of this case study was to examine, explore and assess the influences the intellectually-gifted black, Hispanic and Pan/Asian girls perceive as affecting their future life planning. People continue their heritage in culture by pursuing the attitudes and beliefs of their forebears. It is clearly evident that these girls have done just that. 
Recommendations for Further Study

The recommendations listed are suggestions for further research related to the influences perceived by intellectually-gifted, ethnically-diverse adolescent girls.

1. The sample subjects were from San Diego County only. Generalizability would increase if further research were conducted on a national basis.

2. A review of current literature reveals a deficiency in the number of studies looking at the influence of mother's attitudes, and beliefs about marriage, careers, and life planning -- particularly, research focusing on those from ethnically-diverse cultures.

3. Additional research needs to be conducted to develop "culture-free" measures of identifying gifted young women from ethnically-diverse cultures.

4. Further research is needed to investigate the beliefs and attitudes of the women in ethnically-diverse cultures who work to supplement the family income or to support the family and the attitudes of women who have professional careers. 
5. Though these girls were quite young, it was evident that they seemed to have an idea of what they wanted to do with their lives. However, because of their youth, it would be valuable to conduct a longitudinal study of these girls through the twelfth grade. The information could provide additional strategies about kinds of intervention that could be carried out through high school years.

6. Because this study was designed as a seminal investigation about career choice influences of girls from ethnic populations, a study encompassing only one ethnic group utilizing a larger sample would provide increased generalizability.

7. More research is needed to develop and evaluate the effectiveness of coping strategies to help ethnicallydiverse girls learn ways to handle the expectations of her culture as well as those aspirations she might like to achieve. 


\section{BIBLIOGRAPHY}

Aiken, L. R. Jr. (1970). Non-intellectual variables and mathematics achievement. Journal of School Psychology, 8, 28-36.

Alexander, P. and Muia, J. (1982). Gifted Education: A Comprehensive Roundup. Rockville: Aspen Systems, Corp. Almquist, E. and Angrist, S. (1970). "Career salience and atypicality of occupational choice among college women." Journal of Marriage and the Family, 32(1), pp. 242-249. Almquist, E. (1974). Sex stereotypes in occupational choice: The case for colege women. Journal of Vocational Behavior, 1974, 5, 13-21.

Altman, S. and Grossman, F. (1977). Women's career plans and maternal employment. Psychology of Women Quarterly, I. 365-376.

Alvino, J., McDonnel, R. and Richert, S. (1981). National Survey of identification practices in gifted and talented education. Exceptional Children, 48(2), 124-132.

Alvino, J. and wieler, J. (1979). How standardized testing fails to identify the gifted and what teachers can do about it. Phi Delta Kappan, 61, 106-109. American Association of University Women (1984 - Sept.). "Facts for Activists." Graduate Woman, 78(8),p. 6 . 
Anastasi, A. (1982). Psychological Testing (5th Ed.).

New York: Macmillan.

Angrist, S. (1972). "The study of sex roles" in J.M.

Bardwick (Ed.), Readings on the Psychology of Women.

New York: Harper and Row.

Angrist, S. and Almquist, E. (1975). Careers and

Contingencies. New York: Kennikat Press.

Angrist, S. and Almquist, E. (1970). "Career salience and

atypicality of occupational choice among college women."

Journal of Marriage and the Family, 32, 242-249.

Arciniega, T. (1971). Public education response to the

Mexican-American student. Texas: Innovative Resources, Inc.

Austin, A. and Draper, D. (1981). Peer relationships of the academically gifted: A review. Gifted Child Quarterly. $\underline{25}(3)$, pp. 129-133.

Baca, L. (1980). Issues in the education of the culturally diverse exceptional children. Exceptional Children, $\underline{46}(8), 583$.

Barbe, w. (1965). Psychology and Education of the Gifted (2nd Edition). New York: Irvington Publishers. Barbe, W. (1955). A study of family background of the gifted. Journal of Educational Psychology, 47, 302-309. Barbe. W. and Renzuilli, J. (Eds.) (1974). Psychology and Education of the Gifted. New York: Wiley \& Sons. Bardwick, J. (1972). Readings on the Psychology of Women. New York: Harper \& Row. 
Barnett, R. and Baruch, G. (1978) - The competent woman:

Perspectives on development. New York: Irvington Publishers, Inc.

Barry, H., Bacon, M., Child, I. (1957). A cross-cultural survey of some sex differences in socialization. Journal of Abnormal and Social Psychology, 55, 327-332.

Baruch, G. (1976). Maternal influence upon college women's attitudes towards women and work. Developmental Psychology, 6(1), 32-37.

Benbow, C. and Stanley; J. (1980). Intellectually Talented Students: Family Profiles, Gifted Child Quarterly, 24(3), 119-122.

Benbow, C. and Stanley, J. (1983). Academic Precocity. Baltimore - Johns Hopkins University Press. Bernal, E., Jr. (1976 March). Gifted programs for the culturally different. NASSP Bulletin, 67-76.

Bernal, E. (1974). "Gifted Mexican-American children: An ethno-scientific perspective." California Journal of Educational Research, 25, 261-273.

Bernal, E. and Reyna, J. (1974). Analysis of giftedness in Mexican-American children and design of a prototype identification instrument. Austin, TX: Southwest Educational Development Laboratory. Beller, H. and Weiss, S. (1970). The father-daughter relationship and the personality development of the female. Journal of Genetic Psychology, 116, 79-93. 
Bernard, J. (1976). Where are we now? Some thoughts on the current scene. Psychology of Women Quarterly, 1, 21-37.

Birch, J. W. "The Gifted" - Review of Educational Research, $1963, \underline{33}(1), 83-98$.

Blackburn, A. and Erickson, D. (1986). "Predicatble crises of the gifted student." Journal of Counseling and Development, 64, 552-555.

Blackwell, J. (1986). Mainstreaming outsiders: "The production of black professions." The Chronicle of Higher Education, XXXII, (9), p. 22.

Blau, P. and Duncan, O. (1967). The American Occupational Structure. New York: Wiley. Blaubergs, M. (1980). Sex-role stereotyping and gifted girls' experience and education. Roeper Review, $\underline{2}$, 13-15.

Block, J., Denker, E. and Tittle, C. (1981). Perceived influences on career choices of eleventh graders: Sex, SES and ethnic group comparisons, Sex Roles, $Z_{\text {L }}$ (9), 895-904.

Bloom, B. and Sosniak, I. (1981). Talent development and schooling. Educational Leadership, 39, 85-94.

Boardman, A., Lloyd, A. and Wood, D. (1984). "The process of education for twelfth grade Asian-American students." In Endo, R. "Race and Educational Amibitions: The case of Japanese-Americans. p/AAMHRC Research Review, 3(2), 1-3. 
Borg, W. R. and Gall, M. D. (1979). Educational Research: An Introduction (3rd ed.). New York: Longman. Bradley, R. and Caldwell, B. (1980). The relation of home environment cognitive competence and IQ among males and females. Child Development, 51, 1140-1148. Bridge, G. (1979). The determinants of educational outcomes: The impact of families, peers, teachers and schools. Ballinger: Cambridge. Journal of Sociology, 65 , $337-347,(1960)$.

Bronfenbrenner, U. (1979). The Ecology of Human Development. Cambridge, MA: Harvard University Press.

Broverman, I., Vogel, S., Broverman, D., Clarkson, F. and Rosenkrantz, P. (1972). Sex-role stereotypes: A current appraisal. Journal of Social Isues, $28,58-78$. Brown, B. (1982). Peer Pressure -- The extent and effects of peer pressure among high school students: A retrospective analysis. Journal of Youth and Adolescence, $11(2)$. Broschart, K. R. (1979). The avoidance syndrome and professional careers for women. National Association for Women Deans, Administrators and Counselors Journal, 42, 34-36. Bruch, C. (1976). Assessment of creativity in culturally different children. Gifted Child Quarterly, 19(2), $164-174$.

Bruch, C. (1969). Problems and intuition in the education of gifted students. Gifted Child Quarterly, 13, 92-97. Bruch, C. (1971). Modification of procedures for identification of the disadvantaged gifted. The Gifted Child Quarterly, 15, 267-272. 
Burkhardt, F. (1957). Teacher selection of superior children. Unpublished Master's Thesis, San Diego State University. Burlew, A. K. (1982). Psychology of Women, $6,(3), 312-326$. Burlin, F. (1976). The relationship of parental education and maternal work in occupational status to occupational aspiration in adolescent females. Journal of Vocational Behavior, 9, 99-104.

California Administrative Code, Title 5, Section 3820 . California Administrative Code, Sections 33031, 52201, 52202, 52203.

California Postsecondary Education Commission (1985-Dec.)

California state Department of Education (1984). The Gateway: Gifted and Talented Education in California Public Schools. Sacramento: Office of state Printing. Callahan, C. (1981). The gifted girl: An anomaly? in Barbe, W. and Renzulli, J. (Eds.). Psychology and Education of the Gifted. New York: Wiley Sons, 498-508. Callahan, C. (1979). The gifted and talented woman. In A. H. Passow (Ed.), The gifted and talented: Their education and development, 78th Yearbook of the National Society

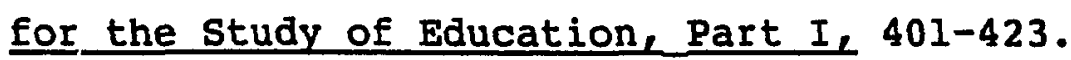

Card, J., Stele, I., Abeles, R. (1980). "Sex differences in realization of individual potential for achievement." Journal of Vocational Behavior, 17, 1-20.

Carter, T. P. and Segura, R. D. (1979). Mexican-Americans in school: A decade of change. New York: College Entrance Examination Book. 
Cashmore, E. (1983). A summary of the arguments of Ernest Cashmore's book, Black Sportsmen, (ERIC 143-749). Cass, J. C. and Tiedeman, D. V. (1960). Vocational development and the election of a high school curriculum. The Personnel and Guidance Journal, 60, 315-326. Casserly, P. (1979), Helping young women take math and science seriously in school. In N. Colangelo and zaffran, R. (Eds), New Voices in Counseling the Gifted, 346-369. Casserly, P. (1980). "Factors affecting female participation in advanced placement programs in mathematics, chemistry and physics" in L. Fox, L. Brody and D. Tobin (Eds), Women and the Mathematical Mystique. Baltimore: The Johns Hopkins University Press.

Cates, W. (1985). A practical guide to educational research. Englewood Cliffs, N.J., Prentice-Hall. Centra, J. (1980). "Graduate degree aspirations of ethnic student groups." American Educational Research Journal, 17, 459-478.

Chambers, J., Barron, F., Sprecher, J. (1980). Identifying gifted Mexican-American students. Gifted Child Quarterly, $\underline{24}(3), 123-128$.

Chen, J. and Goon, S. (1976). Recognition of the gifted from among disadvantaged Asian children. The Gifted Child Quarterly, $\mathrm{xx}_{\text {, }}(2), 157-163$.

Chetwynd, J. and Harnett, D. (Eds)(1978). The Sex Role System. London: Routledge and Kegan Paul. 
Chipman, S. and Thomas V.(1984). The participation of women and minorities in mathematical, scientific and technical fields. Paper presented to Office of Naval Research. Chusmir, L. H. (1983). Characteristics and predictive dimensions of women who make non-traditional vocational choices. The Personnel and Guidance Journal, 62, 43-47. Clark, B. (1980) 2nd Ed. Growing Up Gifted. Columbus: Charles E. Merrill Publishing Co. Cohen, J. (1983). Peer influences on college aspirations with initial aspirations controlled. American Sociological Review, 48, 728-734.

Cohen, L. and Manion, L. (1985). Research methods in education. Dover, New Hampshire: Croom Helm. Colangelo, N. (1985). Counseling needs of culturally diverse gifted students. Roeper Review, 8 (1), pp. 33-35. Colangelo, N. and Lafrenz, N. (1981 - Winter). Counseling the culturally diverse gifted. Gifted Child Quarterly, 25(1), pp. 27-30.

Colangelo, N., Rosenthal, D. and Dettman, D. (1984). Maternal employment and job satisfaction and their relationships to children's perceptions and behaviors. Sex Roles, $10,(9 / 10), 693-698$. Colangelo,.N. and Zaffran, R. T. (1979). New Voices in Counseling the Gifted, Kendall/Hunt Publishing Co. Coleman, J. (1980). Friendship and peer group in adolescence. In J. Adelson (Ed.), Handbook of Adolescent Psychology. New York: Wiley. 
Coleman, J. (1961). The Adolescent Society. New York City: Free Press.

Coleman, J., Campbell, E., Hobson, C., McPartland, J., Mood, A., Weinfeld, F. (1966). Quality of Educational Opportunity. In Shinn, R. Culture and School. San Francisco: Intext Educational Publishers.

Coleman, L. (1985). Schooling the Gifted. Menlo Park, CA.: Addison-Wesley Publications, Co.

Commission for the Review of the Master Plan for Higher Education (1986 - Mar.). The challenge of change: A reassessment of the California Community Colleges, Sacramento, CA.

Corder, J. and Stephen, C. (1984). Females' combination of work and family roles: adolescents' aspirations. Journal of Marriage and the Family.

Cornell, D. (1984). Families of Gifted Children. Ann Arbor: Oniversity of Michigan Research Press.

Cray-Andrews, M. (1983-84). Gifted female adoloscent perceptions of career and lifestyle aspirations (Doctoral dissertation, University of Connecticut, 1983-84). Dissertation Abstracts International, 44/09, p. 2732A.

Cross, P. (1983). Factors associated with pursuit of non-traditional careers among college women. (Doctoral dissertation, University of California at Los Angeles, 1983). Dissertation Abstracts International, 44/02, 398-A. 
Curtis, R. (1975). Adolescent orientations toward parents and peers. Adolescence, $x_{,}(40), 7-12$.

Davidson, H., Greenberg, J. and Gerver, J. (1962).

"Characteristics of successful school achievers from

a severely deprived environment." Mimeo. N.Y., The City

College of the City University of New York.

Davidson, J. (1980 - April). Urban black youth and career

development. Journal of Non-White Concerns. 119-139.

Davies, M. and Kandel, D. B. (1981). Parental and peer

influences on adolescents' educational plans: Some

further evidence. American Journal of Sociology,

87, (1), 363-387.

Davis, G. and Rimm, S. (1985). Education of the Gifted and Talented. Englewood Cliffs, New Jersey: Prentice-Hall, Inc.

Davis, G. and Rimm, S. (1979). Identification and counseling of the creatively gifted. In Colangelo, N. and Zaffran, R. (Eds.), New Voices in Counseling the Gifted. Dubuque, Iowa, 225-236.

Davis, P. (1978). Community-base efforts to increase the identification of a number of gifted minority children. In Torrance Dare We Hope Again? Ypsilanti, MI. (ERIC Ed. 176 487).

Delles, M., Gaier, E. and Emihovich, C. (1979). Maternal employment and selected behaviors, and attitudes of preadolescents and adolescents. Adolescence, 14, 579-589. 
Devereaux, E. (1970). The role of peer-group experience in moral development. In Hill, J. (Ed.) Minnesota Symposium on Child Psychology (Vol. 4), Minneapolis University of Minnesota Press.

Dickinson, Rita M. (1970). Caring for the Gifted. North Quincy, The Christopher Publishing House, p. 87.

Diggs, R. (1974- May) . Education across cultures. Exceptional Children. 40, (8), 578-583. Duck, S. (1975). "Personality similarity and friendship choices by adolescents." European Journal of Social Psychology, $\underline{5}, 351-365$.

Dweck, C. and Bush, E. (1976). Sex differences in learned helplessness: Differential debilitation with peer and adult evaluators. Developmental Psychology, $12,(2)$, 147-156.

Dweck, C, Goetz, T. and Strauss, N. (1980). Sex differences in learned helplessness: IV an experimental and naturalistic study of failure generalization and its mediators. Journal of Personality and Social Psychology, 38(3), 441-452.

Duran, R. (1983) . Hispanics' Education and Background: Predictors of College Achievement. New York: College Entrance Examination Board.

Eccles, J. (1985). Sex differences in achievement patterns. In Psychology and Gender, T. Sonderegger (ed.). Iincoln, NE.: University of Nebraska Press. 
Education of gifted and talented pupils (1979). California State Department of Education, Sacramento, CA. Elder, G. H. Jr. (1980). "Adolescence in historical perspective." In J. Adelson (Ed), Handbook of Adolescent Psychology. New York: Wiley. Elder, G. H. Jr. (1974). Children of the Great Depression. Chicago: University of Chicago Press. Ellis, R. and Herrman, M. (1983). Three dimensions of occupational choice: A research note on measuring the career intentions of college women. Social Forces, 61 , (3), 893-903.

Emmerick, H. (1978). The influence of parents and peers on choices made by adolescents. Journal of Youth and Adolescence, $7,175-180$.

Endo, C. (1982). "Social background of Japanese medical students." Pacific Sociological Review.

Endo, R. (1984). Race and educational ambitions: The case of the Japanese-Americans. P/AAMHRC Research Review, $3,(2), 1-3$.

Entwistle, D. and Baker, D. (1986). "Gender and young children's expectations for performance in arithmetic." In D. Scott-Jones and M. Clark, The School Experiences of Black Girls, Phi Delta Kappan, 67, (7), 520-526. Epstein, C. (1970). Woman's place, options and limits in professional careers. Berkeley: University of California Press. 
Evans, N. (Ed.)(1985). "Women's Development Across the Iife Space." Facilitating the Development of Women: New Directions for student Services \#29. Jossey-Bass, 9-27.

Exum, H. (1983). Key issues in family counseling with gifted and talented Black students. Roeper Review, $\underline{5}(3), 28-31$.

Exum, H. and Colangelo, N. (1981). Culturally-diverse gifted: The need for ethnic identity development. Roeper Review, 3, 15-17.

Faunce, P. (1967). Academic careers of gifted women. Personnel and Guidance Journal, 46, (3), 252-257. Fennema, E. and Ayer, J. (1984). Equity or equality in education for Women. Berkeley: McCutchan. Fitzpatrick, J. L. (1978). Academic underachievement, other direction, and attitudes toward women's roles in bright adolescent females. Journal of Educational Psychology, 70, 645-650.

Fleming, m. and Malone, M. R. (1983). "The relationship of student characteristics and student performance in science as viewed by Meta-Analysis Research." Journal of Research in Science Teaching, 20, 481-495.

Foster, W. and Seltzer, A. (1986). A portrayal of individual in the urban ghetto. Journal of Counseling and Development, 64, 579-582.

Fox, L. (1981). Preparing gifted girls for future leadership roles. $\mathrm{G} / \mathrm{C} / \mathrm{T}, 7-11$. 
Fox, L. (1977). Sex differences: Implications for program planning for the academically gifted. In Stanley, J. C., George, W. C. and Solano, C. H. (Eds.). The Gifted and the Creative: A Fifty-Year Perspective. Baltimore: Johns Hopkins University Press.

Fox, I. (1982). The study of social processes that inhibit or enhance the development of competence and interest in mathematics among highly able young women. Final Report, September, 1979 - January, 1982. Baltimore: JohnsHopkins University. (ERIC Document Reproduction Service No. EC 150310 )

Fox, L, Tobin, D. and Brody, L. (1981). Career development of gifted and talented women. Journal of Career Education, 7, 289-298.

Frazier, N. and Sadken, R. (1973). Sexism in School and Society. New York: Harper and Row. Gallagher, J. (1985). Teaching the Gifted Child (3rd ed.). Boston: Allyn and Bacon.

Garrison, H. (1979-Dec). Gender differences in the career aspirations of recent cohorts of high school seniors. Social Problems, $27,(2), 170-185$.

Gay, J. (1978). A proposed plan for identifying black gifted children. The Gifted Child Quarterly, 22, 353-359.

Gibbs, J. (1984). Black adolescents and youth: An endangered species. American Journal of Orthopsychiatry, 54, 6-21. 
Giele, J. (1982). Women's work and family roles. In J. Z. Giele (Ed.), Women in the Middle Years, New York: Wiley. Giele, J. (1978). Women and the future: Changing sex roles in Modern America. New York: Free Press. Gilligan, C. (1982). In a different voice. Cambridge: Harvard University Press. Gold, D. and Andrus, D. (1978). Comparisons of adolescent children with employed and non-employed mothers. MerrillPalmer Quarterly, 24, 243-254.

Goldberg, M. (1958). Motivation of the gifted. In Henry, N. (Ed.) Education for the Gifted, NSEE, 57, II, Chicago: University of Chicago Press, 87-107. Goodlad, J. (1984). A Place Called School. New York: MC-Graw-Hill. Greene, A., Beyard-Tyler, K., and Sullivan, H. (1982). Attitudinal effects of the use of role models. Journal of Educational Psychology, 74,(3), 393-398.

Grevious, C. (1985). "A comparison of occupational aspirations of urban black college students." Journal of Negro Education, 54(1), 35-42.

Groth, N. (1971). Differences in parental environment needed for degree achievement for gifted men and women. The Gifted Child Quarterly, 257-260.

Groth, N. (1975). Success and creativity in male and female professors. The Gifted Child Quarterly, XIX(4), 328-335. Haber, S. (1980). Cognitive support for the career choices of college women. Sex Roles, $6(1), 129-138$. 
Hackney, H. (1981). The gifted child, the family and the school. Gifted Child Quarterly, 25(2), 51-54.

Harty, H., Adkins, D. and Sherwood, R. (1984). "Predictability of giftedness identification indices for two recognized approaches to elementary school gifted education." Journal of Educational Research, $77(6)$, 337-342.

Haven, E. W. (1972-March). Factors associated with the selection of advanced academic mathematics courses by girls in high school. Research Bulletin, Princeton: Educational Testing Service.

Head, L. (1978). "The determinants of occupational expectations of urban black high school students." Dissertation Abstracts International, 39, 955B, (University Microfilms No. 7813664$)$.

Heilbrun, A. (1969). Parental identification and the patterning of vocational interests in college males and females. Journal of Counseling Psychology, 16, 342-347. Henderson, G. (Ed.)(1979). Understanding and Counseling Ethnic Minorities, Springfield, IL, Charles C. Thomas. Henderson, R. (1981). Home environment and intellectual performance. In R. W. Henderson (Ed.) Parent-Child Interaction. New York: Academic Press. Hernandez, N. (1973). "Variables affecting achievement of middle school Mexican-American students." Review of Educational Research, 43, 1-40. 
Herzog, A. and Bachman, J. (1982). Sex-role attitudes among high school seniors. Ann Arbor: The University of Michigan.

High, M. and Udall, A. (1983). Teacher ratings of students in relation to ethnicity of students and school ethnic balance. Journal for Education of Gifted, $\underline{6}(3), 154-165$. Hoffman, L. (1972). Early childhood experiences and women's achievement motives. Journal of Social Issues, 28 , 129-156.

Hoffman, C., Tsuneyoshi, S., Ebina, M. and Fite, H. (1984). A comparison of adult males' and females' interactions with girls and boys. Sex Roles, 11, 9-10.

Hollander, E. and Marcia, J. (1970). Parental determinants of peer orientation and self-orientation among preadolescents. Developmental Psychology, 2, 292-302. Horner, M. (1972). Toward an understanding of achievement related conflicts in women. Journal of Social Issues, 28, 26-31.

Horner, M. (1968). Sex differences in achievement motivation and performance in competitive and non-competitive situations. Dissertation Abstracts International, 1968, 13/01-B. (University Microfilms No. 69-12135)

Hunsaker, J. (1986). A critical analysis of the fear of success concept. A paper presented to California State Psychological Association, San Francisco, CA. Hunt, J. (1980). Sex stratification and male biography. From Deprivation to Abundance. The Sociological Quarterly, 21, 143-156. 
Hunter, F. (1984). Socializing procedures in parent-child and friendship relations during adolescence. Developmental Psychology, 20(6), 1092-1099. Hurlock, E. (1972), Child Development. New York: McGrawHill.

Ihinger-Tallman, M. (1982). Family interaction, gender and status attainment value. Sex Roles, $\underline{8}(5)$, 543-555. Jenkins, M. (1948). Case studies of Negro children of Benet 160 and above. Journal of Negro Education, 12, 159-166. Jepsen, D. (1981). Longitudinal career patterns of the gifted: A summary of research findings. Journal of Career Education, I(4), 279-288 (ERIC Document Reproduction Service No. EC 133 761).

Jordan, J. and Grossi, J. (Eds.)(1980). An administrator's handbook on Designing Programs for the Gifted and Talented. Council for Exceptional Children and Assoc. for Gifted, Reston, VA.

Judy, G. (1984). Kindergarten admissions in independent schools with suggested guidelines for admissions. Doctoral Dissertation, University of San Diego, 44/12, 3594-A (Dissertation Abstracts International, University Microfilms NO. DA840 7809).

June, L. and Fooks, G. (1980-April). Key influences on the career directions of and choices of black university professionals. Journal of Non-White Concerns, 157-166. Kagen, J. (1964). The child's sex role classification of school subjects. Child Development, 35, 1051-1056. 
Kagen, J. and Moss, N. (1962). Birth to maturity: A study in psychological development. New York: Wiley. Kahl, J. (1953). Educational and occupational aspirations of 'common man' boys. Harvard Educational Review, IVII, 186-203.

Kahl, J. (1982). Double dilemma: Minorities and women in science education. Journal of Career Education, $\underline{8}$, $58-65$.

Kahn, C. (1979). Women's choice of a dual role: Brief notes on a developmental determinant. In Evans, N. (Ed.) Facilitating the development of women, New Directions for Student Services. San Francisco: Jossey-Bass, Inc. Karabel, J. and Astin, A. W. (1975). Social class academic ability and college quality. Social Forces, 53, 381-398. Karamessinis, N. (1980-May,June). Personality and perceptions of the gifted. $\mathrm{G} / \mathrm{C} / \mathrm{T}_{l} 11-13$.

Kerckhoff, A. and Huff, J. (1974). Parental influence on educational goals. Sociometry, 37 , (3), 307-327. Kessler, E. (1976). Women: An anthropological view. New York: Holt-Rinehart and Winston.

Kerr, B. (1985 - Sept.). Smart girls, gifted women: Special guidance concerns. RR VIII, 30-33.

Khatena, J. (1982). Educational Psychology of the Gifted. New York: John Wiley.

Kim, B. L. (1978) . The Asian Americans: Changing Patterns, Changing Needs. Montclair, N.J., Association of Korean Christian Scholars in North America, Inc. 
Kirk, S. and Gallagher, J. (1983). Educating exceptional children. Boston: Houghton Mifflin.

Kirschenbaum, R. (1983-April,May). Let's cut out the cut-off score in the identification of the gifted. Roeper Review, $\underline{5}(4), 6-10$.

Kluckhon, R. (1954). Dominant and variant value orientation. In Personality in Nature, Society and Culture. New York: Alfred A Knopf.

Kohn, M. (1969). Cass and conformity: A study in values. Homewood, IL: Dorsey.

Komarovsky, M. (1985). Women in College. New York: Basic Books, Inc. Publishers.

LaGaipa, J. (1979). A developmental study of the meaning of friendship in adolescence. Journal of Adolescence, $\underline{2}_{4}$ 201-213.

Laosa, L. (1982). School, occupations, culture and family: the impact of parental schooling on the parent-child relationship. Journal of Educational Psychology, 74(6), 791-827.

Lee, c. 91985). Successful rural black adolescents: A psychological profile. Adolescence, 20(77), 131-142.

Leonard, P. (1984). Career education for black youth: A perspective. The Neqro Educational Review, $\mathrm{xxXV}_{\text {, }}$ July, 102-111.

Lewis, M. (1976). What do we mean when we say 'infant intelligence scores'? A sociopolitical question. In M. Leurs (Ed.) Origins of Intelligence. New York: Plenum Press. 
Lewis, R. and St. John, N. (1974). Contributions of crossracial friendship to minority group achievement in desegregated classrooms. Sociometry, 37, 79-91.

Lindgren, H. (1980). Educational Psychology in the Classroom. New York: Oxford Press.

Lindstrom, R. and VanSant, S. (1986). Spcial issues in working with gifted minority adolescents. Journal of Counseling and Development, $\underline{46}$, 583-586.

Los Angeles Times $(5 / 9 / 86)$. Conference Looks at Nuclear Family in Ferment. p. 1.

Lueptow, L. (1984). Adolescent Sex Roles and Social Change. New York: Columbia University Press. Lutz, F. and Ramsey, M. (1974). The use of anthropological field methods in education. In Borg, W. and Gall, M. (Eds.), Education Research: An Introduction. New York: Longman, Inc.

Lynn, D. (1966). The process of learning parental and sexrole identification. Journal of Marriage and the Family, 28, 466-470.

Maccia, Elizabeth Steiner; Coleman, Martha Ann; Estep, Myrna; Shiel, Trudy Miller-Springfield; Charles Thomas (1975). How ideology shapes women's lives.

Maccoby, E. and Jacklin, C. (1974). The psychology of sex differences. Stanford, CA.: Stanford University Press. Macke, A. and Morgan, W. (1978). Maternal employment, race, and work orientation of high school girls. Social Forces, 57(1), 187-204. 
Maestas, L. (1983). Academic performance across cultures:

An examination of the effects of value similarity.

Educational Research Quarterly, $7(4), 24-34$.

Mallinger, K. (1984). Women, work and change: A study of

women who leave nursing for other occupations. (Doctoral

Dissertation, University of California, San Diego).

Dissertation Abstracts Internations, 45, 1876-A

Malone, C. and Shope, G. (1978). Career expectations of

primary grade children related to socio-economic status.

Gifted Child Quarterly, 22, 322-324.

Marion, R. (1980). Parenting the gifted, working with

parents of the disadvantaged or culturally different

child. Roeper Review, 2 $(1), 32-34$.

Marjoribanks, K. (1984). Ethnicity, family, environment and

adolescents' aspirations: A follow-up study. Journal of

Educational Research, 77(3), 166-171.

Marjoribanks, K. (1978). Bloom's model of human develoment:

A regression surface analysis. International Journal of

Behavioral Development, 1 , 193-206.

Margoribanks, K. (1979). Families and their learning

environments. London: Routledge and Kegan Paul.

Marland, S. P. Jr. (1972). Education of the gifted and

talented: Report to the Congress of the United States

by the Commissioner of Education. Washington, D.C.:

U. S. Government Printing Office.

Marland, M. (Ed.)(1983). Sex differentiation and schooling.

London: Heineman Education Books. 
Masten, Wm. (1985). Identification of gifted minority students: Past research, future directions. Roeper Review, VIII, (2), 83-85.

Martinson, R. (1972). An analysis of problems and priorities; Advocate survey and statistical source. In S. Marland (Ed.) Education of Gifted and Talented: Report to the Congress of the United States by the Commissioner of Education. Washington, D.C.: U. S. Government Printing Office.

Martinson, R. (1974). The identification of the gifted and talented. Ventura CA. Office of the Ventura County Superintendent of Schools.

Mason, E. and Bramble, W. (1978). Understanding and Conducting Research: Applications in Education and the Behavioral Sciences. New York: McGraw-Hill Book Company. McBroom, W. (1981). Parental relationships, socioeconomic status, and sex-role expectations. Sex Roles, I(10), 1027-1033.

McBroom, W. (1985 Spring). The influence of parental status variables on the status aspirations of youths. Adolescence, $\mathrm{Xx},(77), 115-127$.

McCarthy, D. (1972). Manual for the McCarthy Scales of Children's Abilities. New York: New York Psychological Corporation. 
McClelland, D. C., Atkinson, J. E., Clark, R. A., and Lowell, E. L. (1965). The Achievement Motive. Englewood Cliffs, N.J.: Prentice-Hall (Appleton). McDonald, G. (1977-Nov). Parental identification by adolescent: A social science approach. Journal of Marriage and the Family, 39, 705-719.

McKenzie, J. (1986). The influence of identification practices, race and SES on the identification of gifted students. Gifted Child Quarterly, 30, 93-95.

McMillan, J. and Schumacher, S. (1984). Research in Education: A conceptual introduction. Boston: Little, Brown and Co. McNair, D. and Brown, D. (1983). Predicting the occupational aspirations, occupational expectations and career maturity of black and white male and female loth graders. Vocational Guidance Quarterly, Sept. 1983, 29-36. Meeker, M. (1975). Structure of Intellect (SOI) Learning Abilities Test. El Segundo, CA.: SOI Institute. Mejia, D. (1983). The development of Mexican-American children. In G. Powel (Ed.) The Psychological Development of Minority Children. New York: Brenner/Mazel, Inc. Mercantel, S. (1982). A comparison of gifted and non-gifted adolescent girls for sex-role identity, attitudes toward the feminine role and stated career choice. (Doctoral Dissertation, McNeese State University, 1982). Dissertation Abstracts International, 43, 2-A. Mercer, J. and Lewis, J. (1978), New York Psychology Corp. Mercer, J. and Lewis, J. (1981). System of Multicultural Pluralistic Assessment. 
Miller, B. and Price, M. (1981). The Gifted Child, the Family and the Community. New York: Walker \& Co.

Minuchin, S. (1974). Families and Family Therapy. Cambridge: Harvard University Press.

Mirande, Alfredo and Enriquez, E. (1980). La Chicana: The Mexican-American Woman. Chicago: The University of Chicago Press.

Mirande, A. (1977-Nov). The Chicano family: A reanalysis of conflicting views. Journal of Marriage and the Family, $6(1), 747-756$.

Miyahira, S. (1977). College women's career orientations as related to work values and background factors. Dissertation Abstracts International, 37(8-A), 4868. Monks, F. and Ferguson, T. (1983). Gifted adolescents: An analysis of their psychosocial development. Journal of Youth and Adolescence, 12(1), 1-18.

Morse, J. and Bruch, C. (1970). Gifted women: More issues than answers. Educational Horizons, 49, 25-32. Nakanishi, D. and Hirano-Nakanishi, M. (Eds.)(1983). The Education of Asian and Pacific Americans: Historical Perspectives and Prescriptions for the Future. Phoenix, Az., The Oryx Press.

Nielsen, L. (1982). How to motivate adolescents. Englewood Cliffs, N.J.: Prentice-Hall. Oliver, L. (1975). The relationship of parental attitudes and parental identification to career and homemaking orientation in college women. Journal of Vocational Behavior, $6,1-8$. 
Oppenheimer, V. (1975). The sex labeling of jobs. In Medrick, M., Tangri, S., and Hoffman, L. (Eds.). Women and Achievement: Social and Motivational Analysis. New York: John Wiley.

Painter, E. (1976). A comparison of achievement and ability in children of high intellectual potential. Unpublished Master's Thesis, London University, 1976.

Pallone, N., Rickard, F. and Hurley, R. (1970). Key influences of occupational preference among black youth. Journal of Counseling Psychology, 17, 498-501.

Parsons, T. (1959). The school class as a social system: Some of its functions in American society. Harvard Educational Review, XXIX, 297-318.

Parsons, T. (1955). Family structure and socialization of the child. In T. Parsons and R. F. Bales (Eds.) Family, Socialization and Interaction Process. Glencoe, IL.: Free Press, 35-131.

Passow, A. (Ed.) (1979). The Gifted and Talented: Their Education and Development. Seventy-Eighth Yearbook of National society for the study of Education. Chicago: University of Chicago Press.

Patchen, M., Hoffman, G., and Brown, W. (1980). Academic performance of black high school students under different conditions of contact with white peers. Sociology of Education, 33-51.

Patton, M. (1980). Qualitative Evaluation Methods. Beverly Hills: Sage Productions. 
Payton, C. (1985). Addressing the special needs of minority women. In Evans, N. (Ed.) Facilitating the Development of Women. New Directions for student Services, San Francisco: Jossey-Bass.

Pegnato, C. and Birch, J. (1959). Locating gifted children in junior high schools: A comparison of methods. Exceptional Children, 25, 300-304. Perino, S. and Male, J. (1981). Parenting the Gifted. New York: R. R. Bowker Co. Phi Delta Kappan (1986, Feb) . Hispanics least educated, lowest paid of all major U. S. population groups. $\underline{67}$ (6), p. 474 .

Portes, A. and wilson, K. (1976). Black-white differences in educational attainment. American Sociological Review, 41, 414-431.

Powell, G. (Ed.)(1983). The Psychological Development of Minority Group Children. New York: Brunner/Mazel, Inc. Rainwater, L. (1970). The problem of lower class culture. Journal of Social Issues, 26, 133-148. Renzulli, J. (1970). The identification and development of talent potential among the disadvantaged. Contemporary Education, 42, 122-125. Robinson, H. and Robinson, N. (1965). The mentally retarded child: A psychological approach. In Diggs, R. (May 1974) Exceptional Children, $\underline{40}(8), 578-584$. Rodenstein, J., Pfleger, L., and Colangelo, N. (1977 Fall). Career development of gifted women. The Gifted Child Quarterly, XXI, $3,340-347$. 
Rodenstein, J. and Glickhauf-Hughes, C. (1979). Career and lifestyle determinants of highly gifted women. Gifted Child Quarterly, 21, 340-347. Rodenstein, J. (1980). Career and lifestyle determinants of gifted women. Guidance Institute for Talented Students (University of Wisconsin at Madison), ERIC Document Reproduction Service No. ED 194689. Rodman, B. N. (1986-Jan). Blacks in college: Further declines seen. Education Week, $V_{f}(18), 1$. Roedell, W. C., Jackson, N. E. and Robinson, H. B. (1980). The gifted young child. New York: Teacher's College Press, Columbia University. Rollins, J. and White, P. (1982). The relationship between mothers' and daughters' sex-role attitudes and selfconcepts in three types of family environment. Sex Roles, 8(11), 1141-1155.

Romer, N. and Cherry, D. (1980). Ethnic and social class differences in children's sex-role concepts. Sex Roles, $\underline{6}(2), 245-263$.

Rosen, B. C. (1959). Family structure and achievement motivation. American Sociological Review, 26, 574-584. Rosen, B. C. (1959). Race, ethnicity and the achievement syndrome. American Sociological Review, XXIV, 47-60. Rosen, B. and Aneshense? (1978). Sex differences in the educational-occupational expectation process. Social Forces, 57(1), 164-204. 
Rosenthal, D. and Hansen, J. (1981). The impact of maternal employment on children's perceptions of parents and personal development. Sex Roles, Z(6), 593-598. Rotter, J. (1950). Incomplete Sentences Blank - High School Form. New York: The Psychological Corporation. Rubin, J., Provenzano, F. and Iuria, Z. (1974). The eye of the beholder: Parents' views on sex of newborns. American Journal of Orthopsychiatry, 44, 512-519. Rubin, V. (1986). Women's work. Science 86, I, 58-65. Ruhland, D. Brittle, M., Norris, S., \& Oakes, R. (1978). Determinants of career goals in junior and senior high school women. Missouri University-Rolla. (ERIC Document Reproduction Service No. 185 356)

Sadker, M. and Sadker, D. (1986). Sexism in the classroom. Phi Delta Kappan, 67, 572-575.

Safter, H. and Bruch, C. (1981 - Fall). Use of the DGG model for differential guidance for the gifted. Gifted Child Quarterly, 25(4), 167-174.

Samuda, R. (1975). Psychological Testing of American Minorities: Issues and Consequences. New York: Dodd, Mead.

San Diego Evening Tribune (1986, Feb. 4). The Asian family: garden of values. $B-1$.

San Diego Union (1985, November 10). More women working still getting less. AA-8. 
Santos, R. (1983). Social and emotional development of Filipino children. In G. Powell (Ed.), The Psychosocial Development of Minority Children. New York: Brunner/Mazel, Inc.

Sato, I. (1974). The culturally different gifted child -the dawning of his day. Exceptional Children, 40(8), 572-576.

Sax, G. (1958). Empirical Foundations of Educational Research. Engleweood Cliffs, N.J.: Prentice-Hall. Schaefer, C. (1970). A psychological study of ten exceptionally creative girls. Exceptional Children, 36, 431-441.

Schneider, F. and Coutts, L. (1985). Person orientation of male and female high school students: To the educational disadvantage of males? Sex Roles, 13(1-2), 47-63. Schwartz, L. (1980). Advocacy for the neglected gifted females. Gifted Child Quarterly, 21(3), 115-117. Schulenberg, J., Vondracek, F. and Crouter, A. (1984). The influence of the family on vocational development. Journal of Marriage and the Family, 46(1), 129-142. Scott-Jones, D. and Clark, M. (1986). The school experiences of black girls: The interaction of gender, race and socioeconomic status. Phi Delta Kappan, 67(7), 520-526. Sellin, D. and Birch, J. (1980). Educating gifted and talented learners. Rockville, MD.: Aspen Publications. Selman, R. (1980). The growth of interpersonal understanding developmental and clinical analysis. New York: Academic Press. 
Shade, B. (1978). Sociopsychological characteristics of achieving black children. In Gallagher, J. Teaching the Gifted Child, 1985. Boston: Allyn and Bacon. Shaw, M. C. and McCuen, J. T. (1960). The onset of academic underachievement in bright children. Journal of Educational Psychology, 51, 103-108. Shepard, w. (1980). Mothers and fathers, sons and daughters: Perceptions of young adults. Sex Roles, $6(3), 421-433$. Sherer, H. (1977). Antecedent conditions and academic achievement of ethnically different students. Dissertation Abstracts International, 28, 2993A. (University Microfilms No. 67-16017)

Skagmer, R. and Fitzgibbon, C. (1972 Apr.). Mentally gifted disadvantaged students: An investigation of methods of identification including the use of 'Culture Fair Tests' at the English grade level. Final Report. (ERIC Document Reproduction Service No. 080583 )

Slee, F. (1968). Feminine image factor in girls' attitudes to school subjects. British Journal of Educational Psychology, 38, 212-214.

Smith, L., Billiter, B. (1985). Emphasis on education paying off. Los Angeles Times (Dec. 19), Part 1, p. 1. Smith, E. (1980-April). Career development of minorities in non-traditional fields. Journal of Non-White Concerns, 141-155.

Spenner, K. and Featherman, D. (1978). Achievement ambitions. In Annual Review of Sociology. Palo Alto, CA.: Annual Reviews, 4 , 373-420. 
Stanley, J. (1978). Identifying and nurturing the intellectually gifted. In R. E. Clasen and B. Robinson (Eds.) Simple Gifts, Madison, WI: University of Wisconsin Extension.

Staples, R. and Mirande, A. (1980). Racial and cultural variations among American families: A decennial review of the literature on minority families. Journal of Marriage and the Family, 42(4), 887-904.

Stevens, G. and Boyd, M. (1980). The importance of mother: Labor force participation and intergenerational mobility of women. Social Forces, 59(1), 186-199.

St. John, N. (1972). Mothers and children: Congruence and optimism of school-related attitudes. Journal of Marriage and the Family, 34, 422-430.

Strodtbeck, F. (1958). Family interaction, values and achievement. In McClelland, D. et. al. (eds.), Talent and Society, New York: Van Nostrand.

Sue, D., Sue, D., Sue, D. (1983) Psychological development of Chinese-American children. In G. Powel (Ed.) The Psycholog-ical Development of Minority Children. New York: Brunner/Mazel, Inc.

Sue, D. (1981). Counseling the Culturally Different: Theory and Practice. New York: John Wiley and Sons. Sullivan, A. (1973). The identification of gifted and academically talented black students: A hidden exceptionality. The Journal of Special Education, I, 373-379. 
Sundal-Hansen, L. (1985), Work-family linkages: Neglected

factors in career guidance across cultures. The Vocational Guidance Quarterly, 33(3), 202-212.

Super, C. M. (1982). Secular trends in child development and the institutionalization of professional disciplines. Newsletter of the Society for Research in Child Development, 10-11.

Svanum, S., Bringle, R. and McLaughlin, J. (1982). Father absence and cognitive performance in a large sample of sex to eleven-year-old children. Child Development, 53, 136-143.

Swassing, R. (1985). Teaching Gifted Children and Adolescents. Columbus, OH.: Charles E. Merrill.

Tangri, S. (1972). Determinants of occupational role innovation among college women. Journal of Social Issues, 28, 177-199.

Tannenbaum, A. (1983). Gifted Children. New York: MacMillan Publishing Co., Inc.

Terman, L. and Oden, M. (1947). Genetic Studies of Genius: The Gifted Child Grows Up. Stanford: Stanford University Press.

Thomas, G. (1985). College major and career inequality: implications for black students. Journal of Negro Education, S4$(4), 537-547$.

Thomas, C. (1980). Race and sex differences and similarities in the process of college entry. International Journal of Higher Education, 9 , 179-202. 
Thompson, I., Acock, A. and Clark, K. (1985-July). Do parents know their children? The ability of males and females to gauge attitudes of their young adult children. Family Relations, 34(3), 315-320.

Torrance, E. P. (1974) - Torrance Tests of Creative Thinking. Bensenville, IL: Scholastic Testing Service. Torrance, E. P. (1978). Dare we hope again? Gifted Child Quarterly, 22(3), 292-312.

Treiman, D. and Terrell, K. (1975). Sex and the process of status attainment: A comparison of working women and men. American Sociological Review, 40, 174-200.

Tuttle, F. and Becker, L. (1983). Characteristics and identification of the gifted and talented students. Washington, D.C. NEA Publications, 2nd Ed.

U. S. Department of Education, offices for Civil Rights. Data on earned degrees conferred by institutions of higher education by race, ethnicity, and sex. Washington, D. C., $1980-81$.

U. S. Department of Labor (1982). Occupational Projections and Training, Bureau of Labor Statistics, U. S. Government Printing office.

U. S. Department of Labor (1983) - Employment Earnings, Bureau of Labor Statistics, U. S. Government Printing office.

Valencia, R., Henderson, R. and Rankin, R. (1981). The relationship of family constellation and schooling to intellectual performance of Mexican-American children. Journal of Educational Psychology, 73, 524-532. 
Valencia, R., Henderson, R. and Rankin, R. (1981). Evidence of content bias on the McCarthy Scales to Mexican-American children: Implications of test translation and non-biased assessment. Journal of Educational Psychology, $\underline{77}(2)$, 197-207.

Valencia, R. (1983). Stability of the McCarthy Scales of children's abilities over a one-year period for MexicanAmerican children. Psychology in the Schools,

vetter, B. (1986), Women's work. Science 86, (7), 62-63. Vidulich, R. N., Sachs, D. G., and Christman, J. F. (1978). Career choice and change in high ability young women. In Swassing, R., Teaching Gifted Children and Adolescents. Columbus, OH.: Charles E. Merrill Publishing Company, p. 352 .

Wahab, Z. (1973). Barrio school: White schools in a brown community. Paper presented at the Annual Convention of the American Anthropological Association, New Orleans, LA. (ERIC Document Reproduction Service No. ED 114 211) Warner, L. et. al. (1944), Who Shall Be Educated? New York: Harper Row Publishing, p. 11. Wechsler Intelligence Scale for Children Revised (WISC-R), (1974).

Weitzman, N., Berns, B., Friend, R. (1985 Aug.). Traditional and non-traditional mothers' communication with their daughters and sons. Child Development, 吕(4), 894-898. Wells, M. (1985). Gifted Female. G/C/T, I, $\underline{38}, 43-46$. 
White, K. (1982). The relation between socioeconomic status and academic achievement. Psychological Bulletin, 91, 461-481.

Williams, R. (1972). The BITCH Test (Black Intelligence Test of Cultural Homogeneity), Robert L. Williams and Assoc., Inc.

Williamson, J., Karp, D., Dalphin, J. and Gray, P. (1982). The Research Craft. Boston: Little Brown \& Co. Winterbottom, M. The relation of childhood training in independence to achievement motivation. Dissertation: Abstracts International, 13, 2993A. (University Microfilms, No. 00-05113)

Wolleat, P. L. (1979). Guiding the career development of gifted females. In Colangelo, N. and Zaffran, R. T. (Eds.) New Voices in Counseling the Gifted. Dubuque: Kendall-Hunt Publishing Co., pp. 331-345. Wright, J. and Wright, S. (1976). Social class and parental replication and extension of the Kohn thesis. American Sociological Review, 41, 527-537.

Yarborough, B. and Johnson, R. (1983). Identifying the gifted:

A theory-practice gap. Gifted Child Quarterly, 27(3), 135-138.

Ybarra, Lea (1982). When wives work: The impact on the Chicano family. Journal of Marriage and the Family, 44(1), 169-178.

Yin, R. (1984). Case Study Research: Design and Methods. Beverly Hills: Sage Productions. 
Young, R. (1984). Vocational choice and values in adolescent women. Sex Roles, 10(7-8), 485-492.

Young, R. (1983). Career development of adolescents: An ecological perspective. Journal of Youth and Adolescence, $12(5), 401-417$.

Youniss, J. and Smollar, J. (1985). Adolescent Relations With Mothers, Fathers, and Friends. Chicago: The University of Chicago Press.

zajonc, R. (1976) . Birth order and intellectual development. Psychological Review, 82, 74-85.

zajonc, R. (1976) . Family configuration and intelligence. Psychological Review, 82, 74-85.

zettel, (1979). State provisions for educating the gifted and talented. In A. H. Passow (Ed.), The Gifted and Talented: Their Education and Development. 78th Yearbook of the National Society for thge study of Education: Part 1. Chicago: University of Chicago Press. Zuckerman, D. and Sayre, D. (1982). Cultural sex-role expectations and children's sex-role concepts. Sex Roles, $\underline{8}(8), 853-862$. 
APPENDIX A 
Dear Parents:

Your daughter has been asked to participate in a research study about the future lifestyle plans of gifted/highly motivated Mexican-American, Black and Asian girls. The study will include other eighth grade girls at your daughter's school who are also participants in the study.

This study is the topic of my doctoral dissertation at the University of San Diego. The purpose of the study is to discover the cultural influences these girls perceive as as helping to shape their future life plans.

The girls will be asked to answer items on a questionnaire as well as to participate in a group interview with other girls from this school who are participating in the study. Information asked on the questionnaire will include naming the career or occupation they plan to pursue, the kinds of influence they perceive coming from their parents and friends, religious preference of the parents, level of education and occupation of each parent and questions about favorite subjects, as well as how they feel about the grades they get. Interview questions will ask why a certain career or occupation was chosen, whether life planning is discussed with parents, whether she thinks she will actually pursue that career along with questions about whether she could use more help from the school in career planning.

The girls will be asked to meet with me two times at a two-week interval. The first time they will answer the questionnaire and the second time will be for the group interview.

During the interview, the girls will meet with me and the other girls from the school who are participating in this study. All responses will be confidential and no names will be used. The information collected will be used only in combination with others throughout the county of san 
Diego. At no time will your daughter be identified in any published report. A summary of the questionnaire results will be available if you so desire.

It is important that once your daughter has agreed to be in the study, she stay with it until it is completed.

I hope you and your daughter will agree to participate. I look forward to working with her.

\section{Sincerely,}

has my permission to participate in the study. I understand that information in the questionnaire and during the interview will be confidential. 
APPENDIX B

Reproduced with permission of the copyright owner. Further reproduction prohibited without permission. 


\section{Questionnaire}

\section{Directions To Participants}

This is a series of questions about your attitudes or opinions about your relationship with your parents and your future life plans. It is important that you be as honest as you can. If the question is something you have not thought about before, make the best decision you can at the moment.

None of the information is about you personally. The information gathered from the questionnaire will be considered in terms of the whole group's answers, not on individual answers. All the answers from all the questionnaires will be strictly confidential.

The purpose of the questions is to try to determine what kinds of things eighth grade girls are thinking about for their life's work. One of the reasons for gathering this information is to give us adults some ideas wbout the ways we can be of help. With this information we can help girls like yourselves who are in the process of thinking and planning for your future. That is why it is very important and would be the most helpful for you to be as honest as you can right now. 
Please print your middle name

\section{Questions about your family}

1. Are your natural parents:

Living together (both living at home)

- Divorced, separated

One or both parents deceased

2. Which of your natural parents do you feel you are most like?

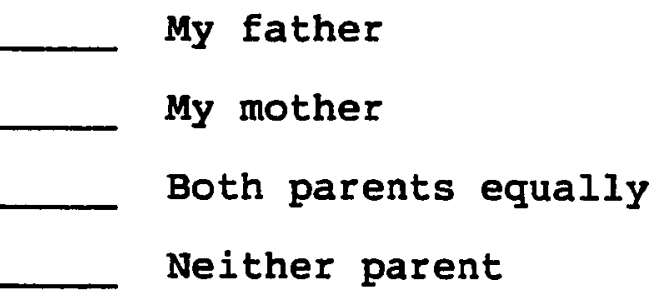

3. How well do you feel your natural mother understands you and what you want out of life?

Very well

Fairly well

Not too well

Not at all 
4. How well do you feel your natural father understands you and what you want out of Iife?

Very well

\section{Fairly well}

Not too well

Not at all

5. How close do you feel to your natural mother and father? Mother Father

Extremely close

Quite close

Fairly close

Not very close

6. How much do you and your parents agree about your plans for your future?

$$
\text { Mother Father }
$$

We are very much in agreement

There is some agreement

There is some disagreement

We have major disagreements

7. Are there other adults with whom you discuss your future plans? (Yes or No)

Who are they? 
8. As you were growing up, how much did your parents encourage you to do things for yourself?

\section{Mother}

Father

A lot of encouragement

Some encouragement

Very little encouragement

No encouragement

9. As you were growing up, how much freedom did your parents give you in making your own decisions?

Mother

Father

A lot of freedom

Some freedom

Very little freedom

No freedom

10. How much have your parents encouraged you to do well in school?

Mother

Father

A lot of encouragement

Some encouragement

Very little encouragement

No encouragement 
11. How far did your parents go in school?

Less than high school

Some high school

High school diploma

Some college

Graduated from a 4-yr college (Bachelor's degree)

Advanced or professional degree

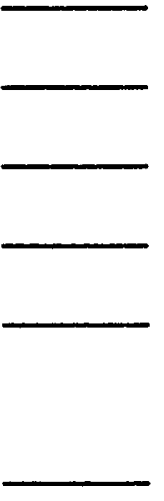

12. Family Background

What do you identify as the predominant ethnic or national background of your ancestors?

Father

Mother

13. Which of the following describes your religious identification and that of your parents?

You Mother Father

$\begin{aligned} & \text { Roman Catholic } \\ & \text { Protestant } \\ & \text { Denomination }\end{aligned}$
Jewish
Buddhist
Muslim
No formal religion
Other (Specify)


14. What is your natural father's occupation?

15. What is your natural mother's occupation?

16. How many children are in your family?

Write the names of the children according to age, from oldest to youngest. Don't forget yourself!

17. About what total income do your parents earn each year? Below $\$ 10,000$

\begin{tabular}{|c|}
\hline Below $\$ 10,000$ \\
\hline$\$ 10.000-\$ 19.900$ \\
\hline$\$ 20,000-\$ 40,000$ \\
\hline$\$ 40,000$ and over \\
\hline Don't know \\
\hline
\end{tabular}


18. How often do you discuss your future goals or aspirations with your friends?

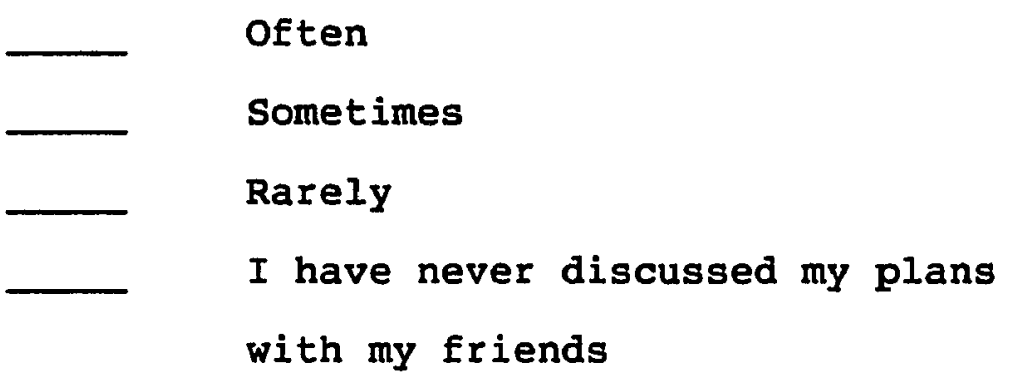

19. Were you born in the United States? (Yes or No)

If not, in what country were you born?

If you were not born in the United States, how old were you when you came to the United States? 


\section{Relationship to Peers}

Here are some things young people sometimes think and talk about. How often have you taked about each of the following with your friends and other kids in your neighborhood and school?

20. Your educational and vocational plans?

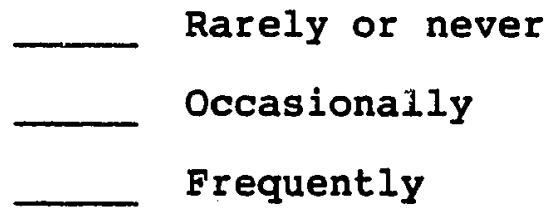

21. TV, sports, movies, popular music?

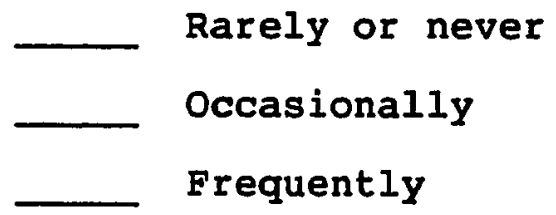

22. Personal values: (Your behavior in different situations, honesty, respect for others, etc.)

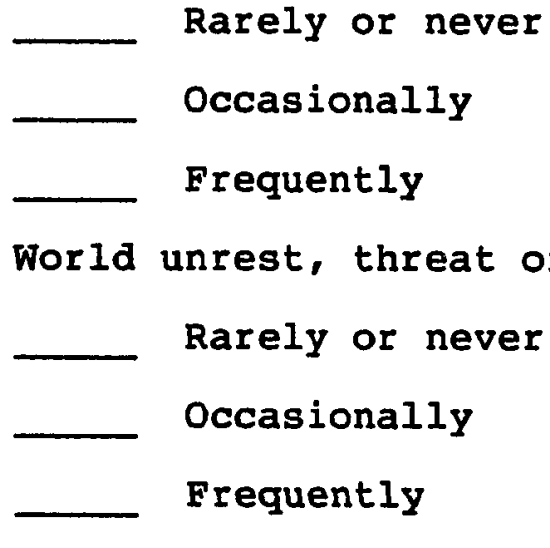

24. News events of the day?

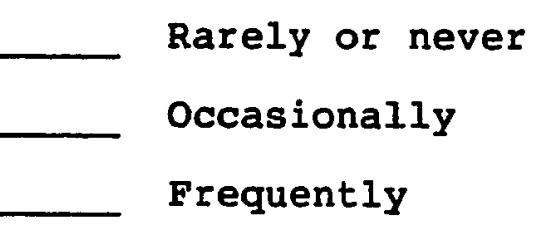


25. Your religious beliefs?

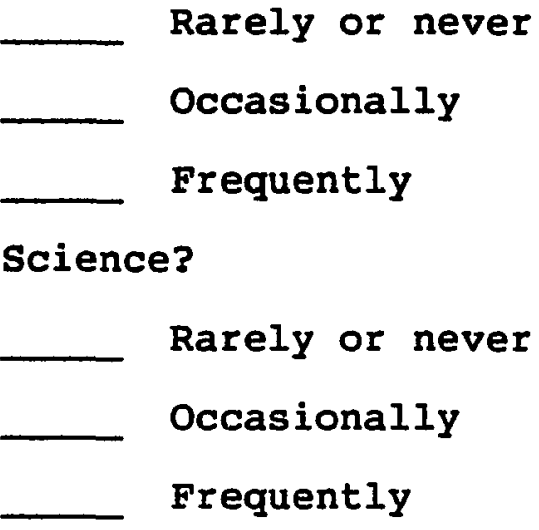

27. School literature and other books you have read?

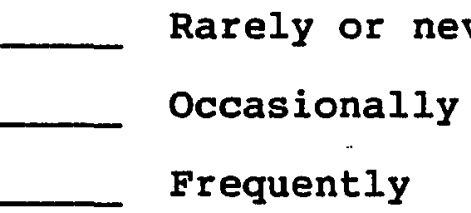

How often have you talked with your parents about the following?

28. Your educational and vocational plans?

Rarely or never

Occasionally

- Frequently

29. TV, sports, movies, popular music?

- Occasionally

Rarely or never

Frequently

30. Personal values: (Your behavior in different situations, religion, honesty?)

occasionally

Rarely or never

Frequently 
31. World unrest, threat of war?

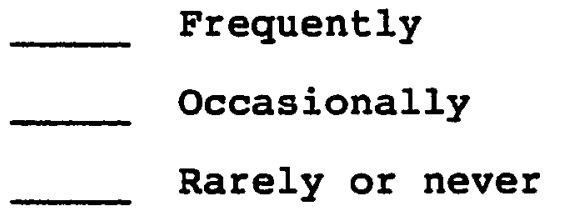

32. News events of the day?

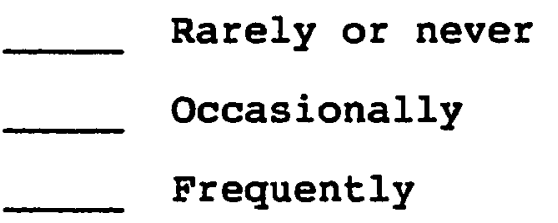

33. Science?

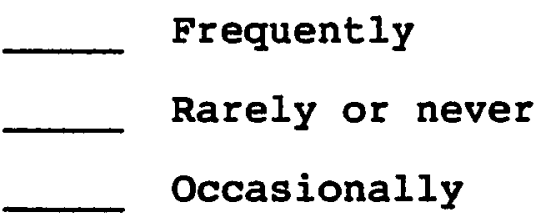

34. Books?

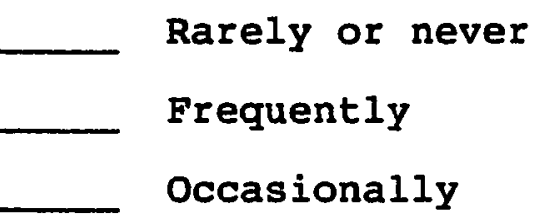

\section{Your Schooling}

35. What are your favorite subjects in school?

36. What are your least favorite? 
37. In what subjects do you receive the best grades?

38. In what subjects do you have the most difficulty?

39. Are you doing as well in school academically as you want to? Yes No

If not, why not?

40. How do you think your grades compare with your friends' grades? (This might include people not in the same class or school but who are friends of yours.)

$\begin{array}{ll}- & \text { Not as good } \\ & \text { Just as good } \\ & \text { Better than theirs } \\ & \text { Don't know }\end{array}$

41. How long have you been in the gifted program? What do you like about your placement in the gifted program? 
42. What are some of the things you do as part of the gifted program?

43. Are there things you don't like about the program?

44. Do you think being in the gifted program will help you in career planning? Yes No Why?

45. What are some ways you think you could use help in career planning?

Looking ahead to your future. Imagine yourself ten years from now.

46. What career/occupation would you like to pursue?

47. What career/occupation do you think you probably will pursue? 
48. Are there reasons you think you might not be able to pursue the career or occupation you have chosen?

49. What do you think will be moat important to you as an adult? Please rank the following in the order of importance, 1-5. That is, the most important would be number 1 , the next most important number 2, and so on.

To be married
To have a career/occupation
To become well-known
To earn a high salary
To have children


50. How likely is it that you will do each of the following things after high school?

a. Attend a vocational or technical school?

Definitely won't

Probably won't

Probably will

- Definitely will

b. Attend a 2-year college only?

Definitely won't

Probably won't

Probably will

- Definitely will

c. Graduate from a 4-year college?

- Definitely won't

Probably won't

- Probably will

- Definitely will

d. Attend a graduate school?

Definitely won't

Probably won't

Probably will

- Definitely will 
APPENDIX C 


\section{Group Interview Questions}

Think about the career choice or occupation that you indicated you wanted to be doing when you are about 25 years old.

1. What are some of the reasons you have chosen that career?

2. What do you think might be the most significant reason preventing you from reaching that goal?

3. How do you think your parent's opinions affect your life planning?

4. If you think your father could choose a lifestyle for you, what do you think it would be? That is, what would he choose for you to do?

5. If your mother could choose a lifestyle for you, what do you think it would be?

6. Who else do you see as influencing your decisions about what you want to do with your life?

7. Tell me some things about your placement in school.

8. Do you think your classes are different from those other students are taking in school? How do you think they are different or why do you think they are about the same?

9. How long have you been in the gifted or highly motivated classes?

10. Do you think being in this program will help you in your career planning? How?

11. Are there ways you think you could use help in career planning? What are they? 